University of Rhode Island

DigitalCommons@URI

Open Access Master's Theses

1972

\title{
A Heuristic Routine for Project-Network Scheduling with Resource Constraints
}

Hector J. Alvarez

University of Rhode Island

Follow this and additional works at: https://digitalcommons.uri.edu/theses

\section{Recommended Citation}

Alvarez, Hector J., "A Heuristic Routine for Project-Network Scheduling with Resource Constraints" (1972). Open Access Master's Theses. Paper 1116.

https://digitalcommons.uri.edu/theses/1116

This Thesis is brought to you for free and open access by DigitalCommons@URI. It has been accepted for inclusion in Open Access Master's Theses by an authorized administrator of DigitalCommons@URI. For more information, please contact digitalcommons-group@uri.edu. 


\section{A HEURISTIC ROUTINE FOR PROJECT-NETWORK}

SCHEDULING WITH RESOURCE CONSTRAINTS

BY

HECTOR J. ALVAREZ

A THESIS SUBMITTED IN PARTIAL FULFIITMENT OF THE REQUIRENENTS FOR THE DEGREE OF

MASTER OF SCIENCE

IN

INDUSTRTAL ENGINEHRTNG

UNIVERSIIY OF RHODE ISIAND

1972 
MASTER OF SCIHNCE THESIS

OF

HECTOR J. ALVAREZ

Approved:

Thesis Committee:
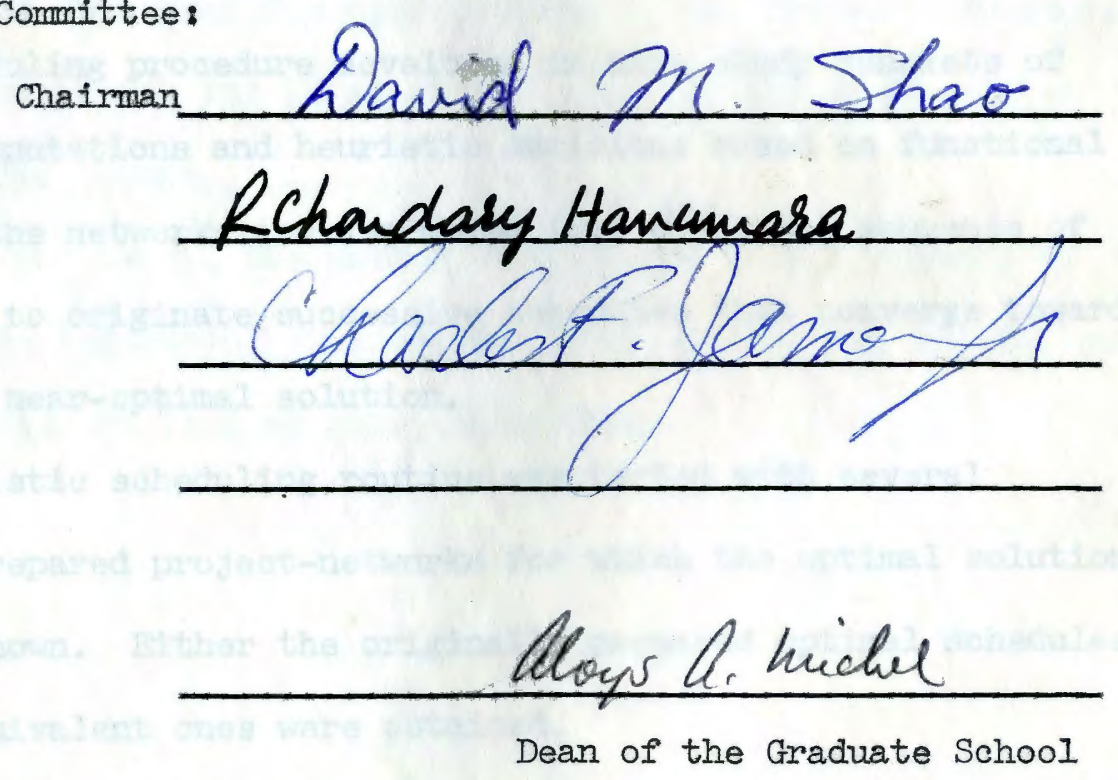

UNIVERSITY OF RHODE ISLAND

1972 


\section{ABSTRACT}

A heuristic scheduling routine was developed in this study for scheduling the activities of a project-network. The objectives of the scheduling process are to minimize the daily allocation of resources, satisfy constraints on the availability of resources, and achieve total completion of the project within a given due date.

Since this type of a problem is a large combinatorial one, an analytical solution is almost impossible, and always impractical, even for small project-networks.

The scheduling procedure developed in this study consists of a series of computations and heuristic decisions based on functional properties of the networks and assembled into a logical sequence of steps designed to originate successive schedules that converge toward the optimal or near-optimal solution.

The heuristic scheduling routine was tested with several artificially prepared project-networks for which the optimal solutions were already known. Either the originally prepared optimal schedules or resource equivalent ones were obtained.

The solution of this problem will find real-life applications in the maintenance functions of varying industrial organizations, and in the construction industry among others. 


\section{ACKNOWLEDGMENTS}

The author wishes to express his sincere gratitude to

Dr. David Shao, professor of Industrial Engineering, for his guidance, valuable suggestions and constant encouragement throughout the entire preparation of this thesis.

The author is indebted to Dr. Charles F. James Jr., chairman of the Industrial Engineering Department, for his friendship, encouragement, and valuable review of the manuscripts.

The author expresses his appreciation to Dr. Choudary Hanumara, professor of Statistics and Computer Science, for his constructive criticism of this thesis.

Last but not least, the author is grateful to all members of the staff of the Industrial Engineering Department of URI and fellow students, who made me feel at home among them. 
DEDICADO CON TODO CARIÑO A MIS PADRES:

Sr. Héctor Guillermo Alvarez

y

Sra. Ana Herrera de Alvarez 
TABIE OF CONTENTS

Page

ABSTRACT ............................. i i

ACKNOWLEDGMENTS ........................ i i

DEDICATION ............................ iv

TABLE OF CONTENTS ..................... v

LIST OF TABLES ....................... vi

LIST OF FIGURES ..................... vii

Chapter

I. INTRODUCTION ....................... I

II. IITERATURE REVIEW ................. 13

III. SINGLE-PROJECT SINGLE-RESOURCE SCHEDULTNG * * * 30

IV. GENERALIZED PROJECT SCHEDULING PROBIFM . . . . 81

V. CONCLUSIONS .................. 89

VI. RFFERENCES . . . . . . . . . . . 92

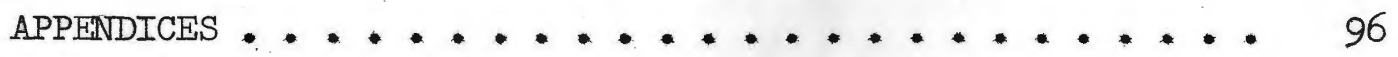

A. COMPUTER PROGRAM OF THE SCHEDULING ROUTINE

B. COMPUTER SOLUTION OF THE EXXAMPLE PROJECT

C. COMPUTER SOLUTION OF THE CONSTRUCTION OF A GAS STATION 


\section{LIST OF TABLES}

Number

Page

I DATA OBTATNED IN THE PIAANNING STEPP.......... 53

II NETWORK CHARACTERISTICS (ACTIVITIES) . . . . . 57

III NETWORK CHARACTERISTICS (EVHNTS AND PROJECT) . . . 59 


\section{LIST OF FIGURES}

Figure

Page

1. RESOURCE IEVELING PROBLEM. ............... 16

2. RESOURCE ALIOCATION PROBLEMM ............... 21

3. ILLUSTRATION OF HU'S METHOD (when M = 3) ......... 29

4. FLOW CHART OF THE SCHEDULING ROUTINE ........... 49

5. EXAMPLE PROJECT-NETWORK ................ 52

6. INITIAL SCHEDULE AND RESOURCE PROFIIE - FXXMPIE PROJECT. * 62

7. SECOND SCHEDULE AND RESOURCE PROFIIE - EIXAMPLE PROJECT * * 64

8. THIRD SCHEDULE AND RESOURCE PROFIIE - EXXAMPLE PROJECT • 66

9. FOURTH SCHEDULE AND RESOURCE PROFILE - EXAMPLE PROJECT . 68

10. FIFTH SCHEDULE AND RESOURCE PROFILE - EXAMPLE PROJECT • 70

11. SIXTH SCHEDULE AND RESOURCE PROFIIE - EXAMPLE PROJECT * 72

12. SEVENTH SCHEDULE AND RESOURCE PROFILE - FXAMPLE PROJECT. . 73

13. HEURISTIC BEST SOLUTION SCHEDULE AND RESOURCE PROFIIE -

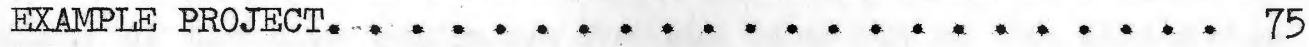




\section{INTRODUCTION}

In 1957 a team of engineers and mathematicians from Du Pont and Sperry Rand Corporation developed a planning, scheduling, and control technique that became known as the Critical Path Method (CPM). At about the same time, the U.S. Navy Special Projects office, working with a firm of management consultants and with Lockheed, developed a management control system that was used successfully for coordinating the work of some 3,000 contractors, suppliers, and government agencies involved in design, development, and fabrication of Polaris missiles under the Navy's Fleet Ballistic Missiles Program; this control system was named PERT (Program Evaluation and Review Technique) and proved to be so successful that the Navy credited it for advancing the completion of the Polaris program by more than two years.

Originally, PERT's methodology was probabilistic due to the uncertainty of the time estimates for the duration of the activities involved in the Polaris program. On the other hand, CPM"s methodology was deterministic, which is understandable since CPM was developed in an environment dominated by constmuction engineering and maintenance activities where time estimates are fairly well defined by experience. As actually practiced today, however, either methodology can use the probabilistic as well as the deterministic model, and neither one seems to be overwhelmingly superior to the other. 
PERT and CPM are widely used project-network planning and scheduling techniques. Both make use of the fundamental approach of dividing the profect into two kinds of basic elements: activities or time consuming elements, and events or time points defined as the start or the end of an activity. The project is represented graphically by a "network" of arrows and circles showIng the time-precedence relations of the activities and events. The "critical path" is found by special calculations depending only on the time-precedence relations of the activities and events and is defined as the longest time consuming chain of activities and events connecting the start event and the end event of a given projectnetwork. The length of the critical path also represents the minimum time needed to complete the project; e.g.: the "earliest project completion time" is determined by the critical path. The problem of scheduling a project is actually concerned with the determination of the starting date and the finish date of each activity in the project. Since the earliest starting time, earliest finish time, latest starting time, latest finish time, activity slack time, and other related Information are obtained through PERT-CPM computations, it is fairly easy to obtain an initial schedule of the project, simply by scheduling the activities without dismupting the time-precedence relations embedded in the network.

PERT-CPM techniques have proved to be very useful when the major concerm is on the variable time, and when it can be assumed that there is an infinite availability of resources and an open budget. However, these assumptions are not always valid. 
From the very beginning of the development of PERT-CPM techniques, there have been suggestions to extend the general utility of network planning and scheduling by including other variables besides time. The major concerns were with the problems of time-cost tradeoff, and of scheduling with limited resources. Project time-cost tradeofe 10,26 is the problem of determining the cost of reducing the project completion time by "crashing" a selected combination of activities. Crashing an activity means reducing its duration, usually accomplished by allocating more resources to this activity.

Project scheduling with limited resources comprises two problems: the first one consists of the allocation of resources to the activities, on a day-by-day basis, up to the limit of available resources, trying to find the earliest project completion time that still satisfies the resource constraints; the second problem is finding a schedule that minimizes the daily resource allocations and at the same time completes the project within the given due date. This second problem is most commonly known as the "resource leveling problem" of project scheduling with limited resources.

Insofar as is known, no generalized analytic technique has proved to be successful in solving a generalized problem of projectnetwork scheduling with limited resources, and only "heuristic" techniques applied to varying situations are widely used in practice. A heuristic is a guide or a method of reducing search in a problem solving situation; the phrase "mle of thumb" is often used synonymously with "heuristic". 
The following definitions and/or assumptions are given to form a basis for the statement and formulation of the problem of leveling resource allocations when scheduling large project-networks. However, more definitions and/or assumptions might be given later on, as a part of the text, when deemed necessary.

1. The project is a "one time project-network with Iimited resources", which means that:

I) once the project is started it will be continued without interruption until its total completion is achieved,

2) the project can be represented by a network showing the time-precedence relations of its activities and events,

3) the project may require several kinds of resources, but at least one kind is subjected to availability constraints,

4) there is no exchange or sharing of allocated resources with another project being executed during the same period of time by the same company or by an affiliate company.

2. The variable time $(t)$ is considered, to be an integer variable expressed in days (tIme-units).

3. "Resources requirements" of an activity (or project) stand for the daily amounts of resources that are needed for its successful completion, "resources availability" refers to the pools of available resources from which the resources requirements can be satisfied, and "resources allocations" refer to the amount of resources drawn from the pools of available resources and assigned to scheduled activities on a day-by-day basis.

4. Each activity behaves like a complete and separate entity within 
the network, that is:

I) once the activity is started it has to be continued until its completion is achieved,

2) any activity requires the same amount of resources during any day of its entire duration,

3) resource requirements of one activity may or may not be equal to the resource requirements of another activity.

4) amounts of resources allocated to one activity cannot be allocated to another activity during the same day.

5. The duration and daily resource requirements of all activities in the network have been calculated through time-cost tradeoff computations and can be considered as fixed values.

6. The total amount of resources allocated in any day is equal to the summation of the individual resource requirements of all the activities scheduled on the same day.

\section{Statement of the Problem}

The problem to be solved in this thesis is the following:

"To find a schedule for the activities of a project-network that minimizes the daily allocations of resources, satisfying stated constraints on the availability of resources, and achieving total completion of the project within a given due date."

The problem as stated above represents a restricted version of the problem of project scheduling with limited resources; restricted because we are interested mainly in minimizing peak resource allocations within a given project due date (e.g., resource leveling problem), 
even if it means to idle some of the avallable resources; this is what makes our problem different from an allocation problem where the main interest is to obtain the earliest project completion by allocating all available resources to suitable subsets of activities, in a day by day basis, until all activities are scheduled.

Some heuristic techniques have been developed for the solution of related problems ${ }^{*}$ which could give a solution to our problem, but the last word is not yet in on project scheduling with limited resources, and continued research leading to the development of new approaches will help to measure the worth of the various scheduling rules that have been suggested. We are safe in saying that new heuristic techniques in this area will be, in fact, valuable for the final development of an analytical solution in the future.

\section{Mathematical Formulation of the Problem}

First we define the required variables and parameters, then we give the formulation of the objective function, and finally we present the integer programming formulation of our problem.

*

These problems are discussed at the beginning of Chapter III. The techniques available in the open literature, and which are interesting to us, are also presented in Chapter III. 


\section{Definition of Variables and Parameters}

1. $t=1,2,3, \ldots, t_{n}$ integer variable representing days of schedule; where $t_{n}$ is the project completion day, e.g., the $\mathrm{n}^{\text {th }}$ day of schedule.

2. $t_{d}$ is a parameter representing the fixed project due date. 3. $j=1,2,3, \ldots$, a integer variable representing activities identification numbers (ATN's), where a is the total number of activities in the network.

4. $i=1,2,3, \ldots, g$ integer variable representing the $g$ kinds of resources required by the activities.

5. $r_{i j}$ represents the requirements for resource $i$ of activity $j$; it is expressed in units of resource per day.

6. $d_{j}$ represents the duration of activity $j$ expressed in days.

7. $\mathrm{X}_{\mathrm{jt}}$ is an integer variable that is either one or zero: $X_{j t}=I$ if the activity $j$ is scheduled during day $t ;$
$X_{j t}=0$ if the activity $j$ is not scheduled during day $t$.

8. Q it is an integer variable representing the total amount of resources i allocated during the day $t$ of the schedule.

9. $K_{i}$ is a parameter representing the fixed amount of resources $i$ available to any combination of activities during any day of the schedule.

10. Since the resource requirements $\left(r_{i j}\right)$ of any activity have to be satisfied by the resource allocation on the schedule, it will always be true that: 


$$
\begin{aligned}
Q_{i t}= & \sum_{j=1}^{a} r_{i j} x_{j t} \\
& \text { for } t=1,2,3, \ldots, t_{n}
\end{aligned}
$$

11. $Q_{i}^{*}$ represents the largest current peak allocation of resource $i$ on the schedule; that is:

$$
Q_{i}^{*} \geq Q_{i t}
$$

for any day $t$.

Formulation of the Objective Function

The objective of our scheduling problem is to minimize the daily allocations of resources, satisfying the stated availability constraints $\left(K_{i}\right.$ for $\left.i=1,2,3, \ldots, g\right)$, and achieving total completion of the project within the given due date $\left(t_{d}\right)$. This objective will be accomplished by minimizing the following objective function (O.F.):

$$
\text { O.F. }=Q_{i}^{*}=\left(\operatorname{maximum} \sum_{j=I}^{a} r_{i j} X_{j t}\right)_{i}
$$

where:

$$
\begin{gathered}
t=1,2,3, \ldots, t_{n} \\
t_{n} \leq t_{d} \\
i=1,2,3, \ldots, 8 \\
Q_{i}^{*} \leq K_{i}
\end{gathered}
$$


Integer Programming Formulation of our Scheduling Problem

The integer programming formulation presented next would provide an analytic solution to the problem of project scheduling with limited resources. We are using here an approach similar to that of Bowman ${ }^{5}$ for the job shop problem. Integer-Iinear Programing formulation:

$$
\begin{aligned}
\operatorname{minimize} & \left(\operatorname{maximum} \sum_{j=1}^{a} r_{i j} x_{j t}\right)_{i} \\
& \text { for all and every } i=1,2,3, \ldots, g \\
& \text { in the range: } \quad t=1,2,3, \ldots, t_{n}
\end{aligned}
$$

subject to the following constraints:

1) time constraint; project due date is not exceeded.

$$
t_{n} \leq t_{d}
$$

2) resource constraints; resources availabilities are not exceeded.

$$
\sum_{j=1}^{a} r_{i j} x_{j t} \leq K_{i}
$$

$$
\begin{aligned}
& \text { for any } \quad i=1,2,3, \ldots, g \\
& \text { and for any: } t=1,2,3, \ldots, t_{n}
\end{aligned}
$$

3) All activities will be performed.

$$
\sum_{t=1}^{t_{n}} X_{j t}=d_{j}
$$

$$
\text { for any } j=1,2,3, \ldots, \text { a }
$$


4) No activity will be split.

$$
\begin{aligned}
a_{j} X_{j t}-d_{j} X_{j}(t+1) & +\sum_{s=t+2}^{t} x_{j s} \leq d_{j} \\
& \text { for any } j=1,2,3, \ldots, a
\end{aligned}
$$

5) No activity will be started before its predecessors are completed; time-precedence relations in the network are not broken.

$$
d_{p} x_{j t} \leq \sum_{s=1}^{t-1} x_{p s}
$$

where: $p=$ any predecessor of $j$

for any: $t=1,2,3, \ldots, t_{n}$

and for any $j=1,2,3, \ldots, a$

It should be noted that this integer programming model does not allow for crashing or stretching of activities. Also it does not assure the finding of the earliest schedule satisfying the above constraints as the Bowman model does (suitable for the resource allocation problem). It does assure, however, the finding of a feasible schedule that completes the project in due date with the minimum daily resource allocation (resource leveling problem).

The large number of variables and equations involved, coupled with additional equations and slack variables necessary to assure an integer solution, would lead to such computational complexities that attempting a solution with this technique is almost impossible, and 
always impractical, even for a small project. Furthermore, a real Iife project with hundreds of activities will surely exceed the capacity of present computers. For the reasons discussed above, we can say that his analytical solution is impractical for our scheduling problem.

The author concentrated his research on developing a heuristic routine that, following the formulation given above, would originate the best feasible schedule. The author wishes to emphasize that the word "best" implies only that we will try to find a feasible schedule with the minimum peak resource allocations, not just any feasible solution. This best feasible solution cannot be assured to be the optimal feasible solution of the scheduling problem, because optimal solutions are assured only by analytical techniques. However, as we shall see in Chapter III, the heuristic routine developed in this study actually originates schedules that converge to the optimal schedule, and there is a good chance of finding a near optimal schedule if not the real optimal one.

There will be projects for which no feasible solution can be found within the given constraints. In this type of situation, we have to decide whether to increase the level of available resources or to allow some days of project slippage - or perhaps both at the same time - to be able to realize the project. "Project slippage" (S) stands for the number of days of delay in the completion time of a project beyond the corresponding fixed due date. In any case, whichever decision we make will originate in unexpected extra cost for the project which must be reduced to a minimum. We say that 
this extra cost is unexpected, because an efficient management usually seeks to set a due date that provides enough flexibility to avoid this kind of situation. We are therefore confronted with the problem, of trading the cost of increasing the level of available resources against the penalty costs of delaying the completion of the project. Dollar penalties for delays are common in project contracts, especially in the construction industry. The heuristic routine, when confronted with this situation of no feasible solution, will originate several schedules with different amounts of project slippage, so that the project manager can decide which one to take. Since the constraint on project duration (e.g. project due date) is broken, we need to set another constraint that replaces it in the formulation: we need to specify a "maximum project slippage" $\left(\mathrm{S}_{\mathrm{m}}\right)$. This new time constraint may be posed as follows:

Alternative time constraints:

$$
t_{n} \leq t_{d}+s
$$

where:

$$
\begin{aligned}
\mathrm{S}= & 0,1,2, \ldots, \mathrm{S}_{\mathrm{m}} \text { is an integer variable that fixes } \\
& \text { different amounts of project slippage. } \\
\mathrm{S}_{\mathrm{m}}= & \text { maximum of project slippage. }
\end{aligned}
$$




\section{IITERATURE REVIEW}

This chapter reviews the various solution techniques that have been proposed to solve problems of project-network scheduling with limited resources. The review is restricted to the presentation of the basic concepts and approaches involved in each technique (important to our research) as described in the open literature. All of these techniques have a common foundation on standard PERT-CPM procedures, and are in general heuristic solutions of non-generalized problems. Analytic solution to the generalized problem of project scheduling with resource constraints has not been successful up to the present date because of the following main difficulties:

1. The large amount of alternatives available for scheduling the various activities which leads to a combinatorial problem of formidable magnitude, even for small sized problems.

2. Embedded interdependence of activities as a result of sharing the same resources that are rarely known; and even if they were known, to incorporate them into the formulation would present a major problem.

3. Some activities can also be split in time, crashed, or extended to suit available levels of resources; if we couple them with 
the possibilities of overtime work and possible substitution of resources, we might be invalidating the original estimates and complicating the formulation to a point where no meaningful solution is possible.

4. Even with a trimmed-down formulation, a practical size project would probably exceed the capacity of present computers and, In any event, would be an inefficlent means of solving the problem.

Analytic formulations of the line balancing problem ${ }^{42}$ and of the job shop problem ${ }^{5}$ can be transformed to provide analytic formulations for problems of project scheduling with limited resources, but they are interesting mainly from the conceptual standpoint of the problems rather than as practical or efficient means of solving them. We are safe in saying that the heuristic techniques aided by the computational power of digital computers will continue to contribute in an important way to solve some of the complex planning and scheduling problems of project management.

Solution techniques for problems of project-network schedulting with limited resources usually take one of the following two forms: a. Resource leveling techniques-These techniques attempt to reduce peak resource allocations as much as the time precedence relations of the activities and events in the network will permit within a given project due date. These techniques are usually suitable for use with, or subsequent to, the time/cost tradeoff analysis. 10,26

b. Resource allocation techniques-These techniques try to 
allocate all available resources to selected subsets of activities on a day-by-day basis, attempting to find the earliest project completion time consistent with the stated level of available resources.

In order to easily identify the scope of the problem that each technique is aimed at solving, we will further identify them as:

1) single-project single-resource techniques,

2) single-project multi-resource techniques,

3) multi-project single-resource techniques, and

4) multi-project multi-resource techniques,

whenever necessary.

\section{Resource Leveling Techniques}

A typical single-project single-resource leveling problem may be posed as follows: the critical path through the network has been determined and all activities have been tentatively scheduled at their earliest start times. When all the activities in the network are scheduled at their earliest start times, we say that we have an "earliest start schedule" for the project. The profile for the daily resource allocations might appear as in Figure I-A. The problem is to level down the peak resource allocations as much as the network will permit, subject to the constraint on project duration given by the project due date $\left(t_{d}\right)$. The resource profile for a feasible solution schedule might appear as in Figure $1-B$.

Burgess and Killebrew ${ }^{7}$ suggest a method of comparing alternate schedules obtained by sequentially moving, in time, slack activities 
and ocuputing the resulting resouroe proftlas. The mesaure of

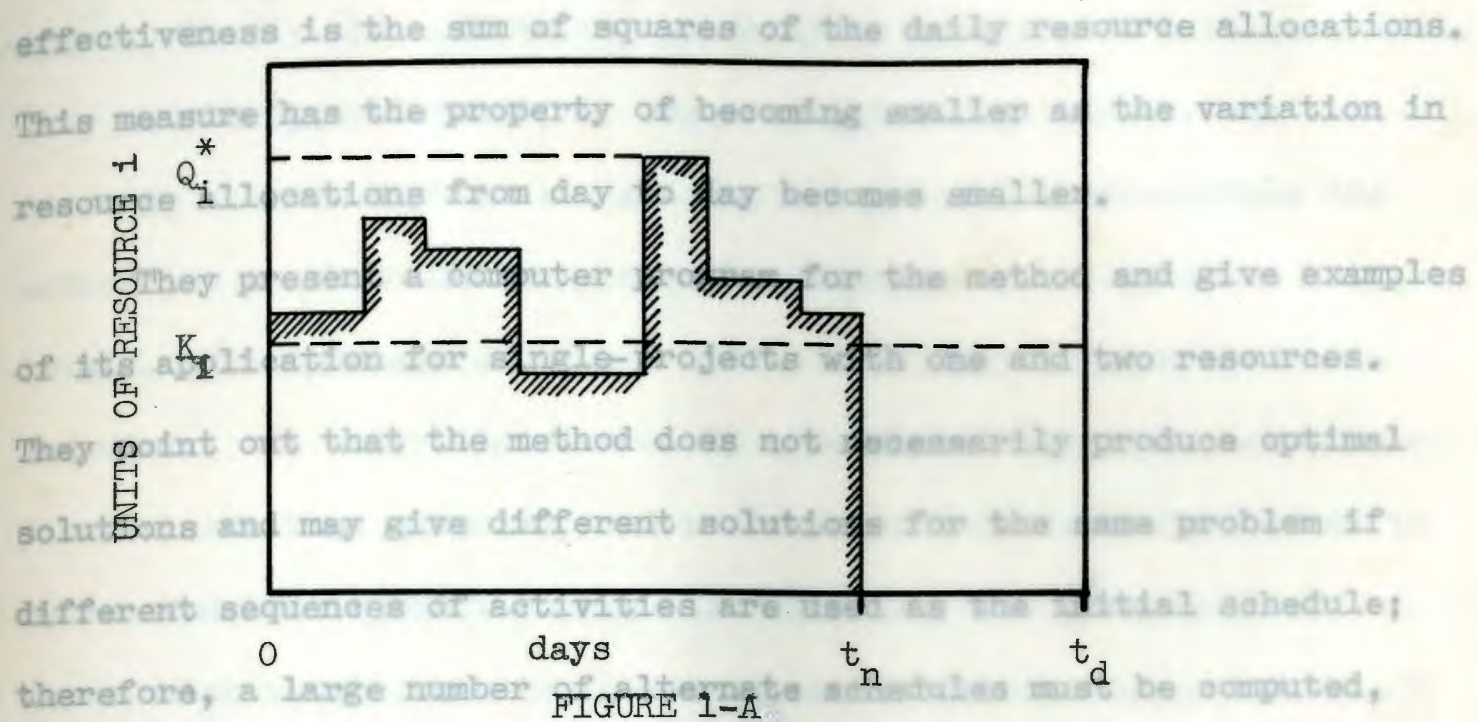

using varying aotivity orderings.

\section{Dendtte presents a ecmputerised ron aveling. \\ TYPICAL RESOURCE PROFILE OF AN EARLY START SCHEDULE}

procedure developed at Bughes Afroraft Company * Like the Burgess.

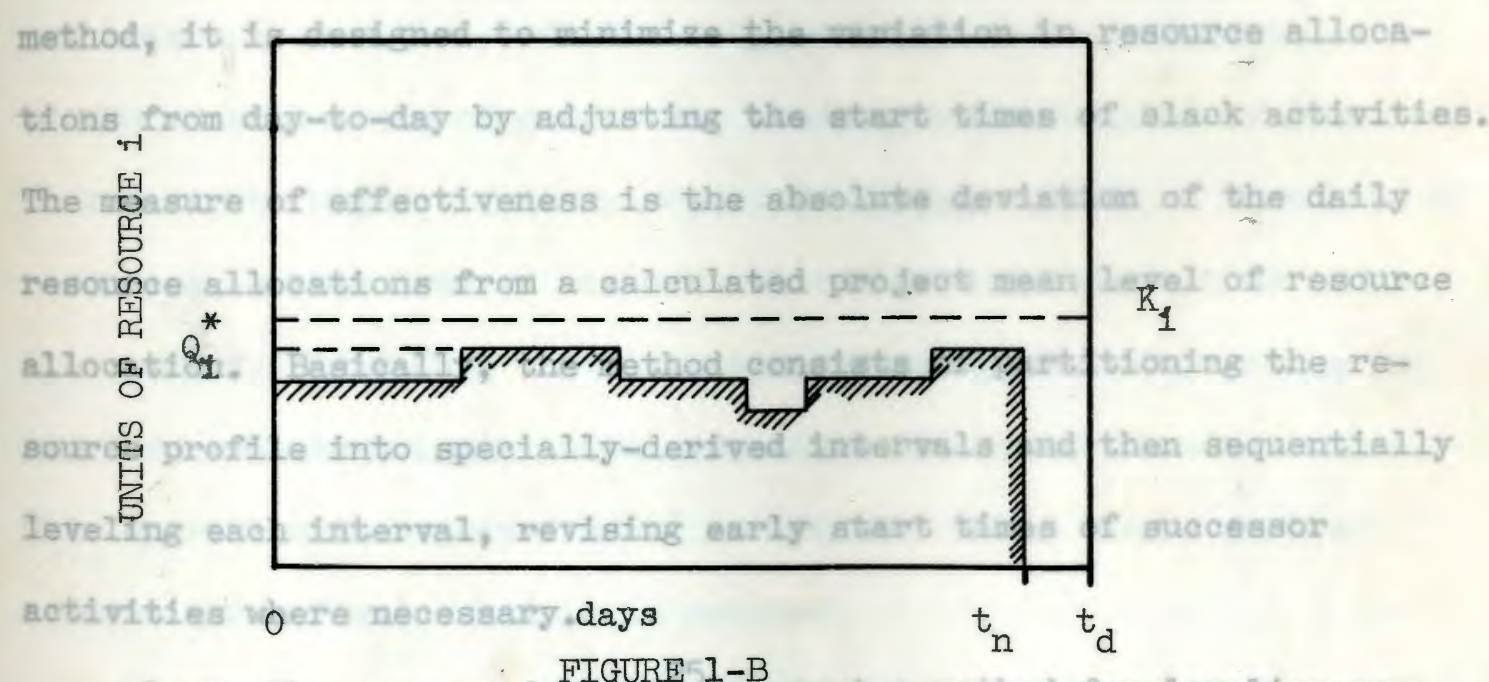

Levy, Thoupson, and FIGURE 1-B sent a method for leveling re-

BCTYPICAL RESOURCE PROFILE OF A FEASIBLE SOLUTION SCHEDULE the two mothods fust desoribed above. Thail problem is essentisily one of malt FIGURE 1. - RESOURCE IEVEIING PROBLEM 12 an early start sohedule, along with total slaok values for all sativities, 1 s 
and computing the resulting resource profiles. The measure of effectiveness is the sum of squares of the daily resource allocations. This measure has the property of becoming smaller as the variation in resource allocations from day to day becomes smaller.

They present a computer program for the method and give examples of its application for single-projects with one and two resources. They point out that the method does not necessarily produce optimal solutions and may give different solutions for the same problem if different sequences of activities are used as the initial schedule; therefore, a large number of alternate schedules must be computed, using varying activity orderings.

Dewitte $^{12}$ presents a computerized resource (manpower) leveling procedure developed at Hughes Aircraft Company. Like the Burgess method, it is designed to minimize the variation in resource allocations from day-to-day by adjusting the start times of slack activities. The measure of effectiveness is the absolute deviation of the daily resource allocations from a calculated project mean level of resource allocation. Basically, the method consists of partitioning the resource profile into specially-derived intervals and then sequentially leveling each interval, revising early start times of successor activities where necessary.

Levy, Thompson, and Wiest ${ }^{25}$ present a method for leveling resource (manpower) allocations which is similar in many respects to the two methods just described above. Their problem is essentially one of multi-project multi-resource. First of all an early start schedule, along with total slack values for all activities, is 
Wilson ${ }^{42}$ presents a method designed to produce the minimum amount of daily resource allocations required to achieve a given project due date. Instead of the random choice, he incorporates a dynamic programming scheme at each iteration to determine feasible subsets of activities to be moved. However, he makes the simplifying assumption that each activity requires one unit of the same kind of resource, and that each activity can be intermupted and started again without penalty. This latter assumption is expressed by subdividing the activities into "tasks" that have a duration equal to one unit of time. The method is simple to use for small projects but becomes cumbersome as the number of events and activities in the network increases. Even though his method would be easy to program for machine operation, Wilson does not discuss it.

In addition to this single-project single-resource solution technique, Wilson also presents an interesting comparison of the resource leveling problem in networks with the assembly line balancing problem.

Black ${ }^{3}$ presents a techinique similar to Wilson's technique just presented above. Black uses the approach of subdividing the activities into unit time portions, the assumption that activities can be split in time, and an adaptation of the line-balancing problem as a base. His methodology is based on the Gutjahr-Nemhauser algorithm for the line-balancing problem. It involves generating of feasible subsets of activities, and then constructing a new network using the generated subsets as activities and stated resource constraints as timeprecedence relations. This method will produce all feasible solutions 
with respect to given resource constraints. It is computationally most efficient when dealing with the single-project multi-resource case, although comparatively speaking it is cumbersome and, in present form, computationally prohibitive for large networks.

\section{Resource Allocation Technicues}

A typical single-project single-resource allocation problem may be posed as follows: the critical path through the network has been determined, as well as the values of the different slack times of all the activities in the network. We start by scheduling a selected subset of activities during the first day so as to allocate all available resources; the rest of the activities are temporarily postponed. We continue scheduling selected subsets of activities on a day-by-day basis, always revising the previous scheduled days to avoid violations of the time-precedence relations in the network, and always trying to allocate all available resources. The resource profile resulting from ten days of scheduling on a thirty-two days project may look like that shown in Figure 2-A. We continue with this day-by-day allocation with scheduling process until we reach the solution schedule, whose resource profile may resemble that shown in Figure 2-B.

The essential heuristics of these resource allocation techniques are those that determine which activities shall be scheduled and which shall be postponed in any day of this progressive scheduling process. The approach most frequently used is to use activities' slacks as a basis of priority, scheduling first those activities which are most critical. 
Kelley 23 presenta a method which $1 \mathrm{a}$ in mung reapeota similar to that presented by Burgesen for the resouros lavaling problam, Kelley

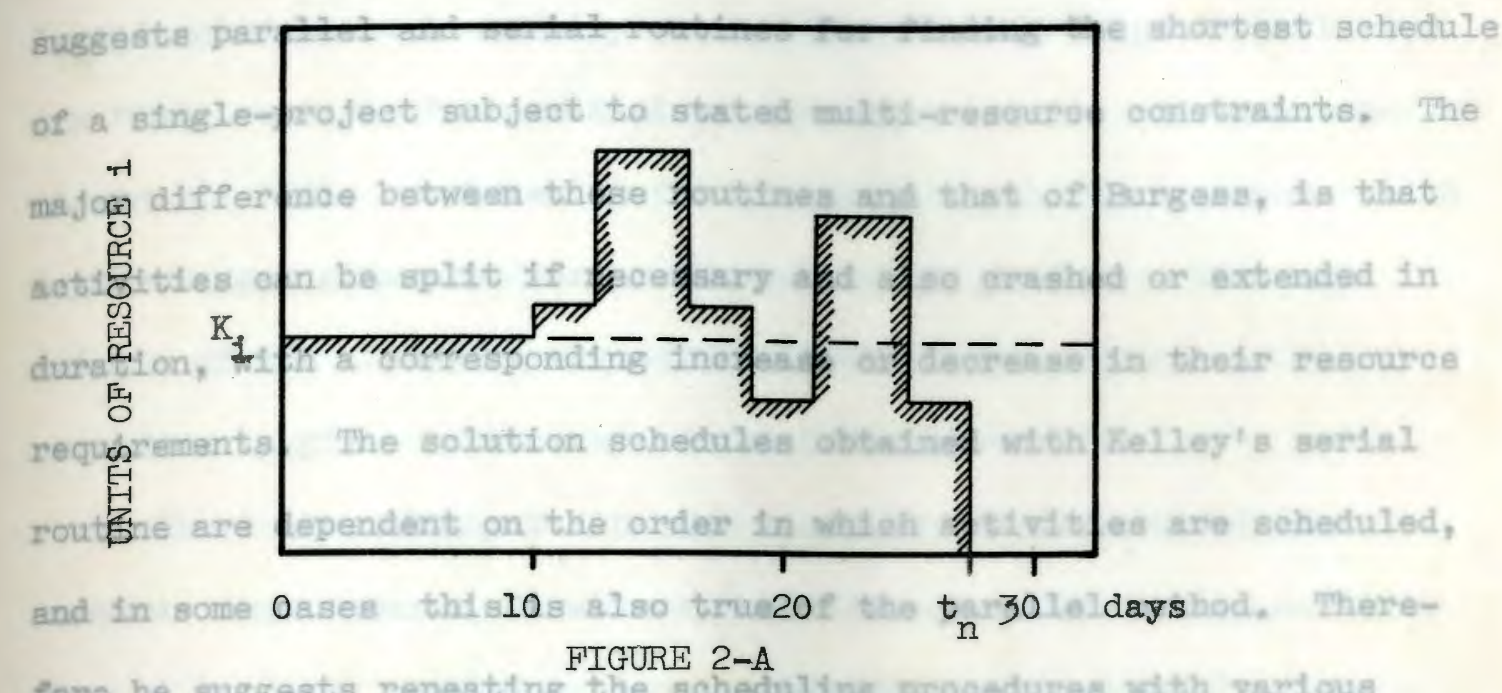

fore he suggests repeating the soheduling proosdures with rartous

sotivities orderings. He also disousses aldititanal rofthoments of the

TYPICAL RESOURCE PROFIIE AFTER TEN DAYS OF PROGRESSIVE RESOURCE AILOCATION WITH SCHEDULING PROCESS

ment (minimum resource allocation needed to atoat an activity), which

would inoresse the practios utility of hils tocanique. He slag

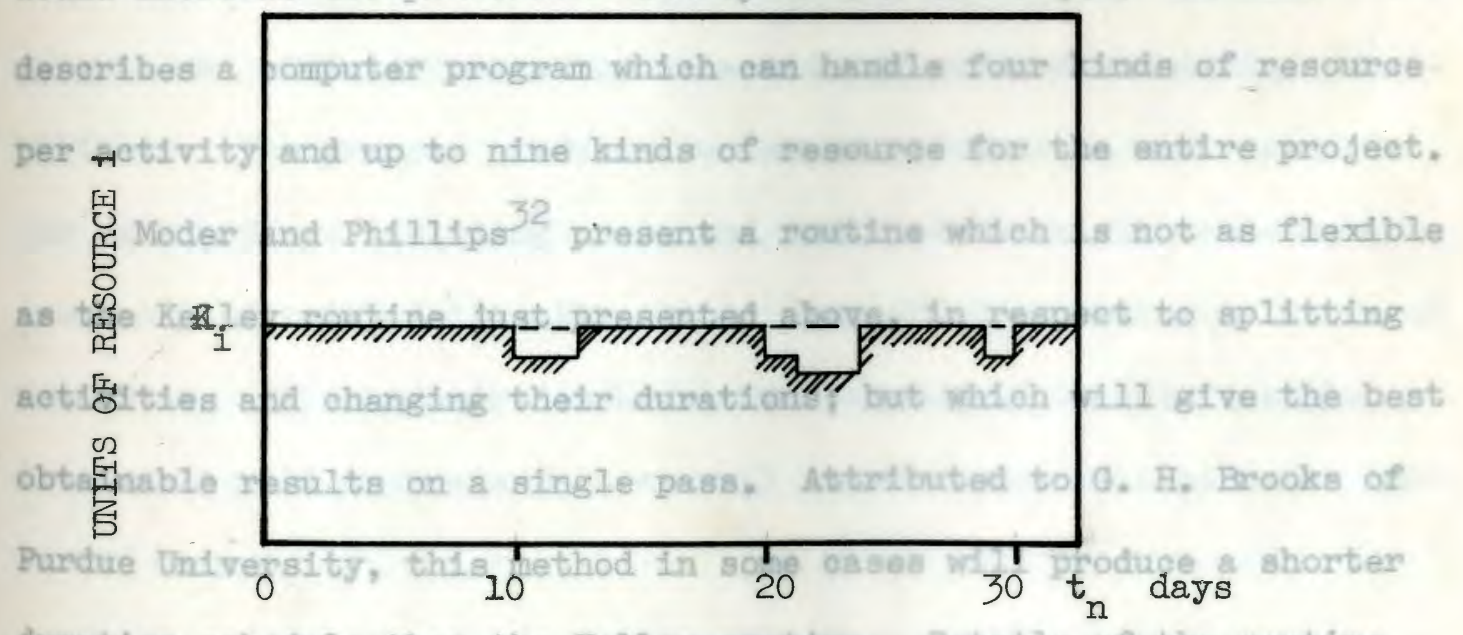

durstion schedule than the FIOURE 2-B

and examples of 1 ts spplication are given in the oited reference. TYPICAL RESOURCE PROFIIE OF THE SOLUTION SCHFDULE Lambourm, and Moshman, Johnson, and iaraen, present a maltiprojeot mul FIGURE 2.--RESOURCE ALIOCATION PROBLEIM Is lmown as RAMPS 
Kelley ${ }^{23}$ presents a method which is in many respects similar to that presented by Burgess 7 for the resource leveling problem. Kelley suggests parallel and serial routines for finding the shortest schedule of a single-project subject to stated multi-resource constraints. The major difference between these routines and that of Burgess, is that activities can be split if necessary and also crashed or extended in duration, with a corresponding increase or decrease in their resource requirements. The solution schedules obtained with Kelley's serlal routine are dependent on the order in which activities are scheduled, and In some cases this is also true of the parallel method. Therefore he suggests repeating the scheduling procedures with various activities orderings. He also discusses additional refinements of the scheduling procedure, such as the use of a "threshold" resource requirement (minimum resource allocation needed to start an activity), which would increase the practical utility of his technique. He also describes a computer program which can handle four kinds of resource per activity and up to nine kinds of resource for the entire project. Moder and Phillips ${ }^{32}$ present a routine which is not as flexible as the Kelley routine just presented above, in respect to splitting activities and changing their durations; but which will give the best obtainable results on a single pass. Attributed to G. H. Brooks of Purdue University, this method in some cases will produce a shorter duration schedule than the Kelley routine. Details of the routine and examples of its application are given in the cited reference. Lambourn, 24 and Moshman, Johnson, and Larsen, 33 present a multiproject multi-resource allocation technique which is known as RAMPS 
("Resource Allocation and Multi-Project Scheduling"). RAMPS is a computerized method designed to handle several projects simultaneousIy and schedule each activity so that project due dates are achieved and "idle resources" are minimized subject to stated resource constraints. "Idle resources" refers to those available resources which have not been allocated during the scheduling process. Although details of the algorithm are not available, a description of the procedure is given in the referenced publications.

Three sets of input data are required for the activities: resource requirements, durations, and cost of splitting one activity once it has been started. Also, certain project information is required, such as starting date, due date, and dollar-penalty rate for project slippage or (alternatively) a project priority rating. Finally the "scheduling objectives" in terms of six factors, such as work continuity, idle resources, et cetera, must be assigned relative weights and will influence the selection of various scheduling possibilities. The program produces two major outputs: a work schedule for each project including costs and daily resource allocations, and a sumary of total daily allocations classified according to kinds of resources. If the desired schedule for a project is not feasible, the output will indicate this as well as the resource constraint that cannot be met.

Since details of the RAMPS computational algorithm are not available in the open literature, we cannot give an analysis of the shortcomings of this technique. However, from the descriptive information provided it is most certainly a heuristic system based on 
juggling slack activities in a manner somewhat similar to techniques described previously. As such, it probably does not neeessarily produce the optimum schedule for a given problem. McGee and Markarian ${ }^{28}$ present a methodology which begins with a time-cost tradeoff formulation of the CPM type. Two sets of timecost data are required for the activities: a "minimum essential effort" (maximum activity duration with minimum resource requirement) and a "crash effort" (minimum duration with maximum resource requirement). A linear function is assumed to exist between these two points. Kinds of resource and constraints on allocations must be given for each time interval. An initial schedule is obtained using the "minimum essential effort" values for allocating resources. If, for this schedule, one or more of the constrained levels of resources are exceeded, slack activities are rescheduled in an attempt to stay within the constraints. If this action proves unsuccessful, they conclude that the fixed project due date cannot be achieved without additional resources. If the schedule allocates resources without exceeding the constrained leviels, a check is made to determine whether the project completion time (given by this schedule) is equal to or less than the fixed project due date. If the project completion time is larger than the project due date, successive crashing of less costIy activities on the critical path is made until the desired due date is achieved, always observing that the constrained levels of resource are not exceeded.

To handle several projects simultaneously the "minimum essential" resource allocation schedule for each project is determined first. 
Then the values for $\mathrm{S}_{i}$ (completion date minus due date for project 1 ) are computed. The project with the largest $S_{1}$ value is crashed first until it achieves its project due date $\left(S_{i}=0\right)$. New comparisons of $S_{i}$ are made to determine which project should be crashed next. Iterations continue in this fashion until all due dates are met (all $\left.S_{1} \leq 0\right)$, or until no further allocations are possible because of the resource constraints.

No computer program is provided for this technique. However, McGee and Markarian do provide logic flow charts of the algorithms involved in their routine.

Wiest ${ }^{38-41}$ has developed a heuristic technique which he calls SPAR-I, and whioh is designed to allocate available resources on a day-by-day basis to project activities listed according to their early start times. His sequential schedule procedure starts by allocating resources, on the first day, to activities selected from a Iist of those currently available and sorted in order of their total slack. The most critical activities, those with the smallest amount of slack, have the highest probability of being scheduled first, and as many of these activities are scheduled as available resources permit. Available activities not scheduled on the first day will be tried on the second day and so on, until all activities are finally scheduled, ylelding a solution to the problem.

Three sets of data are required for the activities: "normal crew size" or normal amount of resources required by the activity, "maximum crew size" or the maximum amount of resources needed to crash the activity to its minimum duration, and "minimum crew size" 
or the minimum amount of resources that still permits the successful completion of the activity. The mules for "crew size" selection are:

1) If an activity to be scheduled is "critical" (the degree of criticality is given by an input parameter), it is placed on a priority list and given special treatment.

2) If sufficient resources are available, the activity is scheduled at 1ts maximum crew size.

3) If insufficient resources are available, then an attempt is made to obtain the required resources by means of the "borrow" and "reschedule" routines, which will be described later on.

4) If all efforts fail, however, and the activity cannot be scheduled even at minimum crew size, then its start date is delayed and will be tried for scheduling on the next day.

5) Before any new activity is scheduled on a given day, all activities already scheduled and still active are examined; if any of these activities is critical and has a crew size less than its maximum, and if resources are available, the activity's crew size is increased as much as possible up to its maximum.

6) If an activity requires several kinds of resources, separate activities are created for each kind of resource and these activities are constrained to start on the same day with the same level of resource allocation - that is, normal, minimum, or maximum crew size.

Borrow from active activities.-If available resources are not sufficient for scheduling some critical activity, we will enter into a routine that examines currently active activities to see if we can 
borrow resources from them. Resources are borrowed from an activity only when the resultant stretching of the activity will not delay the project completion date.

Reschedule of active activities.--Sometimes a critical activity, $\jmath$, can be scheduled, if other activities previously scheduled which use the same kind of resources had been postponed to a later date. This routine scans the list of currently active activities and picks out those which could be postponed without delaying the project completion date. If sufficient resources can be obtained in this way and/or from the borrow routine described above, then activity $j$ is scheduled and the necessary adjustments are made in previous allocations.

SPAR-I is able to accomodate single or multiple projects, variable crew sizes, activities that can be split, shift or non shift scheduling, and various criteria functions for evaluating a schedule. Probabilistic elements in the program can lead to different schedules with successive applications of the program, then the best of these solution schedules can be selected.

SPAR-1 is currently written in FORTRAN-IV and can handle a project with up to 1200 activities, 1000 events, and 25 kinds of resources.

T. C. $\mathrm{Hu}^{21}$ presents an analytic method for minimizing schedule duration of a single-project, given a specified availability of a single-resource, under the simplifying assumption that each activity requires one unit of time and one unit of resource for its completion. The method consists of labeling each node (in an activity-on-node 
network) with the value $a_{i}=X_{1}+1$, where $X_{1}$ is the length of the longest path from node $N_{1}$ to the final node, then grouping $M$ nodes at a time, where $M$ is equal to the number of units of resources ara1lable. The number of such groups is then equal to the minimum number of time-units required for project completion. For example, Figure 3 shows an activity-on-node network with the calculated $a_{i}$ values shown above each node. If there are three untts of resource available during any time unit $(\mathbb{M}=3)$, the nodes could be grouped as shown by the broken lines, always giving preference to high values of $a_{i}$ in first groupings. Since there are six groupings, the project requires six units of time for completion.

Hu proves in his article that this method, which he calls "cutting the longest queue", gives a minimum-time solution schedule for completion of all activities.

Hu's method is very simple to apply for gmall networks, but as the network increases in size (say for more than twenty activities) we quicikly mu into computational complexities. This method could be programmed for machine operation, thus increasing the size of the networks that could be handled.

Unfortunately, we cannot say that Hu's method is a practical one, because it is very unlikely to find a real-life project-network for which his model can be successfully applied. 


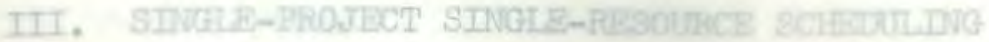

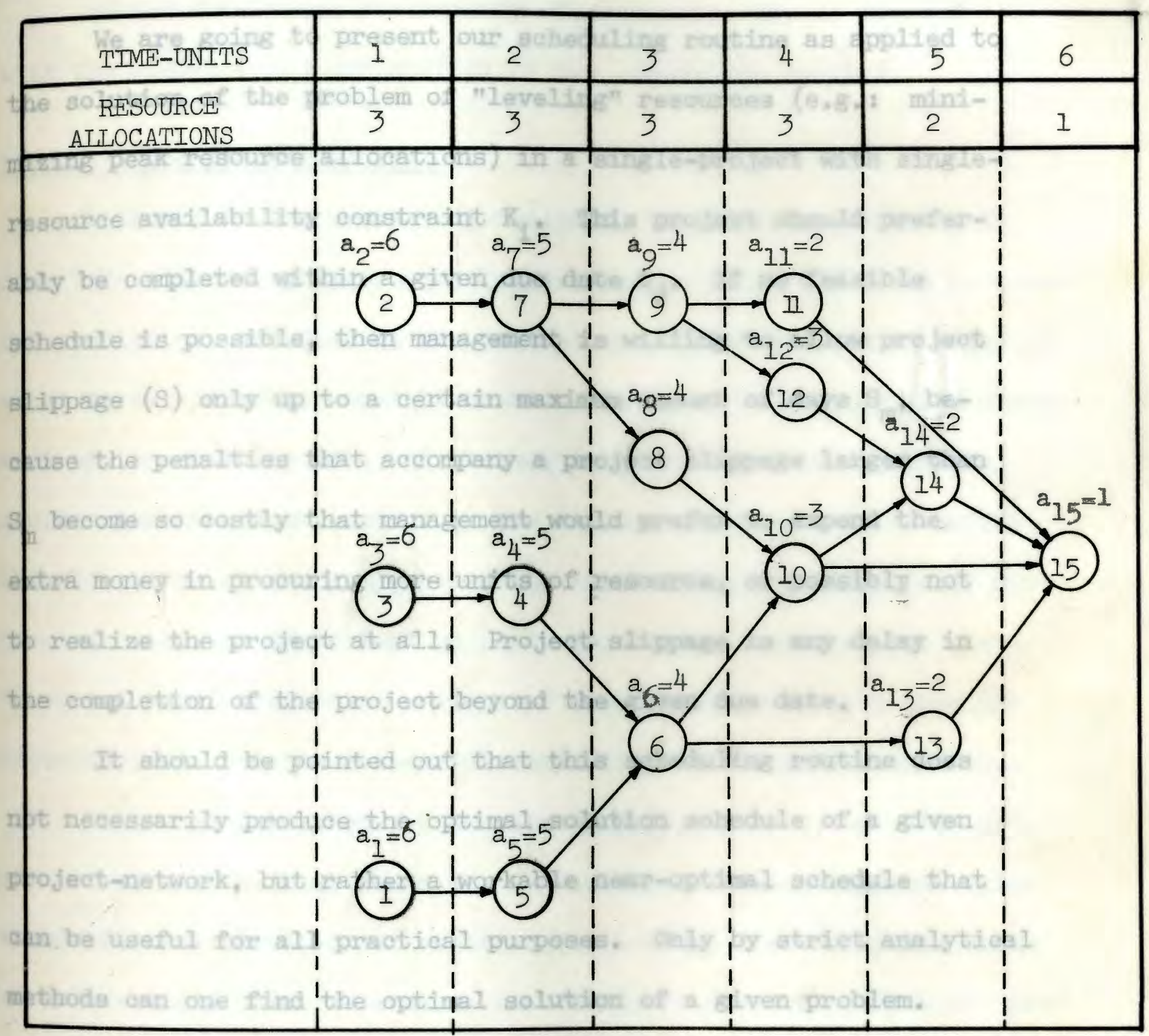

Bowevar, because of the extreme computatilomal cafficulties

FIGURE 3.--Illustration of Fu's method (when $M=3$ ). 


\section{SINGTE-PROJECT SINGLE-RESOURCE SCHEDULING}

We are going to present our scheduling routine as applied to the solution of the problem of "leveling" resources (e.g.: minimizing peak resource allocations) in a single-project with singleresource availability constraint $K_{i}$. This project should preferably be completed within a given due date $t_{d}$. If no feasible schedule is possible, then management is willing to allow project slippage $(S)$ only up to a certain maximum amount of days $S_{m}$, because the penalties that accompany a project slippage larger than $\mathrm{S}_{\mathrm{m}}$ become so costly that management would prefer to expend the extra money in procuring more units of resource, or possibly not to realize the project at all. Project slippage is any delay in the completion of the project beyond the given due date.

It should be pointed out that this scheduling routine does not necessarily produce the optimal solution schedule of a given project-network, but rather a workable near-optimal schedule that can be useful for all practical purposes. Only by strict analytical methods can one find the optimal solution of a given problem. However, because of the extreme computational difficulties encountered when attempting an analytical solution in problems of this type, only heuristic solutions are in common use up to the 
present date. The solution techniques available in the open literature have been discussed in Chapter II. Heuristic is a synonym for "rule of thumb".

Having done these preliminary observations, let us proceed with the step-by-step explanation of the scheduling routine:

\section{Step A. Planning the project}

Planning is the process of analyzing the project, breaking it down into elementary operations (activities) necessary for its successful completion, and finding the technological time-precedence order in which these elementary operations must be done. There must be a statement of the starting date and the due date of the project, whether derived internally or imposed by the customer. One must also define the objectives of the project and its Iimitations. Each activity must have an estimated "duration" or performance time, coupled with its "resource requirements" or amounts of each kind of resource that the activity needs for its successful completion in the given duration.

The project is then represented graphically by a "network" of arrows and circles that shows the technological time-precedence relations of its activities and events. The longest time-consuming chain of arrows and circles determines the "earliest project completion time" and receives the name of "critical path".

The events are assigned identification numbers in such a way so as to prevent two events from having the same number and also taking care that any activity connecting two nodes always goes from a lower event number to a larger event number. Each activity can now be identified by these two event numbers as: $A_{p}, q$, where $p$ stands for 
the identification number of its starting event and $q$ stands for the 1dentification number of its ending event, and where $p$ is always less than q.

The planning process ends with the final listing and tabulation of the data. It is recommended that the following method of Identifying events and activities be used, because it will help to simplify the retrieval of data for future scheduling computations:

1. The events are assigned the identification numbers (EIN's): $1,2,3, \ldots . . e ;$ so that the largest identification number $e$ is assigned to the ending event of the project and is also equal to the total number of events in the network.

2. The events' identification numbers are already identifying the activities, in an implicit way, through the $A_{p, q}$ notation explained before. However, the activities are going to be identified in an explicit way, after they are listed as follows: first, we group the activities according to their p events; second, we list the activities within each group, in ascending order, according to their q events; third, we obtain the total list of activities by writing one group after the other, in ascending order, according to the $p$ events;

fourth, we go through the list of activities assigning the identification numbers (ATN's): $1,2,3, \ldots$, a; so that the largest activity identification number a is also equal to the total number of activities in the network. 
tepe B. Calculation of network characteristics

The data listed and tabulated in the planning step may not be complete for our scheduling purposes. We need to compute or obtain the following information:

For each activity.--Total slack, free slack, independent slack, safety slack, whether it belongs to the critical path or not, whether It is a dummy activity or not, and the amount of "mobility" that each activity has as compared to the mobility of all the other activities in the network (to be measured by the "index of mobility" values); also the earliest start, earliest finish, latest start, and latest finish, if they had not been calculated during the planning step. For each event.--Earliest time, latest time, slack time, and whether it belongs to the critical path or not. For the network.--Earliest project completion time (obtained by calculating the critical path), project slack, project due date, maximum project slippage, maximum resource availability per unit of time $\left(K_{1}\right)$, total number of activities, and total number of events. All these characteristics of the project-network will be used, in one way or another, during the scheduling procedures of our routine; and therefore it is of the utmost importance to obtain their values before we start the scheduling procedures of the following steps.

The definitions and computation algorithms of these network characteristics can be found in almost any textbook dealing with network planning and scheduling, because they form part of the standard terminology and computations of PERT-CPM techniques. The reader interested in obtaining a detailed explanation of these network 
characteristics is referred to Buffa, ${ }^{6}$ Horowitz, ${ }^{20}$ Kelley, ${ }^{23}$ Levy and wiest, ${ }^{26}$ Meyer, 30 Muth, 34 or Waldron. 37 However, since the characteristic of mobility (or flexibility) of the activities is measured in a rather different way in this thesis, we shall explain it.

Mobility of an activity is the property that measures its ability of being rescheduled at a later date (or at an earlier date) relative to its current position in the schedule and without delaying the current project completion time. The mobility of an activity is a direct function of its slack times, and is constrained by the current positions of its neighboring activities, the current project completion time, and the current level of available resources.

We will measure the property of mobility by assigning to each one of the activities in the network an index of mobility, whieh will give the order of the activities according to the amount of mobility that each one has, and also according to the varying degrees of difficulty that they have in making use of this property because of their position in the network.

We are presenting next the algorithm that assigns the index of mobility values to each activity in the network: Index of mobility assignation algorithm.--

1. Set the index of mobility value (IM) equal to the total number of activities in the network (a); that is:

Set:

$$
\mathrm{IM}=\mathrm{a}
$$

2. Assign the current IM value to one of the non-indexed activ- 
ities and then execute rule 3. The rule to decide which one of the still non-indexed activities should be assigned the current IM is as follows:

Assign the current IM value to the non-indexed activity that has the largest amount of total slack. If there is a tie in total slacks, assign this IM to the activity in the tie that has the largest amount of free slack. If there is a tie both in total slacks and free slacks, assign this IM to the activity in the tie that has the largest amount of independent slack. If there is a tie in all three: total slacks, free slacks, and independent slacks, assign this IM to the activity in the tie that has the largest amount of safety slack. If there is still a tie, assign this IM to the activity in the tie that has the largest starting event (event p). If there is still a tie, assign this IM to the activity in the tie that has the largest ending event (event q).

This rule will always assign the current IM value to only one activity because even in the case of ties in all slack times, it is impossible for two activities in a network to have the same starting event and the same ending event.

3. Since the current IM value had been already assigned to one activity (by executing rule 2 above), we should not assign the same IM value to another activity. Therefore, we decrease by one the value of IM before executing mule 4, that 1s, we set:

$$
\text { new } I M=\text { old } I M-1 .
$$


4. Here we simply check the current value of IMI (set by rule 3). IM will be equal to zero when all the activities in the network had already been indexed. Therefore our rule here is: Return to execute mule 2, if the current IM value is larger than zero; if IM is equal to zero, stop the algorithm. It should be emphasized that these index of mobility values will remain the same even if we delay the project completion time given by the critical path - by setting a $t_{n}$ larger than the $t_{n}^{\prime}$ of the early start schedule - because that action only makes the slack times of all activities increase by the same amount of time-units, the amount equal to the difference between the current project completion time $\left(t_{n}\right)$ and the earliest project completion time given by the critical path $\left(t_{n}^{\prime}\right)$.

\section{Step C. Iritial schedule}

We will use as the initial schedule the one in which all the activities are scheduled to begin at their earliest start dates e.g. the "early start schedule" - simply because it is very easy to obtain, since the earliest start and earliest finish dates of the activities come straight from the standard PERT-CPM calculations. Actually any other schedule - any one that is obtained by intuition or by scheduling the activities at random - would be as good as the initial schedule that we are proposing, provided of course that the time-precedence relations in the network are honored.

The corresponding resource profile of our initial schedule is 
then obtained by plotting total daily resource allocations against time.

\section{Step D. Selecting activities for rescheduling}

Looking at the resource profile of our initial schedule (a typical resource profile of an early start schedule was shown in Figure I-A, page 16), it becomes evident that in order to level down the daily resource allocations, we have to cut the peaks and fill in the valleys of the profile. Since it is possible to find several peaks which have the same height and are the tallest of the profile, we have to decide which one of these "highest peaks" will be cut first. As a rule of thumb we will always cut the highest peak which occurs at the farthest day from the project starting date $t_{0}$; that is, the farthest to the right on the resource profile.

This peak was selected because it seems to provide a better chance of being cut than the others. Even if the rescheduling procedures explained in the following steps fall to cut this peak, we could still force the cutting of this peak by delaying the current project completion date. Here again, as in any other heuristic decision, we cannot prove this to be the optimal choice, we can simply say that our decision produces good results and seems to make the best of all the available choices. Hereinafter we shall call this peak the "right most largest peak" or "RMLP".

The RMLP results from the addition of the resource requirements of all the activities scheduled during the same day at which the RMLP occurs; therefore it should be evident that, by rescheduling one of 
these activities to start at a later date, or to end at an earlier date, we wIll cause the reduction of its height (e.g. we will cut it), provided of course that the resource requirements of the rescheduled activity have a value greater than zero.

Next we have to decide which one of the activities contributing to the height of the RMLP will be rescheduled. It is here that we make use of the index of mobility values (IM's) calculated in Step $B$. We list these activities in descending order according to their IM values. This listing of the "activities on the RVLP" is needed for the scheduling procedures of our routine, as we shall explain in the following Step E.

Step E. Realizing the reschedule of the activities

When we reschedule one activity while keeping all the others momentarily still, we are actually moving this activity along the time axis and it is obvious that its resource requirements are also moving accordingly, thus changing the resource profile of the project. Furthermore, this activity could be rescheduled at a later date or an earlier date from its present position in the project schedule; that is, this activity could be moved forward or backward along the time axis. The restrictions that we have for rescheduling activities are: 1. The present position of its starting event (event $p$ ) and that of its ending event (event q); these events actually behave like barriers between which the activity can float freely.

2. The changes in the resource profile that this rescheduling causes should not originate another peak of the same height or of a 
larger height than that of the current RMIP.

3. The activity should be rescheduled as far away as possible from its present position, while filling (resource-wise speaking), the lowest valley that it may reach. This action is convenient for the future scheduling of other activities, since the mobility of the activities is constrained by the height of the current RMIP and by the current positions of its neighbor activities. If the activity cannot be rescheduled at a "better position" - e.g.: all the possible rescheduling positions of this activity only originate peaks of the same height or larger than the current RMLP - we will leave it untouched, and we will say that the activity has been rescheduled in its very same position.

Hereinafter, we shall call "iteration" any successful rescheduling of one activity or group of activities, that cuts the height of the current RIIP by at least one unit of resource, thereby originating a better schedule than the previous one. It should be remembered, however, that the new current RMIP could have the same height as its predecessor, in case we had several peaks of the same height during several different days of our schedule.

There are two types of iteration:

Iteration Type I.--Whether rescheduling forward or backward, this iteration consists of the rescheduling of only one of the activities which are currently scheduled during the same day on which the RVIP occurs. The activities are tried for rescheduling one by one in descending order according to their index of mobility values until an iteration is achieved, or until we exhaust all the 
"activities on the RMLP". This type of iteration is bound by the three restrictions given above.

Iteration Type II.-When rescheduling forward, this iteration consists of rescheduling forward a group of activities, one by one in descending order according to their identification numbers (AIN'S), starting with the activity that has the largest ATN in the network. The largest ATN in our network is "a", which is also equal to the total number of activities in the network, due to the numbering system recommended in Step A. We continue rescheduling forward the activities and updating the position of the events until an iteration is accomplished, or until we have tried to reschedule forward the "activity on the RMLP" that has the lowest ATN number.

When rescheduling backward, this iteration consists of rescheduling backward a group of activities, one by one in ascending order according to their AIN numbers, starting with the activity that has the lowest AIN in the network. The lowest ATN in our network is "1", also due to the numbering system recommended in Step A. We continue rescheduling backward the activities and updating the position of the events until an iteration is accomplished, or until we have tried to reschedule backward the "activity on the RMLP" that has the largest ATI number.

During the research phase of this thesis, it was noticed that the iteration Type II gives better results when it is released from the restriction of "filling the lowest valley that it may reach". It turned out to be better to reschedule the activities as far away as possible, but without originating another peak of the same height as 
the current RMLP. This type of iteration tends to pack the activities to either side of the schedule - resource wise speaking - leaving an empty space in the center of the resource profile. We will have the opportunity of noticing this action later on, on pages 67 and 69.

The following algorithm for trying to obtain an iteration of either type contains the heuristic rules that turned out to give better results during the research phase of this thesis. We know from the execution of the previous steps - the height of the current RMLP as well as the day on which it occurs; we also know which activities are currently scheduled during the same day on which this RVLP occurs as well as their identification numbers (AIN's) and their index of mobility values (IM's).

\section{Rescheduling algorithm}

1. Set the rescheduling direction as "forward".

2. Try to obtain an iteration Type I.

3. If the iteration was achieved, go back to execute Step D (explained on page 37); if the iteration was not achieved, continue.

4. Try to obtain an iteration Type II.

5. If the iteration was achieved, go back to execute Step D;

if the iteration was not achieved, continue.

6. Set the rescheduling direction as "backward".

7. Try to obtain an iteration Type I.

8. If the iteration was achieved, go back to execute Step D; if the iteration was not achieved, continue. 
9. Try to obtain an iteration Type II.

10. If the iteration was achieved, go back to execute Step D; if the iteration was not achieved, continue.

11. Set the rescheduling direction as "forward".

12. Try to obtain an iteration Type II.

13. If the iteration was achieved, go back to execute Step D; if the iteration was not achieved, continue.

14. Set the rescheduling direction as "backward".

15. Try to obtain an iteration Type $I$.

16. If the iteration was achieved, go back to execute Step $D$; if the iteration was not achieved, continue.

17. Try to obtain an iteration Type II.

18. If the iteration was achieved, go back to execute Step D; if the 1teration was not achieved, continue to reschedule backward all the activities of the network - accepting the formation of peaks with a height equal to the height of the current RMLP - and then go to execute Step F (to be explained on page 43). We conclude here that no iteration is possible, because the current schedule is actually the best schedule that our routine can find for the current project completion date (Current $t_{n}$ ). If we wish to obtain a further minimization of the peak resource allocations, we have to delay the project completion date. Whether we can or can not delay the project completion date will be determined by the following steps. 
Step F. Utilizing the project slack

Project slack (PS) is the difference - expressed in days between the given project due date $\left(t_{d}\right)$ and the current project completion date $t_{n}$. According to our assumptions, the time constraint for our project can be equally satisfied by any project completion date equal to or larger than the earliest project completion date given by the critical path of the network $\left(t_{n}{ }^{\prime}\right)$ provided that the $t_{n}$ does not exceed the given $t_{d}$. From the definition of PS, it is evident that we might be faced with one of the following three situations:

1. PS is negative.-This is evidently the result of poor management planning, because a rational manager never commits himself to realize a project in a shorter time than the earliest project completion time given by the critical path of the network. The only action that we can take to avoid the corresponding penalties - for this delay of the project completion beyond the agreed $t_{d}$ - is to start "crashing" selected combinations of activities until the new $t_{n}$ becomes equal to or less than the given $t_{d}$. Crashing activities usually leads to an increase in the resource requirements of the crashed activities, and since this action is beyond the scope of the assumptions given in Chapter I, we will treat any negative PS as if it were a positive project slippage (S). The utilization of project slippage will be explained and discussed later in Step G (page 45). 2. PS is zero.-This situation is not adverse from the point of View of our time constraint, since the $t_{n}$ can be equal to $t_{d}$ and still Field a feasible solution to our problem, provided of course that the 
height of the RMLP of this solution schedule is equal to or shorter than the height of the maximum resource availability allowed for the project $\left(K_{1}\right)$.

If the height of the RMIP of the solution schedule is larger than the height of the given $K_{1}$, then our solution schedule is not feasible - e.g.: the project cannot be realized under the given constraints, $t_{d}$ and $K_{1}$. To be able to realize this project, we have to allow some days of project slippage $(S)$, an increase in the height of the given $\mathrm{K}_{1}$, or both.

3. PS is positive.-This situation is the most advantageous for our scheduling objective of minimizing peak resource allocations, because it provides more mobility for the activities in the network. It is also the most commonly found in real life, because any rational manager will seek to set a project due date that provides him with the opportunity of trying several completion dates without having to pay penalties for project delays. Contracts usually specify penalties only for delays beyond an agreed due date.

The following algorithm summarizes the computations and decisions to be made in this Step $F$ of our scheduling routine:

1. Determine whether the current PS of the project has a negative, zero, or positive value. The formula to be used is:

$$
\text { Current } P S=t_{d}-\text { current } t_{n}
$$

If PS is negative or zero,go to execute rule 2; if PS is positive, go to execute rule 3.

2. Consider this negative or zero PS as though it were a positive project slippage (S) of the same number of days. That is, set: 
current $S=-$ current PS

Then execute Step G (below).

3. The number of slack days this positive PS provides will be used to update the values of the following network characteristics as shown below:

Set:

$$
\text { new current } t_{n}=\text { given } t_{d}
$$

new latest time of event $p=$ current latest time of event $p+$ current PS

$$
\text { for all events: } p=1,2,3, \ldots, e
$$

new latest start of activity $A=$ current latest start of activity $A+$

$$
\text { current PS }
$$

new latest finish of activity $A=$ current latest finish of activity $A+$ current PS

for all activities: $A=1,2,3, \ldots$, a

Then go back to execute Step D (page 37 ).

Step G. Utilizing the project slippage and publishing the solution schedules

Project slippage is any delay in the completion date of the project beyond its corresponding due date; e.g., when the current project completion date $t_{n}$ happens to be larger than the given project due date $t_{d}$. The concept of project slippage is closely related to the concept of project slack: it depends entirely on whether the current $t_{n}$ is smaller or larger than the given $t_{d}$ to call their difference a project slack (PS) or a project slippage (S). That is why we said in Step F (page 43), that a negative PS will be considered as if it were a positive $S$ of the same number of days. 
In project contracting, especially in the construction industry, it is common to specify penalties for delays beyond an agreed due date; e.g., penalties for "project slippage". These penalties are usually in the form of monetary fines which increase at a much faster rate than a simple linear proportionality. For example, a contract may specify that for the first day of slippage the penalty is $\$ 1,000.00$; for two days, $\$ 3,000.00$; for three days, $\$ 6,000.00$, and so on; while in a simple linear proportionality (or one-to-one rate), the penalty for three days of slippage would amount to $\$ 3,000.00$. All this makes the utilization of project slippage most undesirable to any rational manager. On the other hand, to increase the level of available resources over and above the amount normally available (e.g., to increase the given $\mathrm{K}_{1}$ ), is also undesirable because of the cost involved in procuring those extra units of resources. There may even be cases in which those extra units are impossible to procure.

If a manager is confronted with a project-network for which no feasible solution schedule can be found $\left(e_{*}\right.$. , he does not find a schedule which completes the project in due time with the available resources), he would like to know how the daily resource allocations vary in relation to different amounts of project slippage, so that he can make a cost evaluation and select the schedule that gives the less costly combination of project slippage and incrementation of available resources.

It is also obvious that our troubled manager would be willing to allow project slippage only up to a certain maximum number of days 
$S_{m}$ (maximum project slippage), before the penalties get so heavy that he has to accept a large incrementation of available resources, or ultimately decide that realization of the project is not worthwhile. The computations and decisions to be made in this Step G are aimed at providing all the alternative solution schedules necessary to a manager confronted with a situation similar to the one outlined above. Evidently, if the execution of the previous steps had generated a feasible solution schedule, we would be publishing only one, recognized, "heuristic best solution schedule".

The following algorithm summarizes the computations and decisions to be made in this Step $G$ :

1. Compare the height of the current RIILP against the height of the given $K_{1}$. If the height of the current RMLP is larger than the height of $K_{1}$, conclude that the resource constraint is not satisfied and that the current schedule is not a feasible solution to our problem. Then execute rule 3, further below.

If the height of the current RMIP is equal to or smaller than the height of $K_{i}$, conclude that the resource constraint is being satisfied by the current schedule, and that it might give a feasible solution to our problem. Then execute rule 2.

2. Recall the current value of the project slippage (S). If the current value of $S$ is equal to - or less than - zero, conclude that the time constraint is also satisfied by the current schedule, which is therefore our "heuristic best solution schedule"; then publish it and stop all computations.

If the current value of $\mathrm{S}$ is larger than zero, conclude that 
the time constraint is not satisfied by the current schedule, which is therefore not a feasible solution to our scheduling problem. Then execute rule 3.

3.

Publish the current solution schedule because it gives the minimum daily resource allocations for the current $t_{n}$, even though it is not a feasible solution to our scheduling problem; also report whether it was failing to satisfy the resource constraint $K_{1}$, the time constraint $t_{d}$, or both. Then execute rule 4. 4. Compare the current value of $S$ against the value of $S_{m}$ (maximum project slippage to be allowed for this project).

If the current $S$ is smaller than the given $S_{m}$, update the following information:

$$
\text { new current } t_{n}=\text { current } t_{n}+1
$$

new latest time of event $p=$ current latest time of event $p$

$$
+1
$$

$$
\text { for all events : } p=1,2,3, \ldots, e
$$

new latest start of activity $A=$ current latest start of activity $A$

$$
+1
$$

new latest finish of activity $A=$ current latest finish of activity $A$

$$
+1
$$

for all activities : $\mathrm{A}=1,2,3, \ldots, \mathrm{a}$

Then go back to execute Step D (page 37).

If the current $S$ is equal to - or larger than - the given $S_{m}$, stop all computations.

The flow chart given in Figure 4 (page 49) summarizes the 


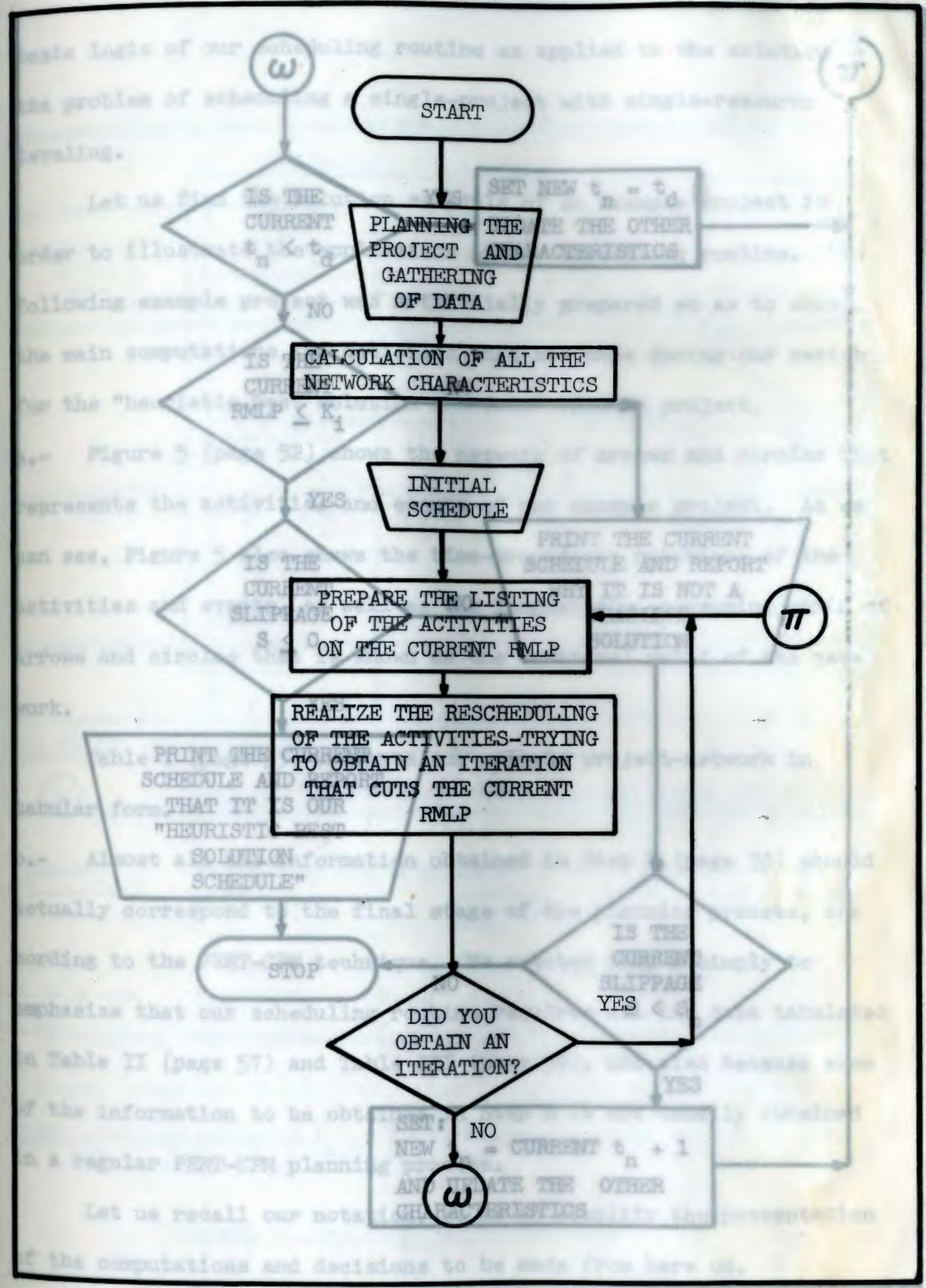

FIOURB FIGURE 4.-FLOW CHART OF THE SCHEDULING ROUTTNE 


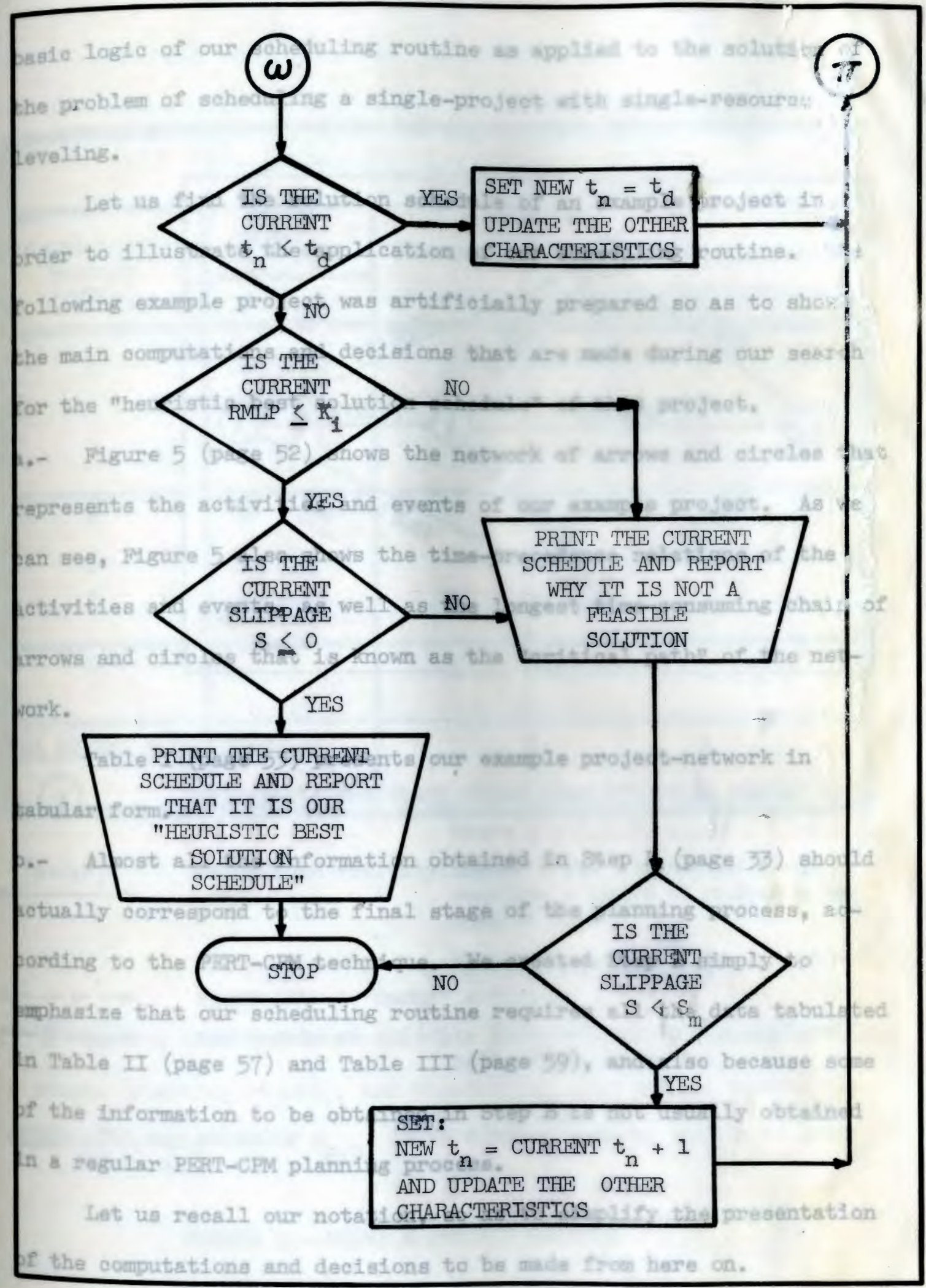

FIGURE 4.-FLOW CHART OF THE SCHEDULING ROUTINE (continued) 
basic logic of our scheduling routine as applied to the solution of the problem of scheduling a single-project with single-resource leveling.

Let us find the solution schedule of an example project in order to illustrate the application of our scheduling routine. The following example project was artificially prepared so as to show the main computations and decisions that are made during our search for the "heuristic best solution schedule" of this project. a.- Figure 5 (page 52) shows the network of arrows and circles that represents the activities and events of our example project. As we can see, Figure 5 also shows the time-precedence relations of the activities and events, as well as the longest time-consuming chain of arrows and circles that is known as the "critical path" of the network.

Table I (page 53) presents our example project-network in tabular form.

b.- Almost all the information obtained in Step B (page 33) should actually correspond to the final stage of the planning process, according to the PERT-CPM technique. We created Step B simply to emphasize that our scheduling routine requires all the data tabulated in Table II (page 57) and Table III (page 59), and also because some of the information to be obtained in Step B is not usually obtained in a regular PERT-CPM planning process.

Let us recall our notation, so as to simplify the presentation of the computations and decisions to be made from here on. 

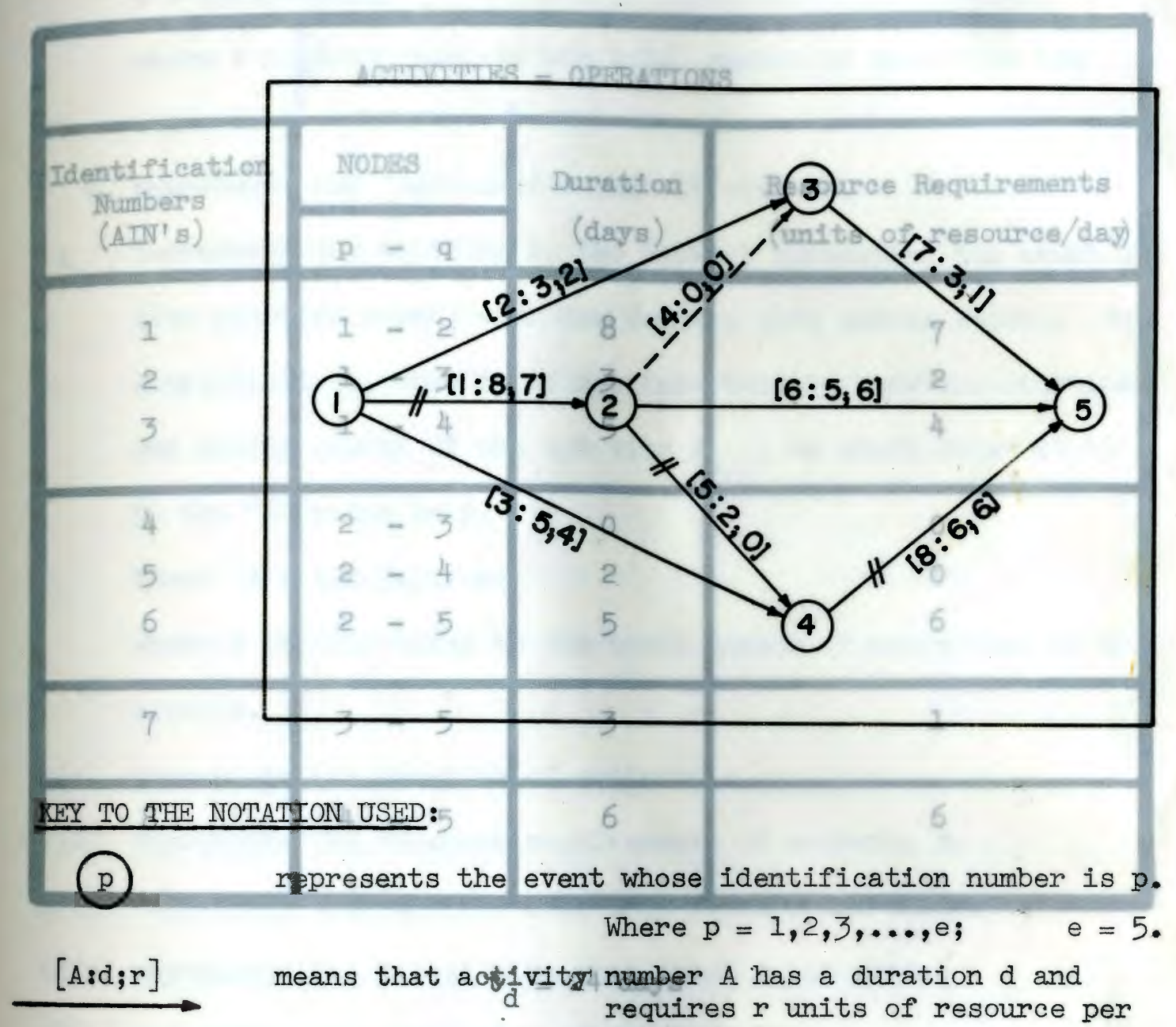

means that aotivity number $A$ has a duration $d$ and requires $r$ units of resource per $S_{m}=3$ unit of time.

$$
\text { Where } A=1,2,3, \ldots, a ; \quad a=8 \text {. }
$$

$--\rightarrow$ represents a "dummy" activity

\# represents an activity that belongs to the critical eir path of the network.

D events (atarting events), and then listed scoording to their NorT:
than $q$.

FIGURE 5. - EXXAMPLE PROJECT-NETWORK 


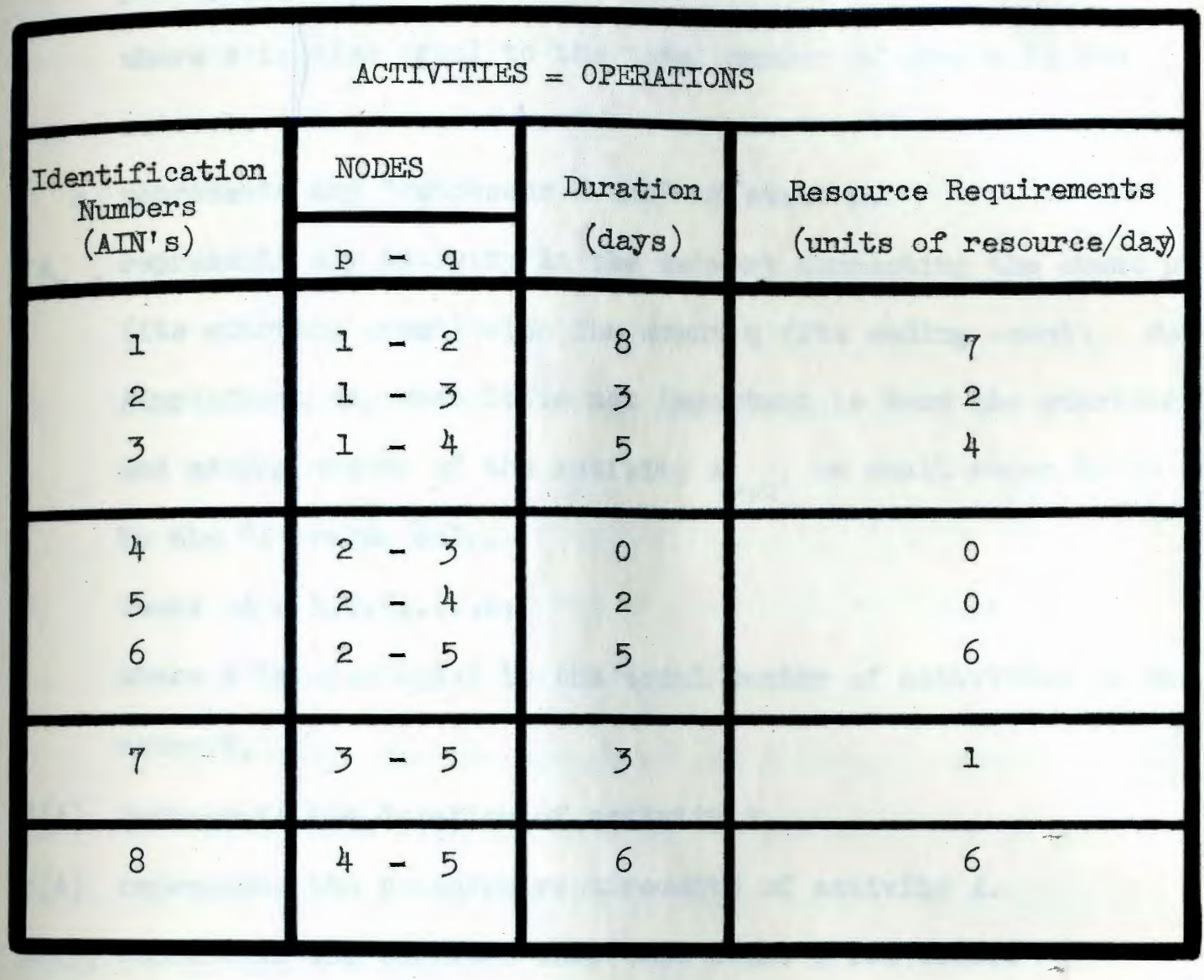

$$
\begin{aligned}
& t_{d}=24 \text { days } \\
& \dot{S}_{m}=3 \text { days } \\
& {K_{1}}_{1}=7 \text { units of resource/day }
\end{aligned}
$$

Observe that the activities are grouped first according to their $p$ events (starting events), and then listed according to their $q$ events (ending events).

\section{TABLE I}


p represents any "event" in the network.

$p=1,2,3, \ldots, e ;$

where $e$ is also equal to the total number of events in the network.

q represents any "successor event" of event p.

$A_{p, q}$ represents any activity in the network connecting the event $p$ (its starting event) with the event q (its ending event). For simplification, when it is not important to know the starting and ending events of the activity $A_{p, q}$, we shall refer to it by the "A" value only.

Then: $A=1,2,3, \ldots, a$;

where a is also equal to the total number of activities in the network.

$d(A)$ represents the duration of activity A.

$r(A)$ represents the resource requirements of activity $\mathbf{A}$.

ET(p) represents the earliest time that event $p$ can occur.

IT(p) represents the latest time that event $p$ can occur.

ST(p) represents the slack time of event p.

ES(A) represents the earliest start of activity $\mathbb{A}$.

EF(A) represents the earliest finish of activity $\mathbf{A}$.

LS(A) represents the latest start of activity $\mathbf{A}$.

LF(A) represents the latest finish of activity $A$.

TS(A) represents the total slack of activity $\mathbb{A}$.

FS(A) represents the free slack of activity A.

IS(A) represents the independent slack of activity $A$.

SS(A) represents the safety slack of activity $A$. 
IM(A) represents the index of mobility of activity $A$.

$t_{n}{ }^{\prime}$ represents the earliest project completion time given by the critical path of the network.

$t_{d}$ represents the given due date for our project

$t_{0}$ represents the starting date of our project, or day zero.

PS represents the project slack.

S represents the current project slippage.

$S_{m} \quad$ represents the maximum project slippage to be allowed for the project.

Then: $S$ is always less than, or equal to, $\mathrm{S}_{\mathrm{m}}$ *

$K_{i}$ represents the maximum level of resources available to any combination of activities during any day.

Let us assume that the values of the following network characteristics had already been obtained in the planning step of our example project, because the setting of these values constitutes the goal of PERT-CPM planning.

Then, the given values are: $t_{0}, t_{d}, \cdot S_{m}, K_{1}, t_{n}{ }^{\prime}$, all $d(A)$ 's, all $r(A)$ 's, all $\operatorname{ES}(A)$ 's, all $\mathrm{EF}(\mathrm{A})$ 's, all $L S(A)$ 's, all $\mathrm{LF}(\mathrm{A})$ 's, all $\operatorname{ET}(\mathrm{p})$ 's, all $\mathrm{LT}(\mathrm{p})$ 's, $e$, and $a$.

The slack times of the activities, events, and project can be calculated by the following formulas:

$$
\begin{array}{ll}
\operatorname{ST}(p) & =\operatorname{LT}(p)-\operatorname{ET}(p) \\
\operatorname{TS}(A) & =\operatorname{LF}(\mathbb{A})-\operatorname{EF}(\mathbb{A})=\operatorname{LS}(\mathbb{A})-\operatorname{ES}(\mathbb{A}) \\
\operatorname{FS}\left(\mathbf{A}_{p, q}\right) & =\operatorname{ET}(q)-\operatorname{EF}\left(A_{p, q}\right) \\
\operatorname{IS}\left(\mathbf{A}_{p, q}\right) & =\operatorname{ET}(q)-d\left(A_{p, q}\right)-\operatorname{LT}(p) \\
\operatorname{SS}\left(\mathbf{A}_{p, q}\right) & =\operatorname{LS}\left(A_{p, q}\right)-\operatorname{LT}(p)
\end{array}
$$


$P S=t_{d}-t_{n}^{\prime} ;$ if $t_{d}>t_{n}^{\prime}$

The activity $\mathbb{A}$ is a dummy if its $d(\mathbb{A})$ is equal to zero.

The activity $A$ belongs to the critical path of the network, if its $\operatorname{TS}(\mathbf{A})$ is zero.

The event $p$ belongs to the critical path of the network, if its $S T(p)$ is zero.

The index of mobility values of the activities were found by following the algorithm given during the presentation of Step $B$ (page 34). However, we will calculate some of these IM values in order to show the application of this algorithm.

1. Set: $I M=a=8$

2. The activity that has the largest TS is activity No. 2.

$$
\operatorname{TS}(2)=10
$$

Then:

$$
\operatorname{IM}(2)=8
$$

3. Set: new $I M=8-I=7$

4. Since $7>0$, return to execute mule 2 .

5. The non-indexed activities that have the largest TS values are: No. 3, No. 4, and No. 7 .

$$
\operatorname{TS}(3)=5 ; \quad \operatorname{TS}(4)=5 ; \quad \operatorname{TS}(7)=5
$$

of these tied activities, the activities with the largest FS values are: No. 3 and No. 7

$$
\operatorname{FS}(3)=5 ; \quad F S(7)=5 ; \quad F S(4)=0 .
$$

of these tied activities the activity that has the largest IS value is activity No. 3 .

$$
\operatorname{IS}(3)=5 ; \quad \operatorname{IS}(7)=0
$$




\begin{tabular}{|c|c|c|c|c|c|}
\hline \multicolumn{6}{|c|}{ ACTIVITIES } \\
\hline \multirow{2}{*}{$\begin{array}{l}\text { Ident. } \\
\text { Nos. } \\
\text { (ATN' s) }\end{array}$} & Events & \multirow{2}{*}{ Duration } & \multirow{2}{*}{$\begin{array}{r}\text { Resource } \\
\text { Req's. }\end{array}$} & \multicolumn{2}{|c|}{ Earliest Times } \\
\hline & $p-q$ & & & Start & Finish \\
\hline 1 & $1-2$ & 8 & 7 & 0 & 8. \\
\hline 2 & $1-3$ & 3 & 2 & 0 & 3 \\
\hline 3 & $1-4$ & 5 & 4 & 0 & 5 \\
\hline 4 & $2-3$ & 0 & 0 & 8 & 8 \\
\hline 5 & $2-4$ & 2 & 0 & 8 & 10 \\
\hline 6 & $2-5$ & 5 & 6 & 8 & 13 \\
\hline 7 & $3-5$ & 3 & 1 & 8 & 11 \\
\hline 8 & $4-5$ & 6 & 6 & 10 & 16 \\
\hline
\end{tabular}

TABLE II 
ACTIVITIES

\begin{tabular}{|c|c|c|c|c|c|c|c|c|}
\hline $\begin{array}{l}\text { Iate } \\
\text { Star }\end{array}$ & rime & & $\mathrm{k}$ & es & afe & $\begin{array}{l}\text { ritice } \\
\text { Path }\end{array}$ & Dummy & $\begin{array}{c}\text { Index } \\
\text { of } \\
\text { Mobility }\end{array}$ \\
\hline 0 & 8 & 0 & 0 & 0 & 0 & Yes & No & 1 \\
\hline 10 & 13 & 10 & 5 & 5 & 10 & No & No & 8 \\
\hline 5 & 10 & 5 & 5 & 5 & 5 & No & No & 7 \\
\hline 13 & 13 & 5 & 0 & 0 & 5 & No & Yes & 5 \\
\hline 8 & 10 & 0 & 0 & 0 & 0 & Yes & No & 2 \\
\hline 11 & 16 & 3 & 3 & 3 & 3 & No & No & 4 \\
\hline 13 & 16 & 5 & 5 & 0 & 0 & No & No & 6 \\
\hline 10 & 16 & 0 & 0 & 0 & 0 & Yes & No & 3 \\
\hline
\end{tabular}

NETWORK CHARACTERISTICS (ACTIVITIES) 


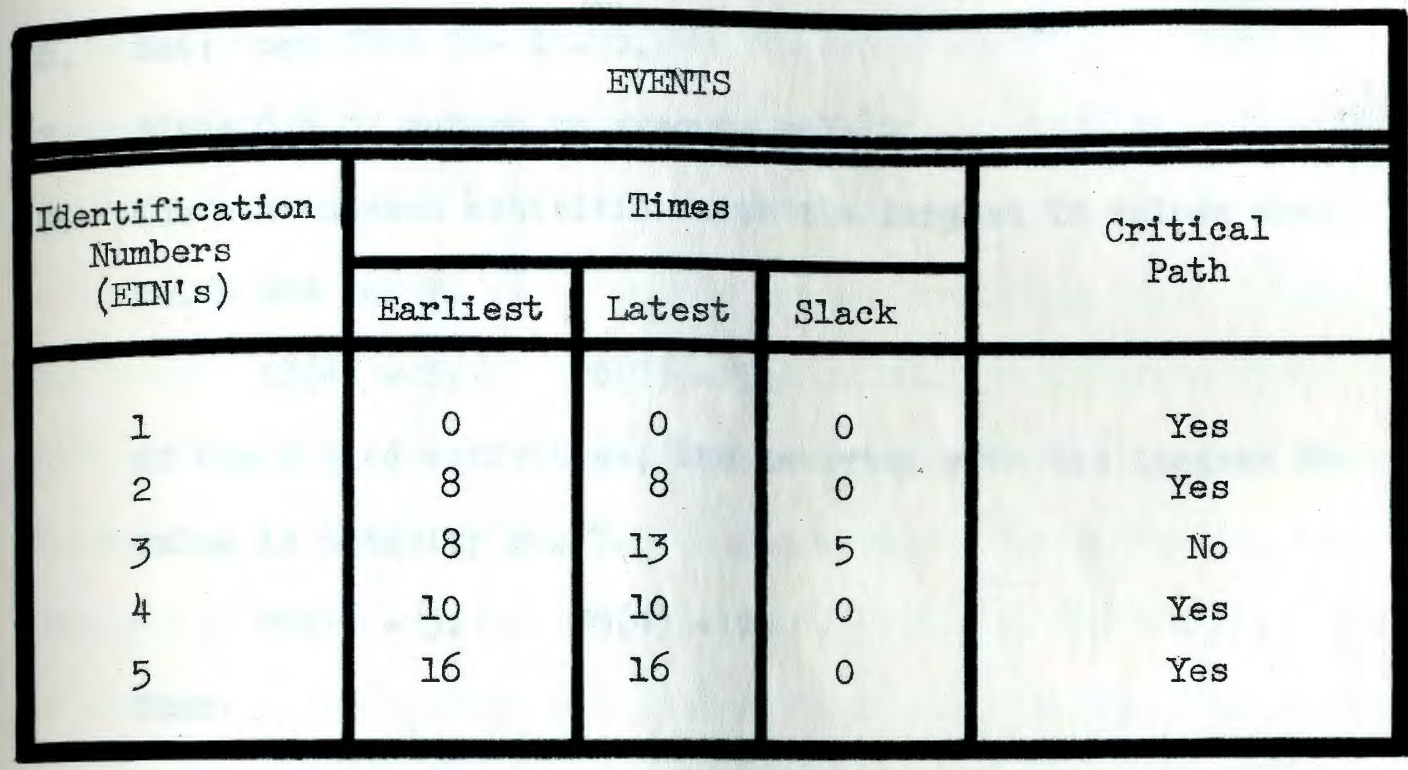

$$
\begin{aligned}
& t_{n}{ }^{\prime}=16 \text { days } \\
& t_{d}=24 \text { days } \\
& \text { PS }=8 \text { days } \\
& S_{m}=3 \text { days } \\
& K_{1}=7 \text { units of resource/day } \\
& \dot{a}=8 \text { activities } \\
& e=5 \text { events }
\end{aligned}
$$

TABLE III

NETWORK CHARACTERISTICS (EVENTS AND PROJECT) 
Then:

$$
\operatorname{IM}(3)=7
$$

6. Set: new $I M=7-1=6$.

7. Since $6>0$, return to execute rule 2.

8. The non-indexed activities with the largest TS values are: No. 4 and No. 7.

$$
\operatorname{TS}(4)=5 ; \quad \operatorname{TS}(7)=5 .
$$

of these tied activities, the activity with the largest FS value is activity No. 7 .

$$
\operatorname{FS}(7)=5 ; \quad F S(4)=0 .
$$

Then:

$$
\operatorname{IM}(7)=6 .
$$

9. Set: new $I M=6-1=5$

10. Since $5>0$, return to execute rule 2 .

If we continue the assignation of IM values according to the rules of this algorithm, we would find the very same IM values listed in Table II (page 57) under the heading "Index of Mobility". We can see in Table II that the larger IM values correspond to the activities that have positive slack times, while the smaller IM values correspond to the activities on the critical path, which can not be delayed without delaying the current project completion time. The IM values are measuring the mobility of each activity with respect to the mobility of all the others.

c.- The injtial schedule for our example project is shown in Flgure 6 (page 62), together with its corresponding resource profile. All the activities and events have been located at their earliest 
times according to the values given in Table II (page 57) and in Table III (page 59); therefore we are using the "early start schedule" of the project. The numbers above the horizontal arrows give the following information for each activity: (I) its identification number A, (2) its duration $d$, and (3) its resource requirements $r$; these parameters were put inside the brackets in the following order $[A: d ; r]$. The larger dots represent the location of the events whose identification numbers are written on the lower right hand side of these dots. There should not be any confusion regarding the fact that we have more than one dot with a given number, because an event is a time-point and as such, this point becomes a line perpendicular to the time axis on our two-dimensional graph. We put one dot on each side of the arrows to remember the activities' starting and ending events, and also to represent graphically their slack times. $t_{0}$ marks the starting date of our project, or the beginning of day one. $t_{n}$ ' marks the "earliest project completion time", which for this schedule is also the "current project completion time" or $t_{n} \cdot t_{d}$ marks the given project due date, which is also our time constraint. $t_{d}{ }^{*}$ marks the latest due date for our project, in case we are forced to utilize some "project slippage" $(S)$, but only up to the given $S_{m}$ or "maximum project slippage", in order to satisfy the resource constraint $\mathrm{K}_{1}$ or "maximum availability of resources" marked by a horizontal-dashed-line on the resource profile. The utilization of project slippage was discussed on page 45 of this thesis. PS shows the available project slack, and RMLP points out the "right most largest peak" of our resource profile the peak we are going to cut by rescheduling one of the activities 


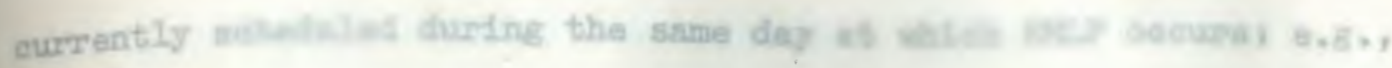

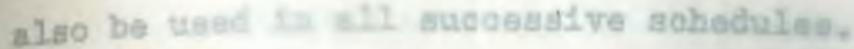
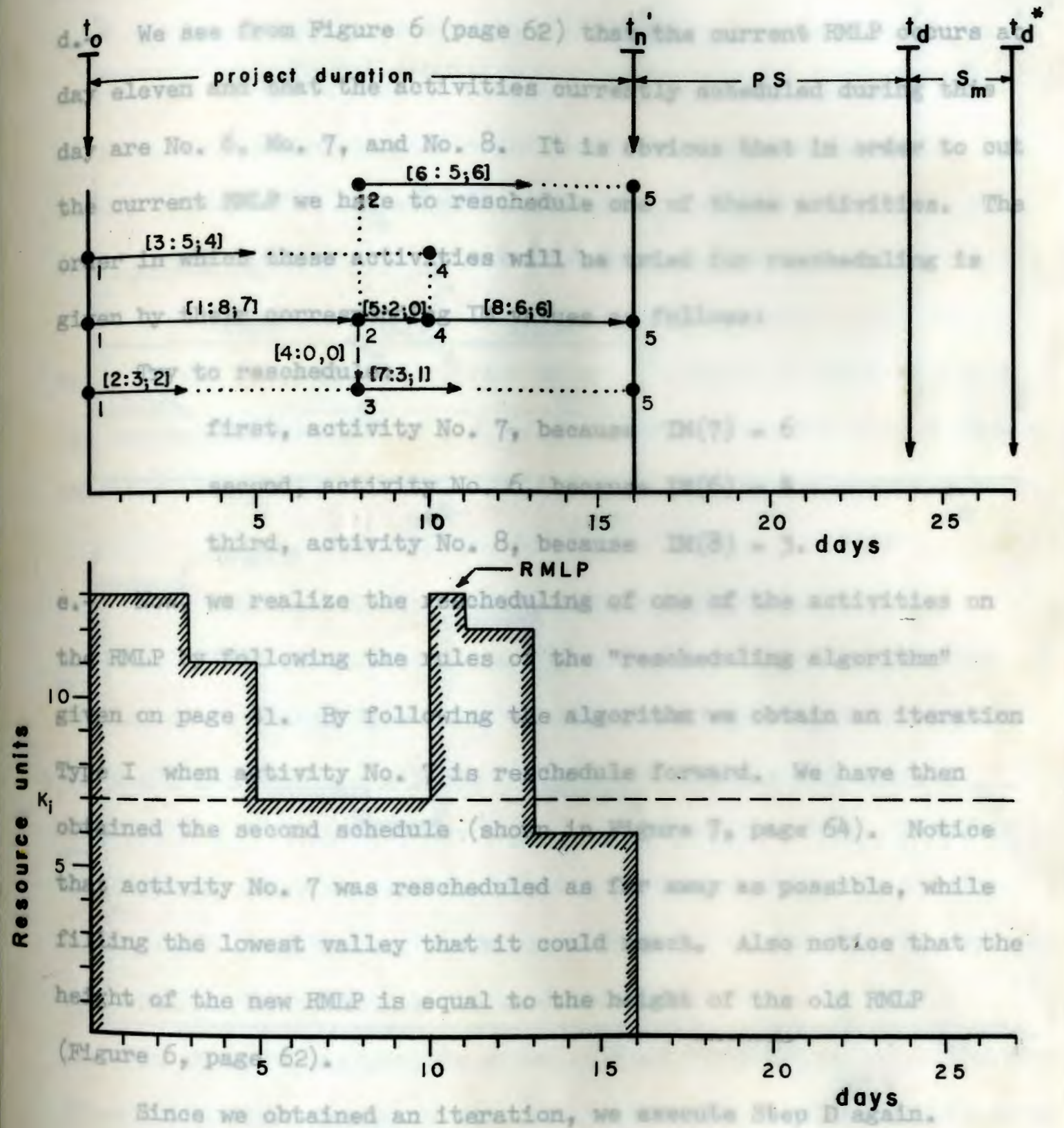

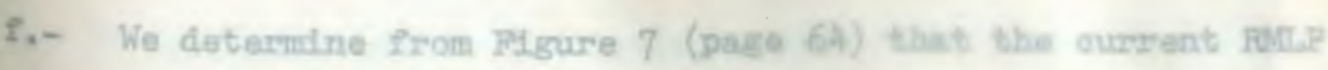

FIGURE 6.-INITIAL SCHEDULE AND RESOURCE PROFILE - FXXAMPLE PROJECT 
currently scheduled during the same day at which RIIP occurs: e.g., by rescheduling the activities on the RMLP. This notation will also be used in all successive schedules. d.- We see from Figure 6 (page 62) that the current RMLP occurs at day eleven and that the activities currently scheduled during this day are No. 6, No. 7, and No. 8. It is obvious that in order to cut the current RVIP we have to reschedule one of these activities. The order in which these activities will be tried for rescheduling is given by their corresponding IM values as follows:

Try to reschedule:

$$
\begin{aligned}
& \text { first, activity No. } 7 \text {, because } \operatorname{IM}(7)=6 \\
& \text { second, activity No. } 6 \text {, because } \operatorname{IM}(6)=4 \\
& \text { third, activity No. } 8 \text {, because } \operatorname{IM}(8)=3 \text {. }
\end{aligned}
$$

e.- Now, we realize the rescheduling of one of the activities on the RMLP by following the rules of the "rescheduling algorithm" given on page 41. By following the algorithm we obtain an iteration Type I when activity No. 7 is reschedule forward. We have then obtained the second schedule (shown in Figure 7, page 64). Notice that activity No. 7 was rescheduled as far away as possible, while fllling the lowest valley that it could reach. Also notice that the height of the new RMLP is equal to the height of the old RMLP (F1gure 6, page 62).

Since we obtained an iteration, we execute Step D again. f.- We determine from Figure 7 (page 64) that the current RNIP occurs at day three, and that the activities on the RMLP are activities No. 1, No. 2, and No. 3. The order for rescheduling is: 
thind a ativity No, 1, becminas
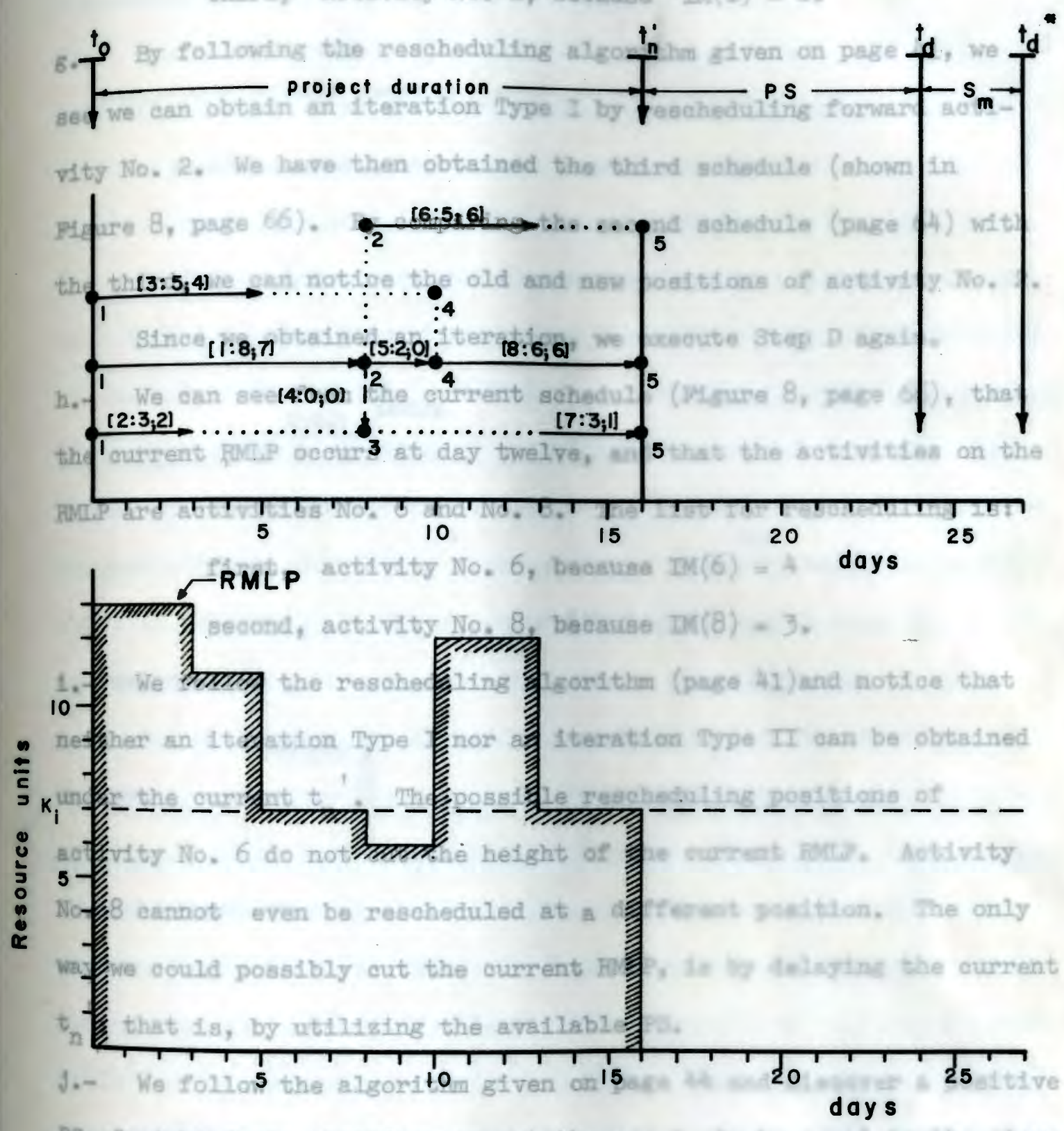

PS of elsbth days therefore we set the new

$t_{d}(24$ days $)$ and update the latest times of wh writs and the latest

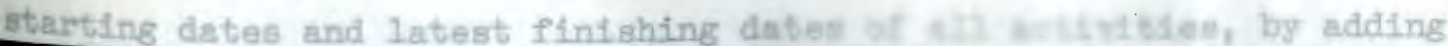

eight days (the value of PS) to them.

FIGURE 7.--SECOND SCHEDULE AND RESOURCE PROFILE - FXAMPLE PROJECT 


$$
\begin{aligned}
& \text { first, activity No. } 2 \text {, because } \operatorname{IM}(2)=8 \\
& \text { second, activity No. } 3 \text {, because } \operatorname{IM}(3)=7 \\
& \text { third, activity No. } 1 \text {, because } \operatorname{IM}(1)=1 .
\end{aligned}
$$

g.- By following the rescheduling algorithm given on page 4I, we see we can obtain an iteration Type I by rescheduling forward activity No. 2. We have then obtained the third schedule (shown in Figure 8, page 66). By comparing the second schedule (page 64) with the third, we can notice the old and new positions of activity No. 2 . Since we obtained an iteration, we execute Step D again. h.- We can see from the current schedule (Figure 8, page 66), that the current RMLP occurs at day twelve, and that the activities on the RMLP are activities No. 6 and No. 8. The list for rescheduling is:

$$
\begin{aligned}
& \text { first, activity No. } 6 \text {, because } \operatorname{IM}(6)=4 \\
& \text { second, activity No. } 8 \text {, because } \operatorname{IM}(8)=3 \text {. }
\end{aligned}
$$

1.- We follow the rescheduling algorithm (page 41) and notice that neither an iteration Type I nor an iteration Type II can be obtained under the current $t_{n}$ '. The possible rescheduling positions of activity No. 6 do not cut the height of the current RMLP. Activity No. 8 cannot even be rescheduled at a different position. The only way we could possibly cut the current RMIP, is by delaying the current $t_{n}^{\prime}$; that is, by utilizing the available PS. j.- We follow the algorithm given on page 44 and discover a positive PS of eigbt days; therefore we set the new $t_{n}$ to be equal to the given $t_{d}(24$ days) and update the latest times of all events, and the latest starting dates and latest finishing dates of all activities, by adding eight days (the value of PS) to them. 
oompleted, we crocute step D agaln.

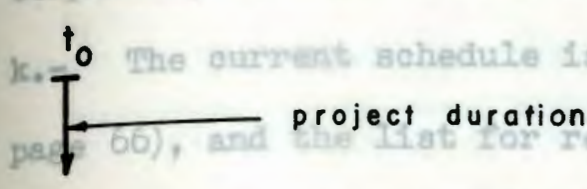

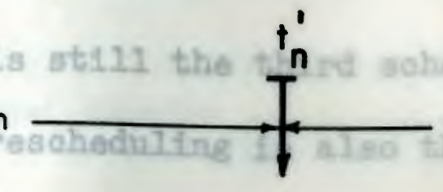

PS

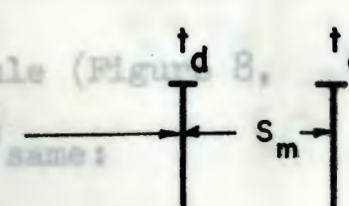

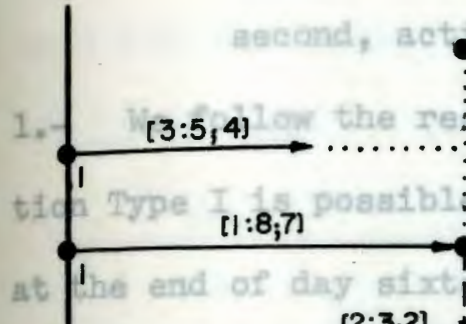

(6) 5,6

5, becanianas
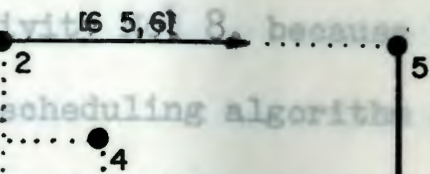

$15: 2,0]$ $[8: 6 ; 6$

$[2: 3,2]+4: 0 ; 0]$

3

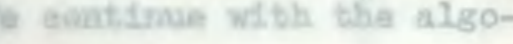

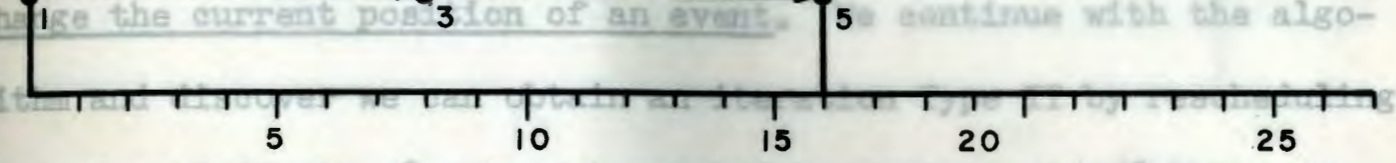

Porward aotivity llo. B; why not reschedule antwituy doys lnstead?

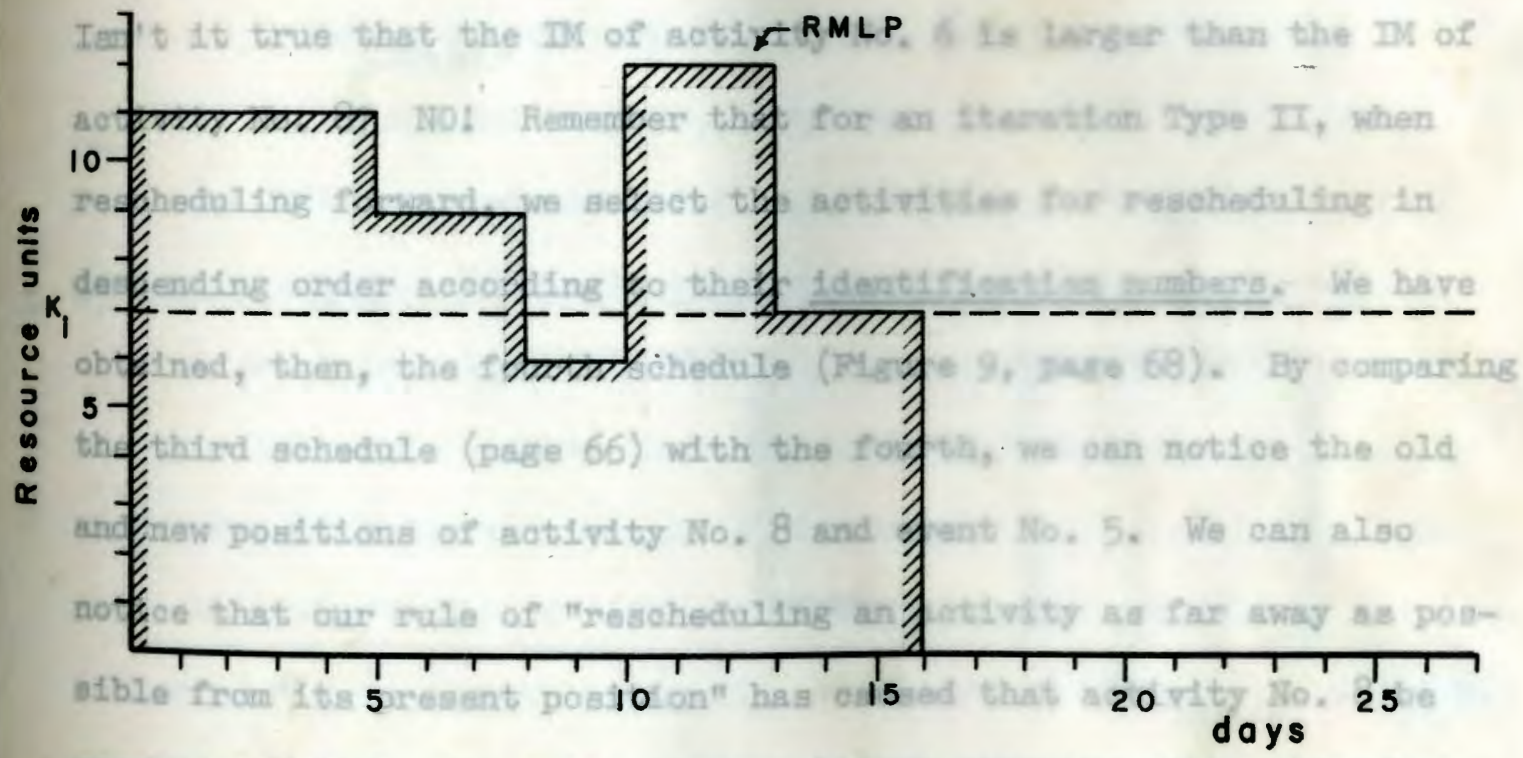

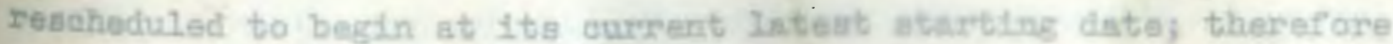

Lesvins an enpty spsee on the resouros preflie. This ahould not

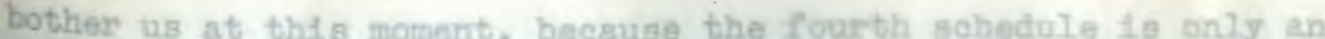

Intormediste che. If we re-read mule 18 of cur resoliedulting algo-

FIGURE 8.-THIRD SCHEDUIE AND RESOURCE PROFIIE - EXAMPIE PROJECT 
These network characteristics are the only ones that need to be updated; all the others remain the same. Once the updating is completed, we execute Step D again.

k. - The current schedule is still the third schedule (Figure 8, page 66), and the list for rescheduling is also the same:

$$
\begin{aligned}
& \text { first, activity No. } 6 \text {, because } \operatorname{IM}(6)=4 \\
& \text { second, activity No. } 8 \text {, because } \operatorname{IM}(8)=3 \text {. }
\end{aligned}
$$

1.- We follow the rescheduling algorithm and notice that no iteration Type I is possible; why? because event No. 5 is still positioned at the end of day sixteen. Remember that an iteration Type I does not change the current position of an event. We continue with the algorithm and discover we can obtain an iteration Type II by rescheduling forward activity No. 8; why not reschedule activity No. 6 instead? Isn't it true that the IM of activity No. 6 is larger than the IM of activity No. 8? NO! Remember that for an iteration Type II, when rescheduling forward, we select the activities for rescheduling in descending order according to their identification numbers. We have obtained, then, the fourth schedule (F1gure 9, page 68). By comparing the third schedule (page 66) with the fourth, we can notice the old and new positions of activity No. 8 and event No. 5. We can also notice that our rule of "rescheduling activity as far away as possible from its present position" has caused that activity No. 8 be rescheduled to begin at its current latest starting date; therefore leaving an empty space on the resource profile. This should not bother us at this moment, because the fourth schedule is only an Intermediate one. If we re-read rule 18 of our rescheduling algo- 
rithm (page 41), we nd11 remeinber that, when no 1terstian of either

type can be obtained we have to reschedule bachard all the

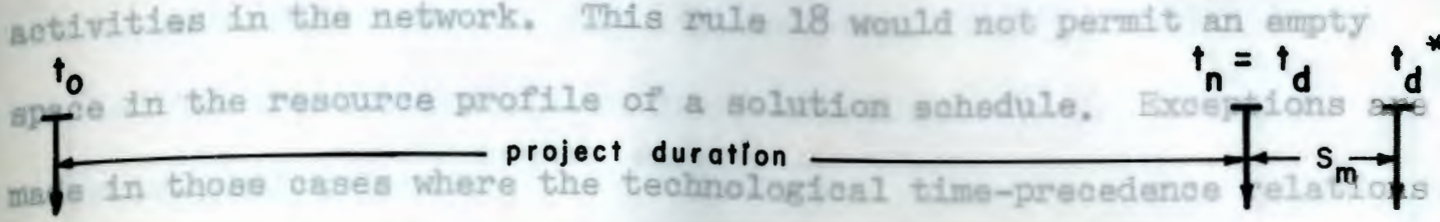

of the activitiles and events force us to sohedule one activity thatb
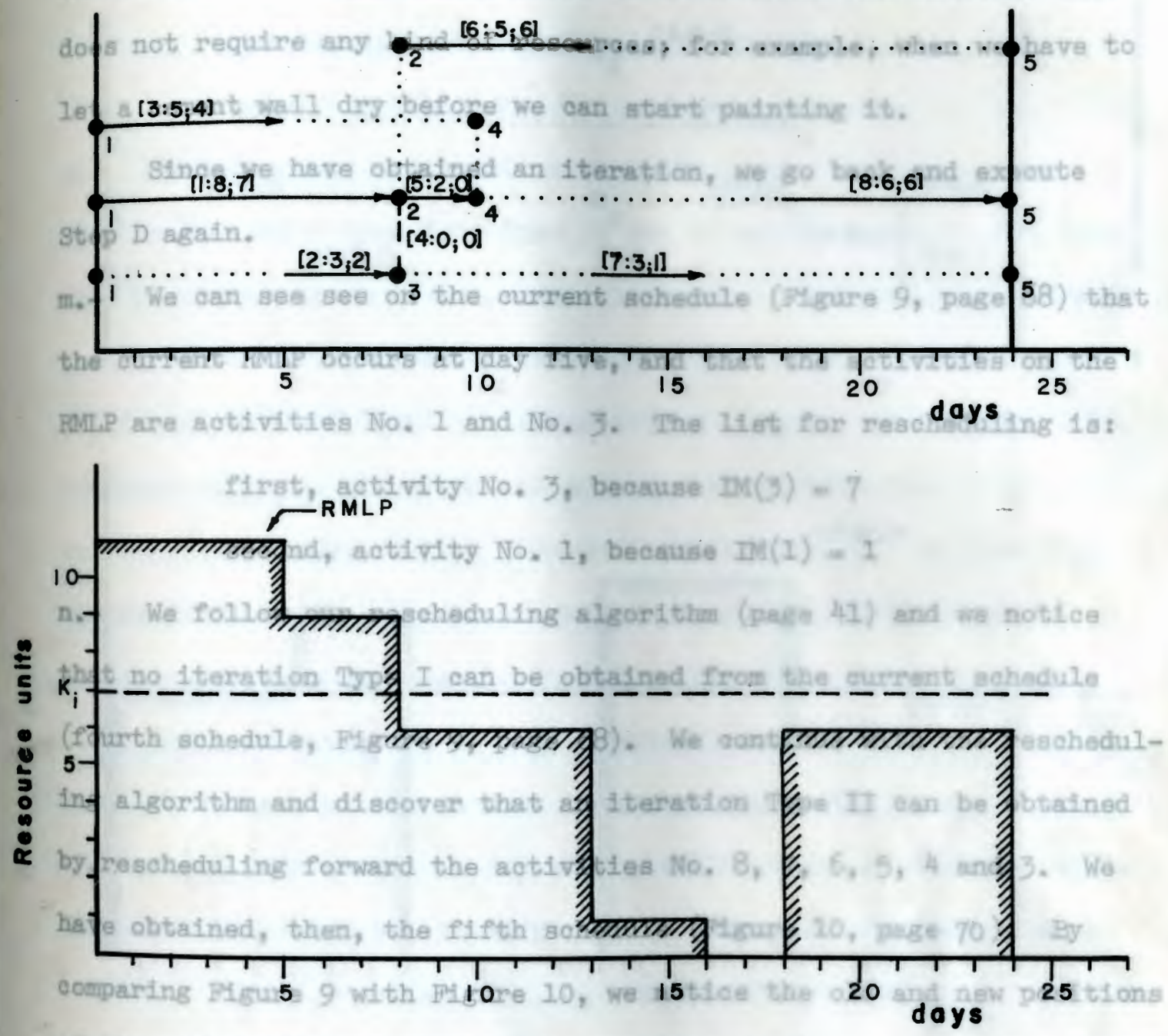

of the sctivitied and events. We can also wen bow an fteration Iype II

paoks the aetivities to alther gide of the ahedule trylng to leave

an earpty spade In the center of the regouras profllilat

Blnce we have obtained an iteration, we return and socedute

FIGURE 9.--FOURTH SCHEDULF AND RESOURCE PROFILE - EXXAMPLE PROJECT 
rithm (page 4l), we will remember that, when no iteration of either type can be obtained we have to reschedule backward all the activities in the network. This rule 18 would not permit an empty space in the resource profile of a solution schedule. Exceptions are made in those cases where the technological time-precedence relations of the activities and events force us to schedule one activity that does not require any kind of resources; for example, when we have to let a cement wall dry before we can start painting it.

Since we have obtained an iteration, we go back and execute Step D again.

m.- We can see see on the current schedule (Figure 9, page 68) that the current RMLP occurs at day five, and that the activities on the RMLP are activities No. I and No. 3. The list for rescheduling is:

$$
\begin{aligned}
& \text { first, activity No. } 3 \text {, because } \operatorname{IM}(3)=7 \\
& \text { second, activity No. } 1 \text {, because } \operatorname{IM}(1)=1
\end{aligned}
$$

n.- We follow our rescheduling algorithm (page 4I) and we notice that no iteration Type I can be obtained from the current schedule (fourth schedule, Figure 9, page 68). We continue with the rescheduling algorithm and discover that an iteration Type II can be obtained by rescheduling forward the activities No. $8,7,6,5,4$ and 3 . We have obtained, then, the fifth schedule (Figure 10, page 70). By comparing Figure 9 with Figure 10, we notice the old and new positions of the activities and events. We can also see how an iteration Type II packs the activities to either side of the schedule trying to leave an empty space in the center of the resource profile.

Since we have obtained an iteration, we return and execute 
step D ance abafin.

0.- We can see on the current bchedule (Blgure 10, page 70) that

the current Fullip ocours at day elghteen, and that the activitieas $\mathbf{t}_{\mathbf{n}}=\mathbf{t}_{\mathbf{d}} \mathbf{t}_{\mathbf{d}}^{*}$

foresoheduling is: project durotion

Rirvt, aotivity No. 3, because $74(3)=7$
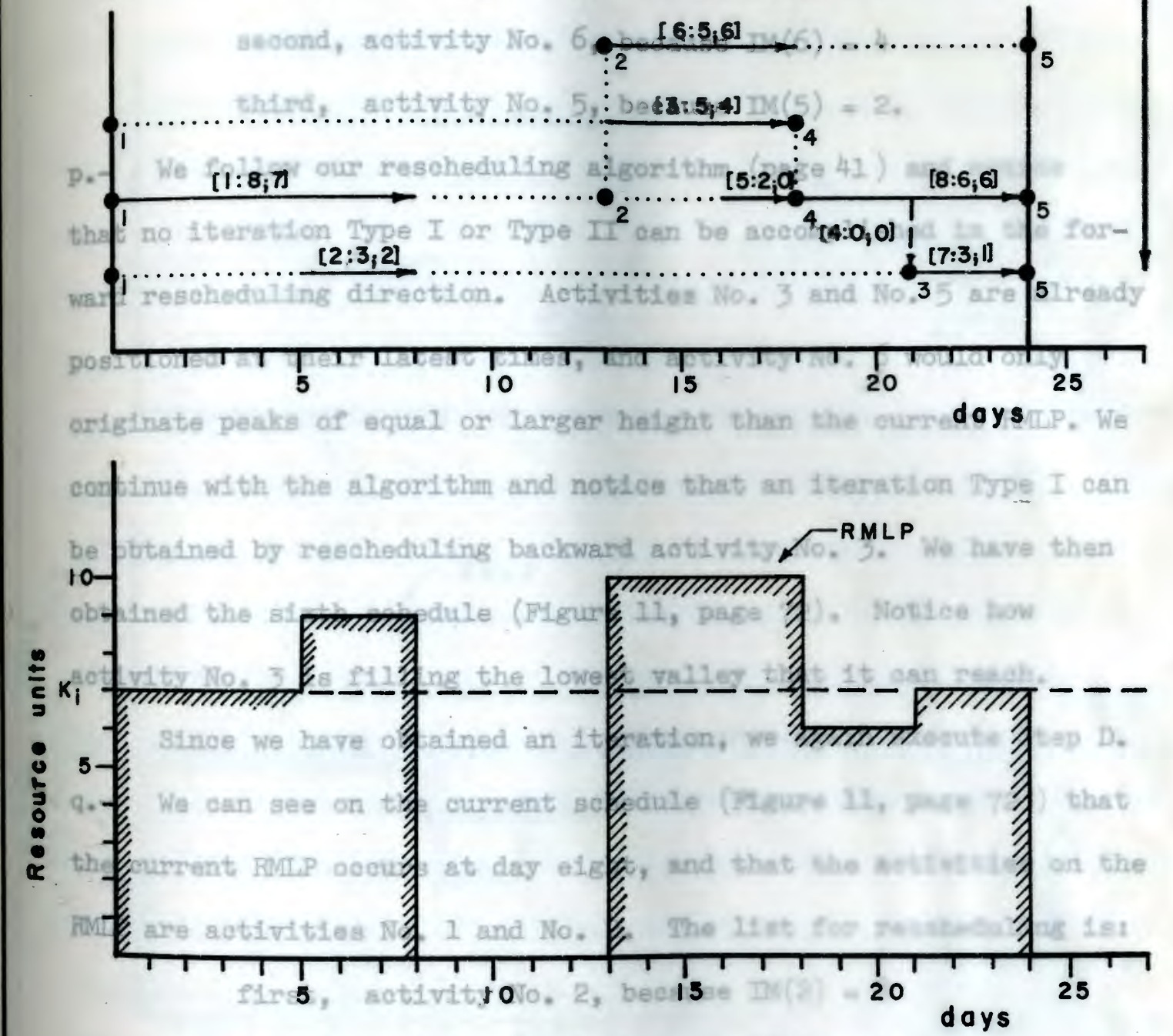

second, sotivity No. 1, beasuse

r.- By following our resoheduling algortthe Gurs iV wo notice

that an iteration Type I is obtained by zas end activy

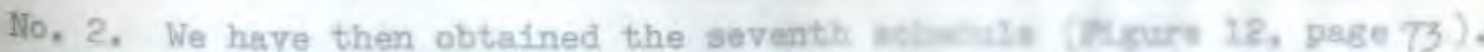

FIGURE 10.-FIFTH SCHEDULE AND RESOURCE PROFIIE - EXXAMPLE PROJECT 
Step D once again.

0.- We can see on the current schedule (Figure 10, page 70) that the current RMLP occurs at day eighteen, and that the activities on the RMLP are the activities No. 3, No. 5 and No. 6. The list for rescheduling is:

$$
\begin{aligned}
& \text { first, activity No. } 3 \text {, because } \operatorname{IM}(3)=7 \\
& \text { second, activity No. } 6 \text {, because } \operatorname{IM}(6)=4 \\
& \text { third, activity No. } 5 \text {, because } \operatorname{IM}(5)=2
\end{aligned}
$$

p.- We follow our rescheduling algorithm (page 4I) and notice that no iteration Type I or Type II can be accomplished in the forward rescheduling direction. Activities No. 3 and No. 5 are already positioned at their latest times, and activity No. 6 would only originate peaks of equal or larger height than the current RMLP. We continue with the algorithm and notice that an iteration Type I can be obtained by rescheduling backward activity No. 3. We have then obtained the sixth schedule (Figure 1l, page 72). Notice how activity No. 3 is filling the lowest valley that it can reach. Since we have obtained an iteration, we again execute Step D. q.- We can see on the current schedule (Figure 11, page 72 ) that the current RIIP occurs at day eight, and that the activities on the RNIP are activities No. I and No. 2. The list for rescheduling is:

$$
\begin{aligned}
& \text { first, activity No. } 2 \text {, because } \operatorname{IM}(2)=8 \\
& \text { second, activity No. } 1 \text {, because } \operatorname{IM}(1)=1 \text {. }
\end{aligned}
$$

r.- By following our rescheduling algorlthm (page 41) we notice that an 1teration Type I is obtained by rescheduling forward activity No. 2. We have then obtained the seventh schedule (Figure 12, page 73 ). 


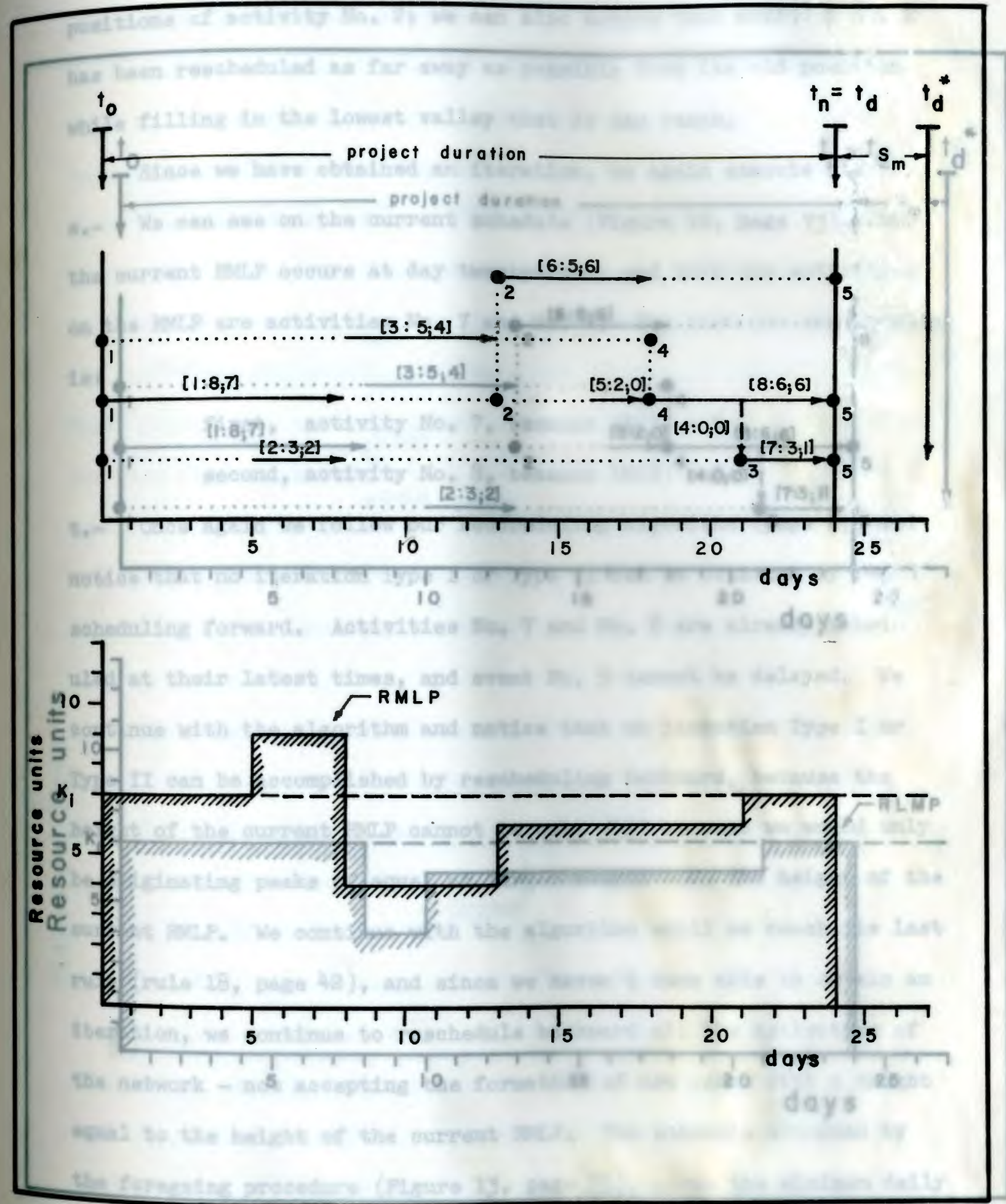

FIGURE 11,--SIXTH SCHEDULE AND RESOURCE PROFILE - EXANPIE PROJECT 


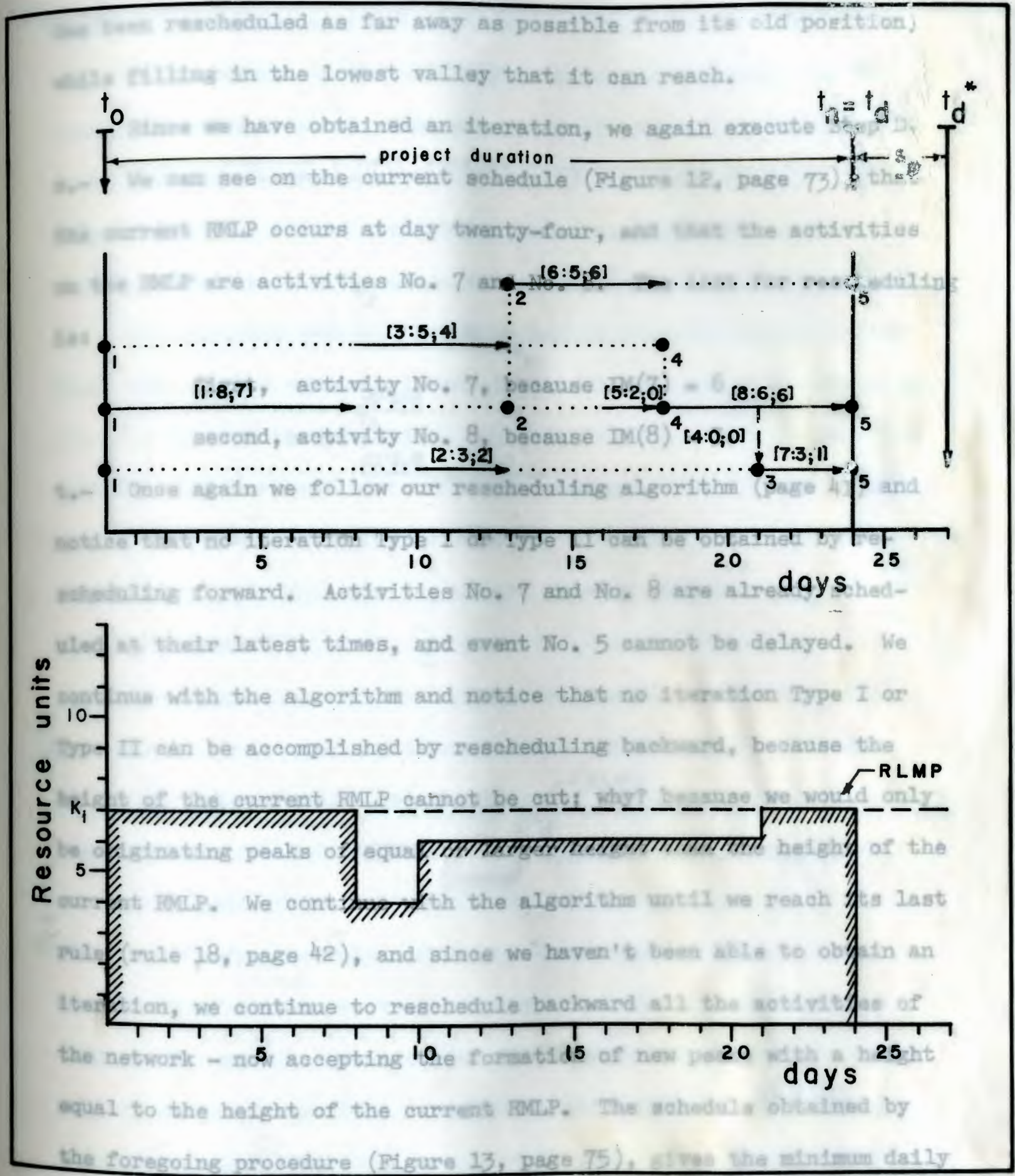

FIGURE 12.-SEVENTH SCHEDULE AND RESOURCE PROFILE - FXAMPLE PROJECT 
By comparing Figure 11 with Figure 12 we can notice the old and new positions of activity No. 2; we can also notice that activity No. 2 has been rescheduled as far away as possible from its old position, while filling in the lowest valley that it can reach.

Since we have obtained an iteration, we again execute Step D. s.- We can see on the current schedule (Figure 12, page 73), that the current RMLP occurs at day twenty-four, and that the activities on the RMLP are activities No. 7 and No. 8. The list for rescheduling is:

$$
\begin{aligned}
& \text { first, activity No. } 7 \text {, because } \operatorname{IM}(7)=6 \\
& \text { second, activity No. } 8 \text {, because } \operatorname{IM}(8)=3 \text {. }
\end{aligned}
$$

t.- Once again we follow our rescheduling algorithm (page 4I) and notice that no iteration Type I or Type II can be obtained by rescheduling forward. Activities No. 7 and No. 8 are already scheduled at their latest times, and event No. 5 cannot be delayed. We continue with the algorithm and notice that no iteration Type I or Type II can be accomplished by rescheduling backward, because the height of the current RMIP cannot be cut; why? because we would only be originating peaks of equal or larger height than the height of the current RMLP. We continue with the algorithm until we reach its last rule (mule 18, page 42), and since we haven't been able to obtain an iteration, we continue to reschedule backward all the activities of the network - now accepting the formation of new peaks with a height equal to the height of the current RMLP. The schedule obtained by the foregoing procedure (Figure 13, page 75), gives the minimum daily resource allocations for the current project completion date 
(ourrent $t_{n}=24$ days). Ey comparing Plgure 12 sith Mgure 13, we notioe the old and new positione of all the sotsivitap and events of

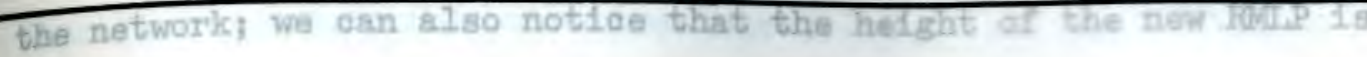
equal to the height of the old FMIP. These two bohodules can be

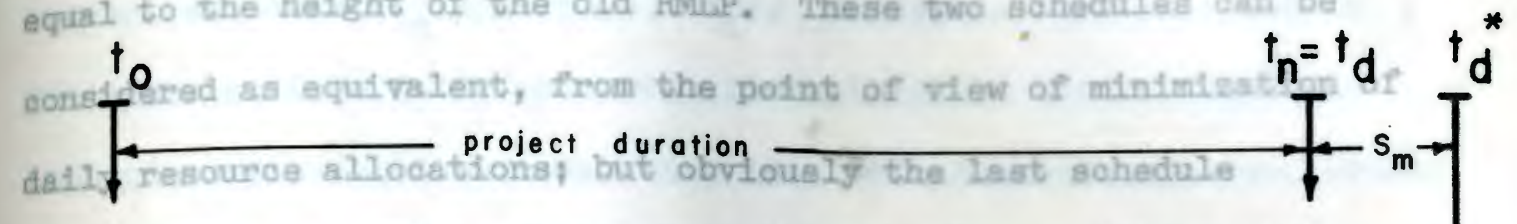
(PIgure 13, page 75) 18 much better than the formar (1Mgure 12,

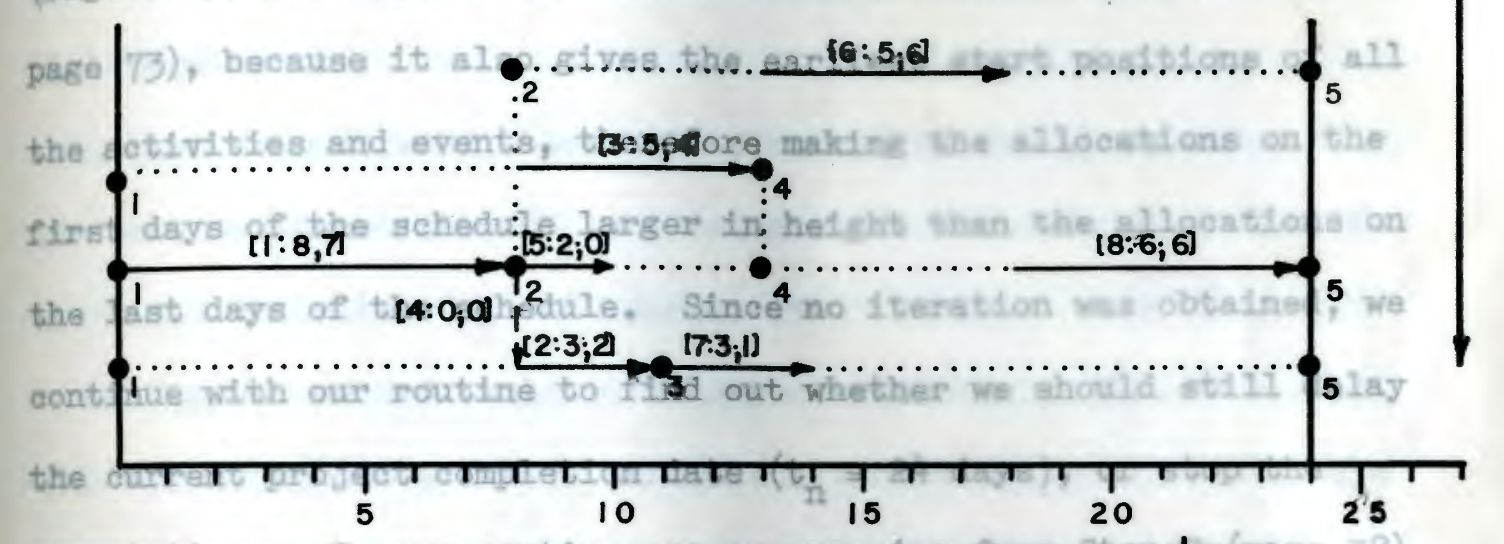

computations. In our routine, we are pasaing from stepdays

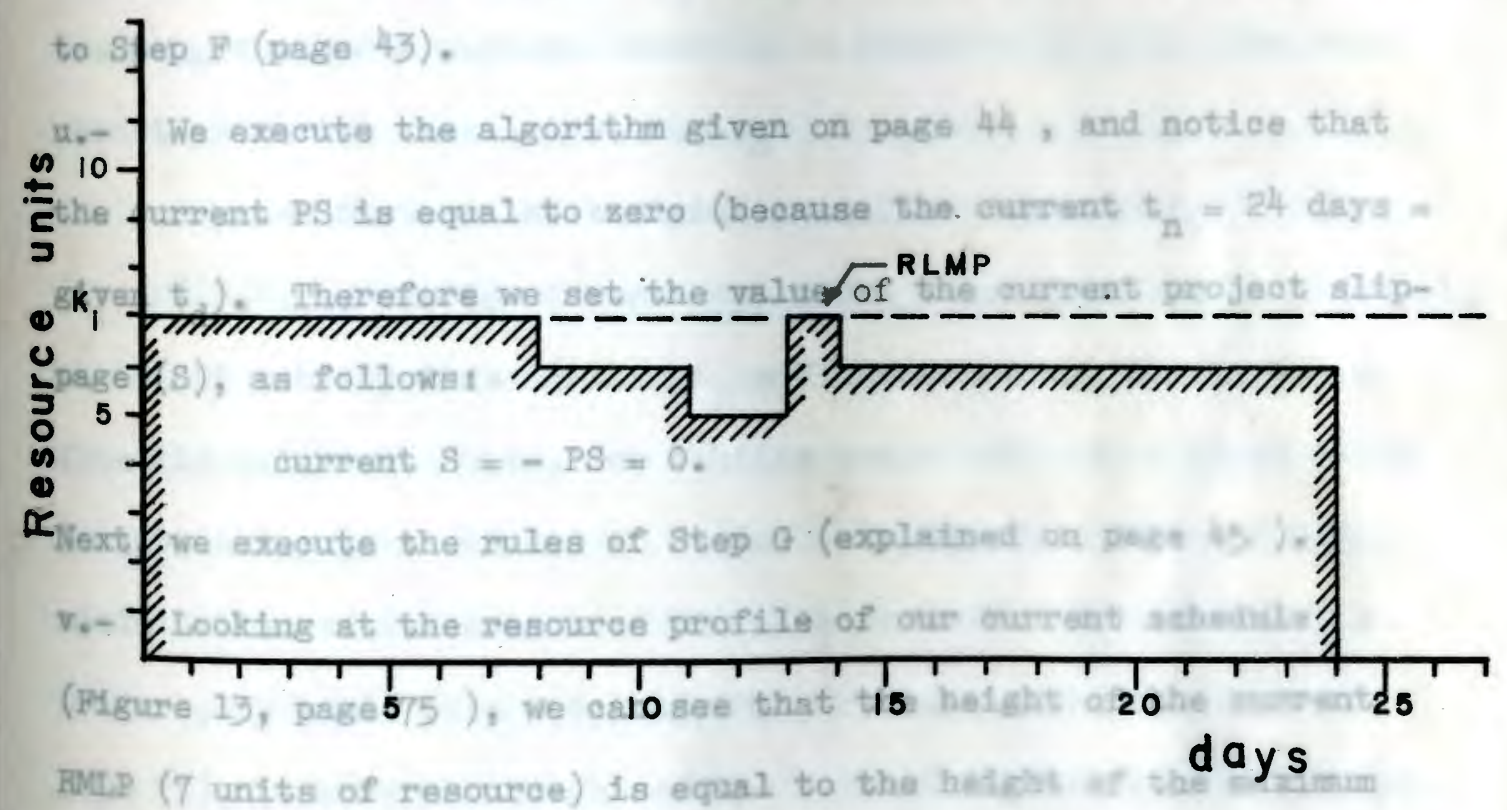

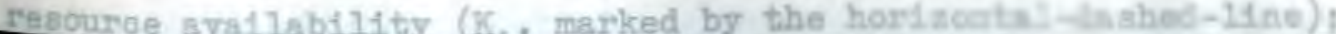

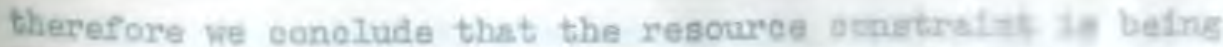

FIGURE 13.--HEURISTIC BEST SOLUTION SCHEDULE AND RESOURCE PROFITE EXANPLE PROJECT 
(current $t_{n}=24$ days). By comparing Figure 12 with Figure 13, we notice the old and new positions of all the activities and events of the network; we can also notice that the height of the new RMLP is equal to the height of the old RMIP. These two schedules can be considered as equivalent, from the point of view of minimization of daily resource allocations; but obviously the last schedule (Figure 13, page 75) is much better than the former (Figure 12, page 73), because it also gives the earliest start positions of all the activities and events, therefore making the allocations on the first days of the schedule larger in height than the allocations on the last days of the schedule. Since no iteration was obtained, we continue with our routine to find out whether we should still delay the current project completion date $\left(t_{n}=24\right.$ days), or stop the computations. In our routine, we are passing from Step E (page 38) to Step F (page 43).

u. - We execute the algorithm given on page 44, and notice that the current PS is equal to zero (because the current $t_{n}=24$ days $=$ given $\left.t_{d}\right)$. Therefore we set the value of the current project slippage $(S)$, as follows:

$$
\text { current } S=-P S=0 \text {. }
$$

Next, we execute the rules of Step $G$ (explained on page 45 ). v.- Looking at the resource profile of our current schedule (Figure 13, page 75 ), we can see that the height of the current RVIP ( 7 units of resource) is equal to the height of the maximum resource availability ( $\mathrm{K}_{1}$, marked by the horizontal-dashed-line); therefore we conclude that the resource constraint is being 
satisfied by the current schedule. We recall the value of the current project slippage $(S)$ and notice that it is equal to zero; we therefore conclude that the time constraint is also satisfied by the current schedule $\left(t_{n}=24\right.$ days $\left.=t_{d}\right)$. Since the current schedule gives the minimum daily resource allocations for the project, and also gives the earliest completion date for all activities and events, we can name it our "heuristic best solution schedule" and then stop the computations.

Let us make some observations regarding the given values for the resource constraint $\left(K_{1}=7\right.$ untts of resource per day), and for the time constraint ( $t_{d}=24$ days).

Suppose we had assigned a larger value to $K_{1}\left(K_{1}=8,9, \ldots\right)$. The heuristic best solution schedule given in Figure 12 would have been the same, because $K_{i}$ is only one of our two yardsticks for deciding whether a current schedule is feasible or not. The other yardstick is the value given for $t_{d}$.

Suppose that we had assigned a smaller. value to $K_{1}$ $\left(K_{1}=6,5,4, \ldots\right.$ units of resource). The schedule given in Figure 13 would not satisfy this smaller $K_{1}$ and therefore would not give a feasible solution. Then, our routine would tell us to start using project slippage - one day at a time - trying to obtain a further minimization of the height of the current RMLP. For our example project, we would have obtained the very same schedule (Figure 13, page 75), because the height of the current RMLP cannot be reduced; why? because activity No. I alone requires seven units of resource per day. If we look at the schedule in Figure 13, we can easily see 
that the current RMLP could be cut by allowing one day of project slippage (PS) (activities No. 6 and No. 8 would be rescheduled one day later), but we can see that the height of the new RMLP (which would occur at day eight) would be equal to the height of the old RVIP (the one presently occuring at day fourteen). The only way that we could possibly reduce the height of this new RMLP would be by extending (as opposed to "crashing") the duration of activity No. I by $X$ days until this activity No. I can be accomplished with only six units of resource per day.

Even though the computations made during the entire execution of our scheduling routine are simple and straightforward, we must recognize that they are lengthy and too numerous for hand calculations. A computer program written in FORTRAN IV for the IBM-360 computer was used to make practical the utilization of our scheduling routine in real-life projects. This computer program realizes all the computations and decisions that compose our scheduling routine. It is given in Appendix $A$ of this thesis. The example problem just explained was fed to the computer and the total computer time utilized was 1.26 minutes ( 1.13 minutes for reading and compiling the program and the data, and .13 minutes for the execution of the calculations). The data-input for this example project, as well as the computer output, is given in Appendix B of this thesis.

A small real-life project (construction of a gas station) composed of 58 activities and 36 events, was also fed to the computer and the total computer time utilized was 12.73 minutes (1.16 minutes for reading and compiling the program and the data, and 11.57 minutes 
for the execution of the calculations). Its computer solution is given in Appendix C. The data-input is not given because it follows the same format as the data-input of Appendix B, and also because all the data-input is contained in the computer output, and can be reconstructed by the interested reader if he wishes to do so.

The printing format of this computer program was prepared to handle networks with up to 70 activities and 70 events. For larger networks this printing format can easily be transformed by an experienced programmer, in order to obtain the schedule on a tabular Iist rather than the pictorial tabulation of the schedule which we are providing. The size of the project that this computer program can handle will then be limited only by the memory-storage capacity of the computer.

It is pointed out that our scheduling routine can cope with the so-called "splitting" of activities (activities that may be Intermupted and then continued at a later date without extra cost), gimply by dividing each "splittable" activity into the required number of sub-activities and sub-events. These sub-activities and sub-events will be incorporated in the data as though they were real activities and events of the original project network. Then, when the "heuristic best solution schedule" is obtained, it will determine whether these splittable activities should be done continuously or with successive interruptions. The original time-precedence relations of the original activities and events remain intact.

It is also pointed out that our scheduling routine can handle those activities that do not have a constant requirement of resources 
during their entire durations: for example, an activity A may have a duration of 2 days and require 4 units of resource during its first day, and 3 units of resource during its second day. Obviously, to keep track of these "non-constant resource requirements" of the activities represents a larger amount of computations and extra care in the preparation of the resource profiles; but we can see that the scheduling routine is not changed. 


\section{GENERALIZED PROJECT SCHEDULING PROBLEIM}

Let us now contemplate the adaptation procedures for our scheduling routine, so that it can cope with more complicated cases of project scheduling with resource constraints. In the following discussions we will assume that the reader is already familiar with the rules and decisions explained in the steps of the "scheduling routine" just presented in Chapter III.

\section{Single-Project Multi-resource Case}

We can consider here, that two different situations could occur:

a. The several kinds of resources required by the activities of the project-network can be weighted and reduced to units of a single common resource. Then, we would be solving again, the singleproject single-resource case; and therefore the "heuristic best solution schedule" can also be found by following the scheduling routine given in Chapter III. This situation may arise in projects for which the several kinds of resources can be transformed and expressed in units of money, area, weight, etc., and where the minimization of this single common resource has priority. Projects realized by government agencies usually have the constraint of a fixed-budgeted-periodical availability of dollars, and obviously, even if the availability of men and equipment can be easily satisfied by the market, we have to 
constrain our expenses to the fixed budget. A repair-project in a long bridge would typify the constraints on total area, or total weight, of the several kinds of resources needed for the repair-project.

Suppose that the given project requires $g$ kinds of resources $(i=1,2,3, \ldots, g)$. Then, the resource requirements of each activity can be represented by the sum of its weighted individual resource requirements as follows:

$$
r\left(A_{j}\right)=\sum_{i=1}^{g} C_{i} z_{i j}
$$

where:

$j \quad$ is the activity identification number.

$C_{i}$ is the cost-weighting factor for resource $i$

$z_{i j}$ is the requirement of resource $i$ of activity $A_{j}$

during any day of its duration.

$\mathrm{C}_{i}$ and $\mathrm{z}_{i j} \geq 0$

Then, the resource constraint can be formulated as follows:

$$
S_{t}=\sum_{j=1}^{a} X_{j t} r\left(A_{j}\right) \leq K^{*}
$$

where:

$t$ represents any day of the schedule.

$X_{j t}$ represents a zero-one variable that takes the value of one when the activity $A_{j}$ is currently scheduled during day $t$, otherwise it takes the value of zero. 
a is equal to the total number of activities in the network.

$S_{t}$ is the total allocation of resources during day $t$.

$\mathrm{K}^{*}$ is the maximum availability of money, or area, or weight, etc.

$r\left(A_{j}\right)$ is as previously defined.

b. The second situation is perhaps the most commonly found in real life; in any case, it is more general. It happens when the several kinds of resources required by the activities of the project-network are so different in nature (or maybe management prefers to keep them separate), that they cannot be weighted and reduced to units of a single common resource. In this situation, the mathematical formulation can be transformed as follows:

Let:

The vector $\overline{r\left(\hat{A}_{j}\right)}$ represents the set of daily resource requirements of activity $\mathrm{A}_{j}$.$$
\overline{r\left(A_{j}\right)}=\left(z_{I j}, z_{2 j}, \ldots, z_{i j}, \ldots, z_{g j}\right)
$$

where:

$A_{j}, z_{i j}$, and $g$ are as previously defined.

The vector $\bar{S}_{t}$ represents the set of allocations of the $g$ kinds of resources during day $t$.

$$
\begin{gathered}
\bar{s}_{t}=\left(\sum_{j=1}^{a} x_{j t} z_{I j}, \sum_{j=1}^{a} x_{j t} z_{2 j}, \ldots, \sum_{j=I}^{a} x_{j t} z_{i j}, \ldots,\right. \\
\left.\quad \sum_{j=1}^{a} x_{j t} z_{g j}\right)
\end{gathered}
$$


where:

$$
\begin{aligned}
& \text { a, } X_{j t}, z_{i j} \text {, and } g \text { are as previously defined. } \\
& \text { The vector } \bar{K} \text { represents the set of maximum daily } \\
& \text { availabilities of the } g \text { kinds of resources } \\
& \bar{K}=\left(K_{1}, K_{2}, \ldots, K_{i}, \ldots, K_{g}\right)
\end{aligned}
$$

where:

$$
\begin{aligned}
& K_{i} \text { is the maximum daily availability of resource } i \text {. } \\
& g \text { is as previously defined. }
\end{aligned}
$$

Then, the resource constraint can be formulated as follows:

$$
\bar{S}_{t} \leq \bar{K} \text {; during any day } t
$$

The adaptation of the scheduling routine given in Chapter III will be accomplished by making the following changes:

1. Provide one resource profile for each of the $g$ kinds of resources.

2. Obtain information from management about the "order of priority" in which the $g$ kinds of resources will be minimized - which kind. is the "most important", which one is the "second-most important", and so on. If no "order of priority" is given, assign the "order of priority" at random.

3. Realize the rescheduling of the activities by cutting the RIIP of the resource profile of the "most important" kind of resources in exactly the same way as explained in Chapter III; but do not accept the formation of peaks of larger height than the height of the current largest peak in each one of the resource profiles of the other "g-I" kinds of resources; e.g.: accept only the 
formation of peaks of equal or smaller height than the height of the current larger peak in each one of the resource profiles of the other $g-1$ kinds of resources.

4. All the other heuristic rules and decisions of the scheduling routine given in Chapter III remain the same.

\section{Multi-Project Single-Resource Case}

This case happens when several projects require the same kind of resources 1 which are only available in a fixed amount.

$K_{1}$ (maximum availability of resource $i$ - during any day of the schedule - to any combination of activities belonging to one or more projects).

For example: a maintenance department, or a shop, that has several projects in its backlog. Each one of these projects requires the same kind of special equipment - or the same kind of highly trained personnel - which is only available in a limited number. The problem is to realize as many projects as possible with the existing resources, and to determine the completion date of each project. This "leveling" problem is very similar to the "allocation" problem. The difference is the objective function of the scheduling procedures. The allocation procedures are aimed at minimizing the project completion dates, while the leveling procedures are aimed at minimizing the daily resource allocations to the given projects; any project completion date could be accepted, as long as it does not go beyond the given due date.

The scheduling routine presented in Chapter III could be used to 
solve this case by finding first the best heuristic schedule of each individual project by using the parameter $K_{1}$ (as previously defined) as the resource constraint. The scheduling routine of Chapter III is applied without any modification to each of these single project single resource sub-cases. Then, we would consider each one of these projects as if they were super-activities of a super-project. The resource requirements of these super-activities are given by the resource profile of their corresponding heuristic best solution schedules. All the super-activities would have the day zero as their earliest start times; their corresponding completion times would give their durations; and their corresponding due dates would give their latest finish times. The resource constraint of the super-project is given by $K_{1}$ (as defined before), and the time constraint is given by the due date of the super-activity that happens to have the largest due date among all these super-activities. The maximum slippage for the super-project is given by the maximum slippage of the super-activity that happens to have the largest due date among all of these superactivities. We would finallỳ obtain the "heuristic best solution schedule" of the super-project by following the heuristic rules and decisions of the scheduling routine given in Chapter III.

\section{Multi-Project Multi-resource Case}

This case happens when a certain industrial concern needs to realize several different projects that require several different kinds of resources which are subjected to availability constraints. The problem is to realize as many projects as possible with the 
existing resources and to determine the completion date of each project. The completion dates should be set, preferably, within the corresponding due dates.

We can also consider here that two situations could occur:

a. A situation where the several kinds of resources required by the activities of the several project-networks can be weighted and reduced to units of a single common resource (money, area, weight, etc.). Then, we would be solving again the multiproject single-resource case, explained immediately preceding.

b. A situation where the several kinds of resources required by the activities of the several project-networks cannot be weighted and reduced to units of a single common resource. The scheduling routine presented in Chapter III could also be used to solve this case, by first finding the best heuristic schedule of each individual project by using the vector $\bar{K}$ (defined on page 84) as the resource constraint, and then by following the procedures outlined on page 84 for the adaptation of the scheduling routine to solve the single-project multi-resource case in a situation where the several kinds of resources cannot be weighted and reduced to a single common kind of resource such as money, weight, etc. Then, we would consider each one of these projects as if they were super-activities of a super-project as previously explained on page 86, with the difference that the resource constraint is now given by the vector $\overline{\mathrm{K}}$ to represent the set of maximum daily availabilities of the several kinds of resources. 


$$
\bar{K}=\left(K_{1}, K_{2}, \ldots, K_{i}, \ldots, K_{z}\right)
$$

where $K_{i}$ and $g$ are as previously defined.

We would finally obtain the best heuristic schedule of the super-project by following the heuristic rules and decisions of the scheduling routine given in Chapter III as adapted by the instructions given on page 84 for the solution of the single-project multi-resource case in a situation where the several kinds of resources cannot be weighted and reduced to a single common kind of resource.

The preceding adaptations of our scheduling routine do give a solution to each one of these more complicated cases of project scheduling with resource constraints; but, obviously, more research is necessary before we could assume that the heuristic solutions of the multi-project cases are also practical and workable. These heuristic solutions of the multi-project cases should be taken only as valuable suggestions for the final development of multi-project scheduling techniques in some. future research. 
V. CONCLUSIONS

The scheduling routine presented and discussed in this thesis will find real-life applications in the construction industry and in the maintenance functions of other industrial concerns where the scheduling of the activities of a single-project under constraints on availability of resources and due date is the scheduling problem, and the minimization of the daily allocations of resources is the objective of the scheduling procedures.

The scheduling routine provides practical and workable means of solving the leveling problem of project scheduling with resource constraints for the single-project single-resource case, and for the single-project multi-resource case. It allows for "splitting" and "non-constant resource requirements" of the activities. The practicality of the scheduling routine is enhanced by the fact that it can be programmed for computer operation, therefore releasing the user from the lengthy, repetitive, and tedious calculations associated with problems of this type. A computer program that realizes all the computations and prints out the solution schedules of the singleproject single-resource case is given in Appendix A. The Appendices $\mathrm{B}$ and $\mathrm{C}$ show computer solutions of two examples.

Two extensions of the scheduling routine that could solve the multi-project single-resource case, and the multi-project multiresource case of the leveling problem of project scheduling with 
resource constraints are presented as suggestions to a future researcher interested in the solution of these cases. However, more research should be done in order to provide practical and workable solutions for these cases.

Several analytical formulations of varying problems of project scheduling with resource constraints have been published; but, as the authors themselves recognize, they are impractical and usually unworkable means of solving real-life problems. They are important, however, from the conceptual point of view. We present in this thesis an integer linear programming formulation of the leveling problem of project scheduling with resource constraints which could yield the optimal solution, but which is almost impossible to solve. Therefore it does not provide workable means of solving the problem.

The literature review summarizes the variety of heuristic approaches that have been proposed for the solution of different problems of project scheduling with resource constraints. The available publications are mainly concerned with. the description of the fundamental heuristics of these scheduling techniques, their goals, and the scope of the problems they are aimed at solving, but very little information, if any, is given about the details of their scheduling procedures. All this precluded a possible comparison of our scheduling routine with the other scheduling techniques. It is emphasized, however, that we tried to incorporate in our scheduling routine as many as possible of those apparently good procedures of the other techniques, and that we supplemented them with new procedures of our own that seemed to yield better results in our specific 
scheduling problem.

We have shown in the solution of the example project that our scheduling routine originates successive schedules that converge towards the optimal solution schedule: e.g., the feasible schedule that gives the minimum daily allocations of resources. Therefore, we can conclude that it provides a good chance of finding a nearoptimal solution schedule, if not the real optimal one. Due to the heuristic nature of the rules and decisions that compose our scheduling routine, we cannot assure the optimality of the solution schedules that it produces. Optimal solution schedules can be assured only by strict analytical techniques. However, since the last word is not yet in on problems of project scheduling with resource constraints, it is believed that new heuristic scheduling techniques based on functional properties of the networks will supplement those already avallable toward the final development of a practical and workable analytic scheduling technique. 


\section{REFERENCES}

1. Berman, E. B*, "Resource Allocation in a PERT Network under Continuous Time-Cost Functions", Management, July 1964.

2. Bigelow, C. G., "Bibliography on Project Planning and Control by Network Analysis: 1959-1961", Operations Research, Vol. 10, No. 5, 1962.

3. Black, O. J., "An Algorithm for Resource Leveling in Project Networks", unpublished paper, Department of Industrial Administration, Yale University, May 1965.

4. Bower, J. I*, "Managing the Resource Allocation Process", Graduate School of Business Administration, Harvard University, Boston, Mass., 1970.

5. Bowman, E. H*, "The Schedule-Sequencing Problem", Operations Research, Vol. 7, No. 5, Sept.-Oct. 1959.

6. Buffa, E. S*, "Production Inventory Systems - Planning and Control", Part VI, "Planning and Scheduling for LargeScale Projects", Richard D. Irwin Inc., Homewood, III. 1968.

7. Burgess, A. R., and Killebrew, J. B., "Variation in Activity Level on a Cyclic Arrow Diagram", Journal of Industrial Engineering, March-April 1962.

8. Clark, C. $E_{*}$, "The Optimum Allocation of Resources among the Activities of a Network" "Journal of Industrial Engineering, VoI. XII, No. 1, Jan. -Feb. 1961.

9. Conway, R* W., "An Experimental Investigation of Priority Assignment in a Job Shop", Memorandum R.M*-3789-P.R., the Rand Corporation, February 1964.

10. Davis, E. W*, "Resource Allocation in Project Network Models A Survey", Journal of Industrial Fugineering, Vol. XVII, No. 4, Apri1 1966.

11. , and Heidorm, G. E., "An Algorithm for Optimal Project Scheduling under Multiple Resource Constraints", Management Science, Vol. 17, No. 12, August 1971. 
12. De Witte, I*, "Manpower Leveling of PERT Networks", Data Processing for Science/Engineering, March-April 1964.

13. Eisner, $\mathrm{H}_{*}$, "A Generalized Network Approach to the Planning and Scheduling of a Research Program", Operations Research, Vol. 9, No. 3, 1961.

14. Fendley, I. G., "The Development of a Complete Multiproject Scheduling System Using a Forecasting and Sequencing Technique", Ph.D. Dissertation, Arizona State University, Tempe, Arizona, September 1966.

15. "Woward the Development of a Complete Multiproject Scheduling System", Journal of Industrial Engineering, Vol. XIX, No. 10, October 1968.

16. Fulkerson, D. R., "Scheduling in Project Networks", Memorandum R.M. $-4137-P . R_{*}$, the Rand Corporation, June, 1964.

17. Ghare, P. M., "Optimal Resource Allocation in Activity Networks", Paper, Operations Research Society of America Meeting, Houston, Texas, November 1965.

18. Heuser, W. A*, Jr*, and Wynne, B. E*, Jr., "An Application of the Critical Path Method to Job-Shop Scheduling - A Case Study", Management Technology, Vol. 3, No. 2, December 1963.

19. Hooper, P. C., "Resource Allocation and Levelling", Proceedings of the Third CPA Symposium, Operations Research Society, London, 1965.

20. Horowitz, J., "Critical Path Scheduling - Management Control through CPM and PERT", the Ronald Press Company, New York, 1967.

21. Hir, T. C., "Parallel Sequencing and Assembly Iine Problems", Operations Research, Vol. 9, No* 6, Nov*-Dec., 1961.

22. Johnson, T. J. R., "An Algorithm for the Resource-Constrained Project Scheduling Problem", unpublished Ph.D. Thesis, School of Management, M.I.T., August 1967.

23. Kelley, J. E*, Jr., "The Critical-Path Method: Resources Planning and Scheduling", Chapter 21 in "Industrial Scheduling" ed. by Math J.F. and Thompson, G.L., Prentice-Hall Inc., Fnglewood Cliffs, New Jersey, 1963.

24. Lambourm, S., "Resource Allocation and Multiproject Scheduling (RAMPS), A New Tool in Planning and Control", Computer Journal, Vol. 5, No. 4, January 1963. 
25. Ievy, F. K., Thompson, G. S., and Wiest, J. D., "Multi-Ship Multi-Shop Workload Smoothing Program", Naval Research Logistics Quarterly, March 1963.

26. __. and Wiest, J. D., "A Menagement Guide to PERT/CPM" Prentice Hall Inc., Finglewood Cliffs, New Jersey, 1969.

27. Martino, R. I*, "Resource Allocation and Scheduling", Project Management and Control Series, Vol. III, New York: American Management Association, 1965.

28. McGee, A. A*, and Markarian, M. D*, "Optimum Allocation of Research/Engineering Manpower within a Multi-Project Organizational Structure", IFEF Transactions on Engineering Management, September 1962.

29. Meyer, W. L*, and Shaffer, L. R*, "Fxtensions of the Critical Path Method through the Application of Integer Programming" Department of Civil Engineering, University of Illinois, July 1963.

30. _. Ritter, J. B*, and Shaffer, I. R., "The Critical Path Method", McGraw-Hil1. Book Company, New York, 1965.

31. Mize, J. H., "A Heuristic Scheduling Model for Multiproject Organizations", Ph.D. Thesis, Purdue University, Lafayette, Indiana, August 1964.

32. Moder, J. J., and Phillips, C. R., "Project Management with CPM and PERT", Reinhold Corporation, New York, 1964.

33. Moshman, J., Johnson, J., and Larsen, M., "RAMPS: A Technique for Resource Allocation and Multiproject Scheduling", Proceedings, Spring Joint Computer Conference, 1963.

34. Muth, J. F., Thompson, G. $I_{*}$, and Winters, P. R*, Editors, "Industrial Scheduling", Prentice-Hall Inc., Finglewood Cliffs, New Jersey, 1963.

35. Pascoe, T. L., "An Experimental Comparison of Heuristic Methods for Allocating Resources", Ph.D. Thesis, Cambridge University, Engineering Department, 1965.

36. Phillips, C* R*, "Fifteen Key Features of Computer Programs for CPM and PERT", Journal of Industrial Engineering, Jan.-Feb. 1964.

37. Waldron, A. J* "Applied Principles of Project Planning and Control", published by A. James Waldron, 371 Kings Highway West, Haddonfield, N. J., April 1966. 
38. Wiest, J. D., "The Scheduling of Large Projects with Iimited Resources", Ph.D. Thesis, Carnegie Institute of Technology, Pittsburgh, Pennsylvania, 1963.

39. _. "Some Properties of Schedules for Large Projects with Limited Resources", Operations Research, Vol. 12, No. 3, May-June 1964.

40. ., "Heuristic Programs for Decision Making", Harvard Business Review, Sept. -0ct. 1966.

41. __. "A Heuristic Model for Scheduling Large Projects with Limited Resources", Management Science, Vol. 13, No. 6, February 1967.

42. Wilson, R. C., "Assembly Line Balancing and Resource Scheduling", University of Michigan Summer Conference on Production and Inventory Control, 1964. 
APPENDIX A

COMPUTER PROGRAM OF THE SCHEDULING ROUTINE 
HEURISTIC SCHEDULING ROUTINE PROJECT SCHEDULING WITH RESOURCE CONSTRAINTS

SINGLE PROJECT SINGLE RESOURCE CASE OF THE LEVELING PROBLEM MASTER OF SCIENCE THESIS - - HECTOR J ALVAREZ

UNIVERSITY OF RHODE ISLAND --- 1971

COMMON KINODE(70), KJNODE (70), KTIME(70), KRSRCE (70), NET(70)

COMMON KEF $(70), N L T(70), K L S(70), K L F(70), K F L O A T(70)$, KFREE $(70)$

COMMON KINDEP $(70)$, KSAFE( 70$)$, NSLACK $(70)$, KRANK $(70)$, LEVEL $(80)$

COMMON KCHOIS $(30)$, KLU, LMAX, MAXTU, NOTA, NAINLM, MMOVER, MAXRES

COMMON YES, SIGNO, YNO, BLANCO, PALO, MSCHED $(70,80)$, SINOP

COMMON NA, NN, NLAST, NSLI P, NTIME, LSLIP, LTIME, NCSCH, MSALE, INCRE

COMMON KES $(70)$, KPOS $(30)$, KPOSRK $(30)$

DIMENSION KKESTA $(70)$, KKEFIN( 70$)$, NNESTA $(70)$, NSCHED $(70,80)$

DIMENSION KESTA(70), KEFIN(70), NESTA(70)

EQUIVALENCE (KFREE (1), KESTA $(1))$, (KINDEP(1), KEF IN $(1))$

EQUIVALENCE (KSAFE (1), NESTA 11$)$ )

NOTA $=0$

LLMAX $=10000$

CALL CALNET

49 CALL REPROF

50 MSALE $=0$

CALL SCHEDU

CALL PEAK

CALL TORITE

SINOP =

IF(MSALE) $\quad 60,60,49$

60 CALL MOVER

IF(MMOVER) $70,70,50$

70 CALL TOLEFT

IF(MSALE) $80,80,49$

80 CALL MOVEL

IF(MMOVER) $90,90,50$

90 SINOP $=S I N O P+1$

IF (SINOP-2) $60,100,100$

100 NOTA $=$

NOSCH$=\mathrm{NOSCH}-1$

CALL SCHEDU

IF (LMAX-LLMAX) $110,120,120$

$11000111 \mathrm{KO}=1$, NA

KKESTA $(K D)=K E S T A(K O)$

KKEFIN $(K O)=K E F \ N(K O)$

NNESTA $(K O)=N E S T A(K O)$

DO $112 \mathrm{NON}=1$, NTIME

112 CONTINUE

NSCHED $(K O, N O N)=M S C H E D(K O, N O N)$

111 CONTINUE 
NNTI ME $=$ NTI ME

NNOSCH$=\mathrm{NOSCH}-1$

MMAXTU $=$ MAXTU

LLMAX = LMAX

120 IFINTIME-LTIME) $124,121,121$

121 IF(LMAX-MAXRES) $126,126,122$

122 IFINSLIP-LSLIP) $123,125,125$

123 NSLIP $=$ NSLI $P+1$

124 NTIME $=$ LTIME+ NSLIP

DO $160 \quad \mathrm{NO}=1$, NN

$N L T(N O)=N L T(N O)+I N C R E$

160 CONTINUE

INCRE $=1$

GO TO 49

125 WRITE $(6,900)$ MAXRES,LTIME, LSLIP

900 FORMATI'1'//T10, 'THE ROUTINE CANNOT FIND AN SCHEDULE WHICH SATISFI +ES THE RESOURCE CONSTRAINT OF LMAX $=1,13, \cdot, \cdot / 1$ T10,' THE BEST HEURI ISTIC SCHEDULE FOR A GIVEN PROJECT DUE TIME OF $, 13,1$ UNITS OF TIME $2 \% / / T 10$, AND WITH A MAXIMUM PROJECT SLIPPAGE CF $1,13, "$ UNITS OF TIM $3 E^{\prime} / / T 10,1 \mathrm{~S}$ THE FOLLOWING : $1 / 1$

GO TO 127

126 WRITE $(6,910)$

910 FORMAT/ $1 / / / / / / / / / / T 10$, 'THE HEURISTIC BEST SOLUTION SCHEDULE FOR + THE GIVEN PROJECT IS: 'I

127 DO $141 \mathrm{KO}=1$, NA

KESTA $(K O)=K K E S T A(K O)$

KEFIN $(K O)=K K E F I N(K O)$

NESTA $(K O)=$ NNESTA $(K O)$

DO $142 \mathrm{NON}=1$, NTIME

IF (NON-NNTIME) $\quad 146,146,145$

$145 \operatorname{MSCHED}(K O, N O N)=0$

GO TO 142

146 MSCHED (KO, NON) =NSCHED (KO, NON )

142 CONTINUE

141 CONTINUE

NTIME = NNTIME

$\mathrm{NOSCH}=\mathrm{NNOSCH}$

MAXTU = MMAXTU

LMAX = LLMAX

NOTA $=$

CALL REPROF

CALL SCHEDU

STOP

END 
SUBROUTINE CALNET

CALCULATES NETWORK CHARACTERISTICS

COMMON KINODE (70), KJNODE $(70)$, KTIME (70), KRSRCE(70), NET(70)

COMMON KEF(70), NLT(70), KLS $(70), K L F(70), K F L O A T(70), K F R E E(70)$

COMMON KINDEP (70), KSAFE( 70$)$, NSLACK $(70)$, KRANK (70), LEVEL (80)

COMMON KCHOIS( 30$)$, KLU, LMAX, MAXTU, NOTA, NAINLM, MMOVER, MAXRES

COMMON YES, SIGNO, YNO, BLANCO, PALO, MSCHED 70,80$)$, SINOP

COMMON NA, NN, NLAST, NSLIP, NTIME, LSLIP, LTIME, NCSCH, MSALE, INCRE COMMON KES $(70)$, KPOS $(30)$, KPOSRK $(30)$

READ $(5,8500)$ YES,SIGNO, YNO, BLANCO, PALO

$c$

READS DATA INPUT

READ $(5,9000)$ NA, LTIME, LSLIP, MAXRES

DO $1000 \quad \mathrm{NO}=1$, NA

1000 READ $(5,9000)$ KINODE (NO), KJNDDE(NO), KTIME(NO), KRSRCE(NO)

C

C CALCULATES EARLY START AND EARLY FINISH FOR ALL ACTIVITIES

C ALSO CALCULATES EARLY TIMES FOR ALL NODES

C

$N N=K J N O D E(N A)$

NLAST $=0$

DO $1001 \mathrm{NNO}=1$, NN

1001 NET $(N N O)=0$

DO $1002 \mathrm{NO}=1$, NA

$I=K ! N O D E(N O)$

$J=K J N O D E(N O)$

KES $(N O)=N E T(I)$

$K E F(N O)=K E S(N O)+K T I M E(N O)$

IF(KEF(NO)-NET (J)) 2,2,1

$1 \operatorname{NET}(J)=\operatorname{KEF}(\mathrm{NO})$

2 IF(KEF(NO) -NLAST) $1002,1002,3$

3 NLAST $=K E F(N O)$

1002 CONT INUE

C

C CALCULATES LATEST START AND LATEST FINISH FOR ALL ACTIVITIES

C ALSO CALCULATES LATE TIMES FOR ALL NODES

c

DO $1003 \mathrm{~K}=1$, NN

1003 NLT $(K)=$ NLAST

DO $1004 \mathrm{NO}=1$, NA

$L=N A+1-N O$

$I=K I N O D E(L)$

$J=K J N O D E(L)$ 
$K L F(L)=N L T(J)$

$K L S(L)=K L F(L)-K T I M E(L)$

IFIKLS(L)-NLT(I)) $4,5,5$

$4 \mathrm{NLT}(I)=\mathrm{KLS}(L)$

5 KFLOAT $(L)=K L S(L)-K E S(L)$

1004 CONTINUE

PRINTS NODES TABLE

CALCULATES SLACK TIMES FOR ALL NODES

WRITE $(6,9001)$

DO $1005 \mathrm{~K}=1$, NN

NSLACK $(K)=N L T(K)-N E T(K)$

IF(NSLACK $(K)) 6,6,7$

6 WRITE $(6,9002) \mathrm{K}, \operatorname{NET}(K), N L T(K), N S L A C K(K), Y E S$

GO TO 1005

7 WRITE $(6,9002) \mathrm{K}, \operatorname{NET}(K), N L T(K), N S L A C K(K), Y N O$

1005 CONTINUE

PRINTS ACTIVITIES TABLE

CALCULATES FLOAT TIMES FOR ALL ACTIVITIES

WRITE $(6,9003)$

DO $1006 \mathrm{~K}=1$, NA

$\operatorname{KFREE}(K)=0$

$K \operatorname{INDEP}(K)=0$

$K S A F E(K)=0$

IF(KFLOAT(K)) $1006,1006,8$

$8 I=K I N O D E(K)$

$J=K J N O D E(K)$

$\operatorname{KFREE}(K)=N E T(J)-K E F(K)$

$\operatorname{KINDEP}(K)=\operatorname{NET}(J)-K \operatorname{TIME}(K)-N L T(I)$

IF $(K I N D E P(K)) \quad 9,10,10$

$9 \operatorname{KINDEP}(K)=0$

$10 K S A F E(K)=K L S(K)-N L T(I)$

1006 CDNTINUE

c

C ASSIGNS IM VALUES TO ALL ACTIVITIES

C

$K R=1$

DO $1007 \mathrm{~K}=1$, NA

$\operatorname{KRANK}(K)=0$

IF $(K F L O A T(K)) 11,11,1007$

$11 \operatorname{KRANK}(K)=K R$

$K R=K R+1$

1007 CONTINUE

$12 K A C=K$

DO $1008 \mathrm{~K}=1$, NA 
IF(KRANK (K) $14,14,1008$

$14 K 1=K+1$

DO $1009 \mathrm{KJ}=\mathrm{K} 1$, NA

IF(KRANK (KJ)) 1009,15,1009

15

IF(KFLOAT(KAC)-KFLOAT(KJ)) 1009,16,19

16 IF(KFREE (KAC)-KFREE(KJ)) $1009,17,19$

17 IF (KINDEP $(K A C)-K I N D E P(K J)) 1009,18,19$

18 IF(KSAFE (KAC)-KSAFE (KJ)) 1009,1009,19

$19 \mathrm{KAC}=\mathrm{K} \cdot \mathrm{J}$

1009 CONTINUE

$K R A N K(K A C)=K R$

$K R=K R+1$

IF(KRANK (K)) $12,12,1008$

1008 CONTINUE

c

c

FINDS OUT WHICH ACTIVITIES LIE ON THE CRITICAL PATH

ALSO FINDS OUT WHICH ACTIVITIES ARE DUMMIES

DO $1010 \mathrm{~K}=1$, NA

IF (KTIME $(K)) \quad 20,20,23$

20 IF (KFLOAT $(K)) 21,21,22$

21 WRITE $(6,9004) \mathrm{K}, K I N O D E(K), K J N O D E(K), K R S R C E(K), K T I M E(K), K E S(K)$, $+K E F(K), K L S(K), K L F(K), K F L O A T(K), K F R E E(K), K I N D E P(K), K S A F E(K)$,

1 YES, YES, KRANK(K)

GO TO 1010 .

22 WRITE $(6,9004) \mathrm{K}, \mathrm{KINODE}(K), K J N O D E(K), K R S R C E(K), K T I M E(K), K E S(K)$, $+K E F(K), K L S(K), K L F(K), K F L O A T(K), K F R E E(K), K I N D E P(K), K S A F E(K)$, 1 YNO, YES, KRANK (K)

GO TO 1010

23 IF(KFLDAT(K)) $24,24,25$

24 WRITE $(6,9004) \mathrm{K}, \mathrm{KINODE}(\mathrm{K}), \mathrm{KJNODE}(K), K R S R C E(K), K T I M E(K), K E S(K)$, $+K E F(K), K L S(K), K L F(K), K F L O A T(K), K F R E E(K), K I N D E P(K), K S A F E(K)$, IYES, YNO, KRANK $(K)$

GO TO 1010

25 WRITE $(6,9004) \mathrm{K}, \operatorname{KINODE}(K), K J N O D E(K), K R S R C E(K), K T I M E(K), K E S(K)$, $+K E F(K), K L S(K), K L F(K), K F L O A T(K), K F R E E(K), K I N D E P(K), K S A F E(K)$, 1 YNO, YNO, KRANK $(K)$

1010 CONTINUE

$c$

C

CALCULATES GENERAL INFORMATION FOR THE PROJECT

C

NOSC $\mathrm{H}=0$

NSL I $P=0$

NTIME $=$ NLAST

DO $1011 \mathrm{~K}=1$. NA

$\operatorname{KFREE}(K)=\operatorname{KES}(K)$

$K \operatorname{INDEP}(K)=K E F(K)$

1011 CONTINUE 
DO $1012 N=1, N N$
$\operatorname{KSAFE}(N)=N E T(N)$

1012 CONTINUE

1015 LTIME $=$ NTIME

1016 INCRE $=$ LTIME-NTIME

WRITE $(6,9005)$ NTIME, LTIME, INCRE, MAXRES, LSLIP

c

FORMATS FOR INPUT-OUTPUT

8500 FORMAT (5A4)

9000 FORMAT (413)

9001 FORMATIIH1/T24,' N O D E S = E V E N T S1//T10,'NUMBER', T20, +'EARLIEST TIME', T38, 'LATEST TIME',T52, 'SLACK', T62, 'CRITICAL PATH' $1 / / 1$

9002 FORMAT (T11, I3,T25, 13,T42,I3,T53,13,T67,144/1)

9003 FORMATIIHI/T50,' A C T I V I T I E S'///T8.'NUMBER',TI5, 'INODE', +T21. 'JNODE', T28, 'RSRCE', T35, 'DURA', T41, 'E-START', T48,' E-FIN', 1T56, 'L-START', T64,' L-FIN',T72, 'TOTAL-F', T80,' FREE-F', T88, 2' IND-F', T96,' SAFE-F', T103, 'C-PATH', T110, 'DUMMY', T116, 'INDEX'/I 9004 FORMATIT6, 3I6,317,T45,7I8,T104,1A4,T110,1A4,T117, I3/1

9005 FORMAT////T12, 'THE EARLIEST PROJECT COMPLETION TIME IS ', I5, 'UNIT +S OF TIME'/T12, 'THE GIVEN PROJECT DUE DATE IS', I5,' UNITS OF TIME' $1 /$ T12, 'THE CURRENT PROJECT SLACK IS', I5,' UNITS OF TIME'/T12, 'THE D 2AILY RESOURCE AVAILABILITY IS',I5,' UNITS CF RESOURCE'/T12, 'THE MA $3 \times$ IMUM PROJECT SLIPPAGE IS', I5, UNITS OF TIME'/1

RETURN

END 
SUBROUTINE REPROF

$c$
$c$
$c$
$c$

CALCULATION OF THE RESCURCE PROFILE

COMMON KINODE (70), KJNODE (70), KTIME (70), KRSRCE(70), NET(70)

COMMON KEF $(70)$, NLT $(70), K L S(70), K L F(70), K F L O A T(70), K F R E E(70)$

COMMON KINDEP $(70)$, KSAFE $(70)$, NSLACK $(70)$, KRANK $(70)$, LEVEL (80)

COMMON KCHOIS $(30)$, KLU, LMAX, MAXTU, NOTA, NAINLM, MMOVER, MAXRES

COMMON YES, SIGNO, YNO, BLANCO, PALO, MSCHED $(70,801$, SINOP

COMMON NA, NN, NLAST, NSLIP, NTIME, LSLIP, LTIME, NCSCH, MSALE, INCRE

COMMON KES $(70)$, KPOS $(30)$, KPOSRK $(30)$

DIMENSION KESTA $(70)$, KEFIN(70), NESTA(70)

EQUIVALENCE (KFREE(1),KESTA $(1)$ ), (KINDEP(1), KEFIN $(1)$ )

EQUIVALENCE (KSAFE(1), NESTA(1))

DO $1100 M=1$, NTIME

$\operatorname{LEVEL}(M)=C$

1100 CONTINUE

DO 1101 MACT $=1$, NA

$M T 1=K E S T A(M A C T)+1$

$M T 2=K E S T A(M A C T)+K T$ IME (MACT)

DO 1101 MTIME $=1$, NTIME

IF (KTIME (MACT) $105,105,102$

102 IF(MTIME-MT1) $105,104,103$

103 IF(MTIME-MT2) $104,104,105$

$104 \operatorname{MSCHED}(M A C T, M T I M E)=K R S R C E(M A C T)$

GO TO 106

105 MSCHED (MAC T, MTI ME) $=0$

106 LEVEL (MTIME) = LEVEL (MTIME) +MSCHED (MACT, MTIME)

1101 CONTINUE

RETURN

END 
SUBROUTINE SCHEDU

C

CALCULATION AND PRINT DUT OF CURRENT SCHEOULE

THE CORRESPONDING RESOURCE PROFILE IS ALSO PRINTED

COMMON KINODE (70), KJNODE(70), KTIME (70), KRSRCE(70), NET(70)

COMMON KEF $(70)$, NLT(70), KLS $(70)$, KLF (70), KFLOAT(70), KFREE(70)

COMMON KINDEP $(70)$, KSAFE (70), NSLACK $(70)$, KRANK $(70), \operatorname{LEVEL}(80)$

COMMON KCHOIS( 30 ), KLU, LMAX, MAXTU, NOTA, NAINLM, MMOVER, MAXRES

COMMON YES, SIGNO, YNO, ELANCO, PALO, MSCHED 70,801 , SINOP

COMMON NA, NN, NLAST, NSLIP, NTI ME, LSLIP, LTIME, NOS CH, MSALE, INCRE

COMMON KES $(70)$, KPOS $(30)$, KPOSRK $(30)$

DIMENSION KESTA (70), KEFIN(70), NESTA(70), SON(70)

EQUIVALENCE (KFREE(1), KESTA(1)), (KINDEP(1), KEFIN 11$)$ )

EQUIVALENCE (KSAFE (1), NESTA(1))

$\mathrm{NOSCH}=\mathrm{NOSCH}+1$

IF (NOTA) $150,150,160$

150 WRITE( 6,9101$)$ NOSCH, NA

NTI $1=N T I M E+1$

DO 1106 MTIME $=1$, NT 1

$M=M T$ IME -1

$c$

C MARKS THE ENDING TIMES OF THE ACTIVITIES

c

DO $1102 \mathrm{~K}=1$, NA

IF (KEFIN $(K)-M) \quad 108,107,108$

$107 \operatorname{SON}(K)=P A L O$

GO TO 1102

$108 \operatorname{SON}(K)=B L A N C O$

1102 CONTINUE

WRITE $(6,9103)$ (SON $(K), K=1$, NA)

$\mathrm{NO}=0$

C

C MARKS THE CURRENT LOCATIONS OF THE NODES

C

DO $1103 \mathrm{~N}=1, \mathrm{NN}$

IF(NESTA $(N)-M) \quad 1103,109,1103$

$109 \mathrm{NO}=\mathrm{ND}+1$

$\operatorname{SON}(N O)=N * 1$.

1103 CONTINUE

IFINO) $120,120,119$

c

119 WRITE $(6,9102)$ (SON $(N), N=1, N O)$

C MARKS THE START TIMES OF THE ACTIVITIES

120 DO $1104 \mathrm{~K}=1$, NA 
110

IF(KESTA $(K)-M) 111,110,111$

GO TO 1104

$111 \operatorname{SON}(K)=B L A N C O$

1104 CONTINUE

WRITE $(6,9103)$ (SON $(K), K=1$, NA)

IF(NT1-MTIME) $\quad 1106,1106,112$

C PRINTS THE CURRENT SCHEDULE AND IT'S CORRESPONDING

RESOURCE PROFILE

112 WRITE $(6,9104)$ MTIME, (MSCHED(K,MTIME), K=1, NA) WRITE $(6,9105)$ LEVELIMTIME)

1106 CONTINUE

NOTA $=50$

c

FORMATS

c

9101 FORMAT(1H1/T32, 'S C HE D U L E N U M B E R', 14/1/

+ T20, 'ACTIVITIES : $1,2,3, \ldots \ldots \ldots .$, I2/T8, 'TIME-UNIT', T114, 'LEVEL'/1

9102 FQRMATIT12, 'NODES LOCATED HERE ARE: $1,20 \mathrm{~F} 3.01$

9103 FORMAT (T16,80A1)

9104 FORMATIT9, I4,T16,8011)

9105 FORMAT(!+', T114, I4)

160 RETURN

END 
SUBROUTINE PEAK

FINDS OUT THE LOCATION OF THE RIGHT-MOST-LARGEST-PEAK (MAXTU) AND SAVES IT'S VALUE (LMAX)

COMMON KINODE (70), KJNODE $(70)$, KTIME $(70)$, KRSRCE( 70$)$, NET(70)

COMMON KEF $(70)$, NLT( 70$)$, KLS $(70)$, KLF $(70)$, KFLOAT $(70)$, KFREE $(70)$

COMMON KINDEP $(70)$, KSAFE( 70$)$, NSLACK $(70)$, KRANK $(70)$, LEVEL (80)

COMMON KCHOIS(3O), KLU, LMAX, MAXTU, NOTA, NAINLM, MMOVER, MAXRES

COMMON YES, SIGNO, YNO, ELANCO, PALO, MSCHED $(70,80)$, SINOP

COMMON NA, NN, NLAST, NSLIP, NTIME, LSLIP, LTIME, NCSCH, MSALE, INCRE

COMMON KES $(70)$, KPOS $(30)$, KPOSRK $(30)$

DIMENSION KESTA(70), KEFIN(70), NESTA(70)

EQUIVALENCE (KFREE (1), KESTA $(1)$ ), (KINDEP(1), KEFIN(1))

EQUIVALENCE (KSAFE (1), NESTA 11 )

LMAX $=0$

DO $1200 M=1$, NTIME

$L=L E V E L(M)$

IF $(L-L M A X) \quad 1200,200,200$

200 LMAX $=L$

$M A X T U=M$

1200 CONTINUE

C

DETERMINES WHICH ACTIVITIES CONTRIBUTE TO BUILD UP LMAX AND SAVES THEIR IDENTIFICATION NUMBERS (KPOS(K)),

AND THEIR INDEX OF MOBILITY NUMBERS (KPOSRK(K)) •

C

$\mathrm{N}=0$

DO $1201 \mathrm{~K}=1$, NA

$M T 1=K E S T A(K)+1$

$M T 2=K E F I N(K)$

IF(MT2-MT1) $1201,201,201$

201 IF (MTI-MAXTU) $202,202,1201$

202 IF(MT2-MAXTU) $1201,203,203$

$203 \mathrm{~N}=\mathrm{N}+1$

$\operatorname{KPOS}(N)=K$

$K \operatorname{KPOSRK}(N)=K R A N K(K)$

1201 CONTINUE

$K L U=0$

$205 K 1=K P O S R K(1)$

$\mathrm{NCHOI}=1$

c

C DETERMINES THE ORDER OF RESCHEDULING

DO $1202 \mathrm{NO}=1, \mathrm{~N}$

$K R=K P O S R K(N O)$ 
IF $(K R-K 1) \quad 1202,1202,206$

$206 K 1=K P O S R K(N O)$

$\mathrm{NCHOI}=\mathrm{NO}$

1202 CONTINUE

$K L U=K L U+1$

KCHOIS $(K L U)=K P O S(N C H O I)$

KPOSRK $($ NCHOI $)=0$

$\operatorname{KPOS}(\mathrm{NCHOI})=0$

IF (N-KLU) $207,207,205$

207 NAINLM $=$ N

RETURN

END 
SUBROUTINE TORITE

C

ITERATION TYPE I -- FORWARDS

COMMON KINODE (70), KJNODE $(70)$, KTIME (70), KRSRCE(70), NET(70)

COMMON KEF (70), NLT $(70)$, KLS $(70)$, KLF $(70)$, KFLOAT $(70), \operatorname{KFREE}(70)$

COMMON KINDEP $(70)$, KSAFE $(70)$, NSLACK $(70)$, KRANK $(70)$, LEVEL (80)

COMMON KCHOIS $(30), K L U, L M A X, M A X T U, N O T A, N A I N L M, M M O V E R$, MAXRES

COMMON YES, SIGNO, YNO, BLANCO, PALO, MSCHED 70,801, SINOP

COMMON NA, NN, NLAST, NSLIP, NTIME, LSLIP, LTIME, NOSCH, MSALE, INCRE

COMMON KES $(70)$, KPOS $(30)$, KPOSRK $(30)$

DIMENSION KESTA $(70)$, KEFIN(70), NESTA(70)

EQUI VALENCE (KFREE $(1)$, KESTA $(1)),($ KINDEP $(1)$, KEFIN $(1))$

EQUIVALENCE (KSAFE 1 ), NESTA1 1$)$ )

$N=N A I N L M$

C

C ATTEMPTS TO RESCHEDULE THE ACTIVITIES AND REPORTS

C WHETHER THE ATTEMPT WAS SUCCESSFUL OR NOT

c

DO $1203 \mathrm{NO}=1, \mathrm{~N}$

$K=K C H O I S(N O)$

$J=K J N D D E(K)$

NJT $=$ NESTA $(J)$

IF (NJT-KEFIN(K) $1203,1203,208$

208 MDIF=NJT-KEFIN(K)

KMDIF = MAXTU-KESTA $K$ )

IF(MDIF-KMDIF) $1203,209,209$

209 NSTEP $=$ MDIF-KMDIF +1

LL $3=$ LMAX

DO 1204 MSTEP $=1$, NSTEP

MXT1 = MAXTU+MSTEP

$M X T 2=M X T 1-1+K T I M E(K)$

$\mathrm{LL} 2=\mathrm{C}$

DO $1205 M 9=M X T 1, M X T 2$

$L E V=L E V E L(M 9)+K R S R C E(K)$

IF (LEV-LMAX) $210,1204,1204$

210 IF (LEV-LL2) $1205,1205,211$

211 LL2=LEV

1205 CONTINUE

IF (LL2-LL3) $212,212,1204$

$212 \mathrm{LL} 3=\mathrm{LL} 2$

MHAPN=MSTEP

1204 CONT INUE

IF $(L L 3-L M A X) \quad 214,1203,1203$

$214 K E S T A(K)=M A X T U+M H A P N-1$

$\operatorname{KEFIN}(K)=\operatorname{KESTA}(K)+K \operatorname{TIME}(K)$ 
MSALE $=100$

NA I NL $M=0$

GO TO 215

1203 CONTINUE

215 RETURN

END 
SUBROUTINE TOLEFT

C

C

C

C

COMMON KINODE $(70)$, KJNODE $(70)$, KTIME $(70)$, KRSRCE( 70$)$, NET(70)

COMMON KEF $(70)$, NLT $(70)$, KLS $(70)$, KLF $(70)$, KFLOAT(70), KFREE(70)

COMMON KINDEP $(70)$, KSAFE $(70)$, NSLACK $(70)$, KRANK $(70)$, LEVEL $(80)$

COMMON KCHOIS(3O), KLU, LMAX, MAXTU, NOTA, NAI NLM, MMOVER, MAXRES

COMMON YES, SIGNO, YNO, BLANCO, PALO, MSCHED $(70,80)$, SINOP

COMMON NA, NN, NLAST, NSLIP, NTI ME, LSLIP, LTIME, NOSCH, MSALE, INCRE

COMMON KES $(70)$, KPOS $(30)$, KPOSRK $(30)$

DIMENSION KESTA (70), KEFIN(70), NESTAI70)

EQUIVALENCE (KFREE (1), KESTA 11$)$ ), (KINDEP(1), KEFIN 11 )

EQUIVALENCE (KSAFE(1), NESTA (1))

$c$

ATTEMPTS TQ RESCHEDULE THE ACTIVITIES AND REPORTS WHETHER THE ATTEMPT WAS SUCCESSFUL OR NOT

DO 1501 NO=1, NAINLM

$K=K C H O I S(N O)$

$I=K I N O D E(K)$

NIT $=$ NESTA(I)

$K S T=K E S T A(K)$

IF(NIT-KST) $501,1501,1501$

501 MDIF $=K S T-N I T$

$K M D I F=K E F I N(K)+1-M A X T U$

IF(MDIF-KMDIF) $1501,502,502$

502 NSTEP $=$ MDIF-KMDIF+1

$L L 1=L M A X$

DO 1502 MSTEP $=1$, NSTEP

$M \times T 2=M A X T U-M S T E P$

$M \times T 1=M X T 2-K T I M E(K)+1$

$L L 2=0$

DO $1503 M 8=M \times T 1, M X T 2$

$M 9=M \times T 2-M 8+M \times T 1$

$L E V 1=L E V E L(M S)$

IF(LEV1-LMAX) $503,1502,1502$

503 IF (M9-KESTA $(K)) \quad 505,505,504$

504 LEV $1=L E V 1-K R S R C E(K)$

505 LEV $=$ LEV $1+K R S R C E(K)$

IF (LEV-LMAX) $506,1502,1502$

506 IF(LEV-LL2) $1503,1503,507$

507 LL $2=$ LEV

1503 CONTINUE

IF (LL2-LL1) $\quad 508,508,1502$

508 LLI $=$ LL? 
MHAPN=MSTEP

1502 CONTINUE

IF (LLI-LMAX) $509,1501,1501$

509 KEFIN $(K)=M A X T U-M H A P N$

KESTA $(K)=K E F I N(K)-K T \operatorname{IME}(K)$

MSALE $=100$

NAINLM $=0$

GO TO 510

1501 CONTINUE

510 RETURN

END 
SUBROUTINE MOVER

C

ITERATION TYPE II -- FCRWAROS

COMMON KINODE $(70)$, KJNODE $(70)$, KTIME $(70)$, KRSRCE( 70$)$, NET( 70$)$ COMMON KEF (70), NLT(70), KLS 170$)$, KLF(70), KFLOAT(70), KFREE(70)

COMMON KINDEP $(70)$, KSAFE $(70)$, NSLACK $(70)$, KRANK $(70)$, LEVEL $(80)$

COMMON KCHOIS $(30)$, KLU, LMAX, MAXTU, NOTA, NAINLM, MMOVER, MAXRES

COMMON YES, SIGNO, YNO, BLANCO, PALO, MSCHED 170,801 , SINOP

COMMON NA, NN, NLAST, NSLIP, NTIME, LSLIP, LTIME, NCSCH, MSALE, INCRE

COMMON KES $(70)$, KPOS $(30)$, KPOSRK $(30)$

DIMENSION KONTRA(70)

DIMENSION KESTA (70), KEFIN(70), NESTA $(70)$, KONTRN(70)

EQUIVALENCE (KFREE(1), KESTA(1)), (KINDEP(1), KEFIN(1))

EQUIVALENCE (KSAFE(1), NESTA $(1)$ ), (KFLOAT(1), KONTRN(1))

C

SETS ALL CONTROLS TO ZERO

DO $1399 \mathrm{~K}=1$, NA

$\operatorname{KONTRN}(K)=0$

KONTRA $(K)=0$

1399 CONTINUE

$c$
$c$
$c$
$c$
$c$

DETERMINES WHICH ACTIVITY - OF THOSE THAT CONTRIBUTE TO BUILD UP LMAX - HAS THE SMALLEST IDENTIFICATION NUMBER. THIS ACTIVITY (K9) WOULD BE THE LAST ACTIVITY TO BE RESCHEDULED, IF LMAX CAN NOT BE CUT.

$K 9=N A$

DO $1400 \quad K=1$, NA INLM

IF (KCHOIS $(K)-K 9) \quad 399,399,1400$

$399 \mathrm{~K} 9=\mathrm{KCHOIS}(\mathrm{K})$

1400 CONTINUE

C

C RESCHEDULES THE ACTIVITIES IN DESCENDING ORDER ACCORDING C TO THEIR IDENTIFICATION NUMBERS, STARTS WITH ACTIVITY NA

C

DO $1401 K=1$, NA

$K I=N A-K+1$

$J=K J N O D E(K 1)$

IF $(K I-K 9) 421,460,460$

460 IF $(J-N N) \quad 401,400,400$

$400 \operatorname{KONTRN}(J)=N L T(N N)$

$401 K 2=K E F I N(K 1)$

NS $=$ NESTA $(J)$

IF (K2-NLT $(J)) \quad 402,407,407$ 
$402 \times 3=N 5$

$403 K 4=K 3-K T I M E(K 1)+1$

IF $(K 2-K 3) 404,407,407$

404 DO $1402 \mathrm{NG}=\mathrm{K} 4, \mathrm{~K} 3$

$L E V=L E V E L(N 6)+K R S R C E(K 1)$

IF(LMAX-LEV) $405,405,1402$

405 IF $(K 2-K 3) \quad 406,407,407$

$406 \quad K 3=K 3-1$

GO TO 403

1402 CONTINUE

$\mathrm{K} 2=\mathrm{K} 3$

407 IF $(N 5-N L T(J)) \quad 408,416,416$

408 IF (KONTRN (J)) $409,409,410$

$409 \operatorname{KONTRN}(J)=N L T(N N)$

DO $1403 \mathrm{~K} 6=1$, NA

ICHE = KINODE $(K 6)$

IF (ICHE-J) $1403,470,1403$

$470 K 5=K E S T A(K 6)$

IF (K5-KONTRN (J) $414,1403,1403$

$414 \operatorname{KONTRN}(J)=K 5$

1403 CONTINUE

410 IF $(N 5-K O N T R N(J)) 411,416,416$

$411 N 5=N 5+1$

GO TO 402

$c$

c

C

$416 K E F I N(K 1)=K 2$

$K E S T A(K 1)=K 2-K T I M E(K 1)$

$K 4=K E S T A(K 1)+1$

C

ADJUSTS CHANGES IN THE RESOURCE PROFILE

CALL REPROF

IF (MAXTU-K4) $417,415,415$

415 IF(MAXTU-KEF IN $(K 1)) \quad 418,418,417$

417 KONTRA $(K 1)=100$

C

$\mathrm{C}$

REPORTS WHETHER THE ITERATION WAS ACCOMPLISHED OR NOT

418 DO $1404 \quad K 7=1$, NAINLM

IF (K1-KCHOIS (K7) $1404,419,1404$

419 IF(KONTRA(KI)) $1404,1404,420$

1404 CONTINUE

1401 CONTINUE

421 MMOVER $=0$

GO TO 422

420 MMOVER $=100$ 
c REPORTS THE NEW POSITIONS OF THE NODES

C 422 DO $1405 \mathrm{~N}=1$, NN

IF(KONTRN(N)) $1405,1405,423$

423 NESTA $(N)=\operatorname{KONTRN}(N)$

1405 CONTINUE

RETURN

END 
SUBRDUTINE MOVEL

ITERATION TYPE II - - BACKWARDS

COMMON KINODE $(70)$, KJNODE $(70)$, KTIME $(70)$, KRSRCE( 70$)$, NET (70) COMMON KEF $(70)$, NLT $(70), K L S(70), K L F(70), K F L O A T(70), K F R E E(70)$ COMMON KINDEP $(70)$, KSAFE $(70)$, NSLACK $(70)$, KRANK $(70)$, LEVEL (80) COMMON KCHOIS(30), KLU, LMAX, MAXTU, NOT A, NAINLM, MMOVER, MAXRES COMMON YES, SIGNO, YNO, BLANCO, PALO, MSCHED $(70,801$, S INOP COMMON NA, NN, NLAST, NSLIP, NTI ME, LSLIP, LTIME, NOSCH, MSALE, INCRE COMMON KES $(70), \operatorname{KPOS}(30), \operatorname{KPOSRK}(30)$

DIMENSION KONTRA $(70)$

DIMENSION KESTA (70), KEFIN(70), NESTA(70), KONTRN(70)

EQUIVALENCE (KFREE (1), KESTA(1), (KINDEP(1), KEFIN(1))

EQUIVALENCE (KSAFE(1), NESTA $(1)),(\operatorname{KFLOAT}(1), \operatorname{KONTRN}(1))$

$T I N O C O=0$

DO $1600 \mathrm{~K}=1$, NA

KONTRN $(K)=0$

KONTRA $(K)=0$

1600 CONTINUE

$c$
$c$
$c$
$c$
$c$
$c$

DETERMINES WHICH ACTIVITY - OF THOSE THAT CONTRIBUTE TO BUILD UP LMAX - HAS THE LARGEST IDENTIFICATION NUMBER. THIS ACTIVITY (K9) WDULD BE THE LAST ACTIVITY TO BE RESCHEDULED, IF LMAX CAN NOT BE CUT.

$\mathrm{K} 9=1$

DO $1601 \mathrm{~K}=1$, NAINLM

IF $(K C H O I S(K)-K 9) \quad 1601,1601,600$

$600 \mathrm{~K} 9=\mathrm{KCHOIS}(\mathrm{K})$

1601 CONTINUE

c

C RESCHEDULES THE ACTIVITIES IN ASCENDING ORDER ACCORDING C TO THEIR IDENTIFICATION NUMBERS, STARTS WITH ACTIVITY 1. C

680 IF (SINOP-1) $1660,1659,1659$

1659 TINOCO $=50$

$K 9=N A$

1660 DO $1602 \mathrm{~K}=1$, NA

$I=K I N O D E(K)$

$I F(K-K 9) 601,601,624$

601 IF II-1) $602,602,603$

602. KONTRN (I)=NET(1)

$603 K 2=K E S T A(K)+1$

N5 $=$ NESTA $(1)+1$

IF(K2-NET(I)-I) $612,612,604$ 
$604 \mathrm{~K} 3=\mathrm{N} 5$

$605 K 4=K 3+K T ! M E(K)-1$

IF $(K 2-K 3) 612,612,606$

606 DO $1603 \quad \mathrm{~N} 6=\mathrm{K} 3, \mathrm{~K} 4$

$L E V I=L E V E L(N 6)$

IF(LEVI-LMAX) $607,610,610$

607 IF (NG-KESTA $(K)-1) 609,608,608$

608 LEV $1=L E V 1-K R S R C E(K)$

$609 L E V=L E V 1+K R S R C E(K)$

IFITINOCO) $630,630,629$

629 IF(LMAX-LEV) $610,1603,1603$

630 IF(LMAX-LEV) $610,610,1603$

610 IF $(K 2-K 3) 612,612,611$

$611 K 3=K 3+1$

GO TO 605

1603 CONTINUE

$K 2=K 3$

612 IF(N5-1-NET(I) $619,619,670$

670 IF (KONTRN(1)) $614,614,617$

614 KONTRN (I) $=$ NET( 11$)$

DO $1604 \mathrm{~K} 6=1$, NA

$J C H E=K J N O D E(K 6)$

IF( JCHE- I) $1604,615,1604$

$615 K 5=K E F I N(K 6)$

IF(K5-KONTRN (I) $1604,1604,616$

616 KONTRN (I) $=K 5$

1604 CONTINUE

617 IF(N5-KONTRN (1)-1) $619,619,618$

$618 N 5=N 5-1$

GO TO 604

REPORTS THE NEW POSITION OF THE ACTIVITY K.

$619 \operatorname{KESTA}(K)=K 2-1$

KEFIN $(K)=K E S T A(K)+K T I M E(K)$

C

ADJUSTS CHANGES IN THE RESCURCE PROFILE

CALL REPROF

IF (MAXTU-K2) $621,620,620$

620 IFIMAXTU-KEFIN(K) $622,622,621$

C

621 KONTRA $(K)=100$

c

REPORTS WHETHER THE ITERATION WAS ACCOMPLISHED OR NOT.

622 IF(TINOCO) $681,681,1602$

681 DO $1605 k 7=1$, NAINLM

IF $(K-K C H O I S(K 7)) 1605,623,1605$ 
EVEL 19

MOVEL

DATE $=71253$

$09 / 19 / 29$

623 IF (KONTRAIK) $1605,1605,625$

1605 CONTINUE

1602 CONTINUE

624 MMOVER $=0$

GO TO 626

625 MMOVER $=100$

REPDRTS THE NEW POSITIONS OF THE NODES.

$626001606 \mathrm{~N}=1, \mathrm{NN}$

IF(KONTRNIN) $1606,1606,627$

627 NESTA $(N)=K O N T R N(N)$

1606 CONTINUE

IF(TINOCO) $643,643,640$

$640 \mathrm{KG}=$

DO $1607 \mathrm{~K} 8=1$, NA

IF (KJNODE (K8)-NN) $1607,641,641$

641 IF(K9-KEFIN(K8)) $642,1607,1607$

$642 K 9=K E F I N(K 8)$

1607 CONTINUE

NESTA $(N N)=K 9$

643 RETURN

END 
APPENDIX B

COMPUTHR SOLUTION OF THE EXAIPLE PROJECT 


\title{
DATA - INPUT
}

\author{
/* \\ //GO.SYSIN DD * \\ YES * NO $\rightarrow$ \\ 008024003007 \\ 001002008007 \\ 001003003002 \\ 001004005004 \\ 002003000000 \\ 002004002000 \\ 002005005006 \\ 003005003001 \\ 004005006006 \\ /*
}

$B-1$ 


$$
N O D E S=E V E N T S
$$

$\begin{array}{ccccc}\text { NUMBER } & \text { EARLIEST TIME } & \text { LATEST TIME } & \text { SLACK } & \text { CRITICAL PATH } \\ 1 & 0 & 0 & 0 & \text { YES } \\ 2 & 8 & 8 & 0 & \text { YES } \\ 3 & 8 & 13 & 5 & \text { NO } \\ 4 & 10 & 10 & 0 & \text { YES } \\ 5 & 16 & 16 & 0 & \text { YES }\end{array}$


A C T I V I T I E S

NUMBER INODE JNODE RSRCE DURA E-START E-FIN L-START L-FI

$\begin{array}{lllllllll}1 & 1 & 2 & 7 & 8 & 0 & 8 & 0 & 8 \\ 2 & 1 & 3 & 2 & 3 & 0 & 3 & 10 & 13 \\ 3 & 1 & 4 & 4 & 5 & 0 & 5 & 5 & 10 \\ 4 & 2 & 3 & 0 & 0 & 8 & 8 & 13 & 13 \\ 5 & 2 & 4 & 0 & 2 & 8 & 10 & 8 & 10 \\ 7 & 2 & 5 & 6 & 5 & 8 & 13 & 11 & 16 \\ 8 & 3 & 5 & 1 & 3 & 8 & 11 & 13 & 16 \\ 7 & 5 & 6 & 6 & 10 & 16 & 10 & 16\end{array}$

TOTAL-F FREE-F IND-F SAFE-F C-PATH DUMMY INDEX

THE EARLIEST PROJECT COMPLETION TIME IS 16 UNITS OF TIME

THE GIVEN PROJECT DUE DATE IS 24 UNITS OF TIME

THE CURRENT PROJECT SLACK IS 8 UNITS OF TIME

THE DAILY RESOURCE AVAILABILITY IS 7 UNITS OF RESOURCE

THE MAXIMUM PROJECT SLIPPAGE IS 3 UNITS OF TIME

\begin{tabular}{rrrrrrr}
0 & 0 & 0 & 0 & YES & NO & 1 \\
\hline 10 & 5 & 5 & 10 & NO & NO & 8 \\
\hline 5 & 5 & 5 & 5 & NO & NO & 7 \\
5 & 0 & 0 & 5 & NO & YES & 5 \\
\hline 0 & 0 & 0 & 0 & YES & NO & 2 \\
\hline 3 & 3 & 3 & 3 & NO & NO & 4 \\
\hline 5 & 5 & 0 & 0 & NO & NO & 6 \\
0 & 0 & 0 & 0 & YES & NO & 3
\end{tabular}


NODES LOCATED HERE ARE : 1.

$1 \quad 72400000$

$272400000^{\circ}$

372400000

470400000

$5 \quad 70400000$ $\neg$

670000000

770000000

870000000

NODES LOCATED HERE ARE : 2. 3.

900000610

1000000610

NODES LOCATED HERE ARE : 4.

$1 1 0 0 0 0 0 6 1 \longdiv { 6 }$

1200000606

1300000606

1400000006

1500000006

1600000006 
NODES LOCATED HERE ARE : 1.

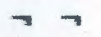

170400000

270400000 .

370400000

470400000

570400000

672000000

$7 \quad 72000000$

872000000 NODES L JOCATED HERE ARE : 2. 3. 900000600

1000000600 NODES LOCATED HERE ARE : 4.

$110000060 \overline{6}$

1200000606

1300000606

1400000016

1500000016

1600000016

NODES LOCATED HERE ARE : 5 . 
THE HEURISTIC BEST SOLUTION SCHEDULE FOR THE GIVEN PROJECT IS : 
TIME-UNIT

ACTIVITIES $: 1,2,3, \ldots \ldots \ldots, 8$

\section{LEVEL}

NODES LOCATED HERE ARE : 1.

170000000

$270000000 \cdot$

370000000

470000000

570000000

670000000

770000000

870000000

NODES LÖCATED HERE ARE : 2.

9 02700000

1002400000 ,

1102400000

NODES LOCATED HERE ARE : 3 .

1200400010

1300400010

NODES LOCATED HERE ARE: 4.

$1400000 \overline{6} 10$

1500000600 
1700000600

1800000600 7

1900000006

6

2000000006

6

2100000006.

2200000006

2300000006

2400000006

NODES LOCATED HERE ARE : 5. 
APPENDIX C

COMPUTER SOLUTION OF THE CONSTRUCTION

OF A GAS STATION 
$N O D E S=E V E N T S$

NUMBER EARLIEST TIME

$\begin{array}{ll}1 & \\ 2 & 5 \\ 3 & 8 \\ 4 & 10 \\ 5 & 14 \\ 6 & 14 \\ 7 & 15 \\ 8 & 18 \\ 9 & 10\end{array}$

10

8

$\begin{array}{cc}0 & 0 \\ 5 & 0 \\ 17 & 9 \\ 19 & 9 \\ 23 & 9 \\ 31 & 9\end{array}$

YES

YES

8

31

16

34

16

10

0

39

31

NO

NO

NO

NO

NO

NO

YES

No

11

15

41

26

NO

12

25

25

0

YES

13

20

36

$16^{\cdots}$

NO

14

29

29

0

YES

31

31

0

YES

16

37

40

3

NO

35

0

YES

18

39

16

NO

19

42

16

NO

20

42

5

NO

37

49

23

NO

21

26

46

11

NO

22

35

46

NO

23

37

37

40

NO

25

40

YES

26

40

44

YES

27

44

45

10

NO

\section{C-I}


$A C T I V I T I E S$

NUMBER INODE JNODE RSRCE DURA E-START E-FIN L-START L-FIN

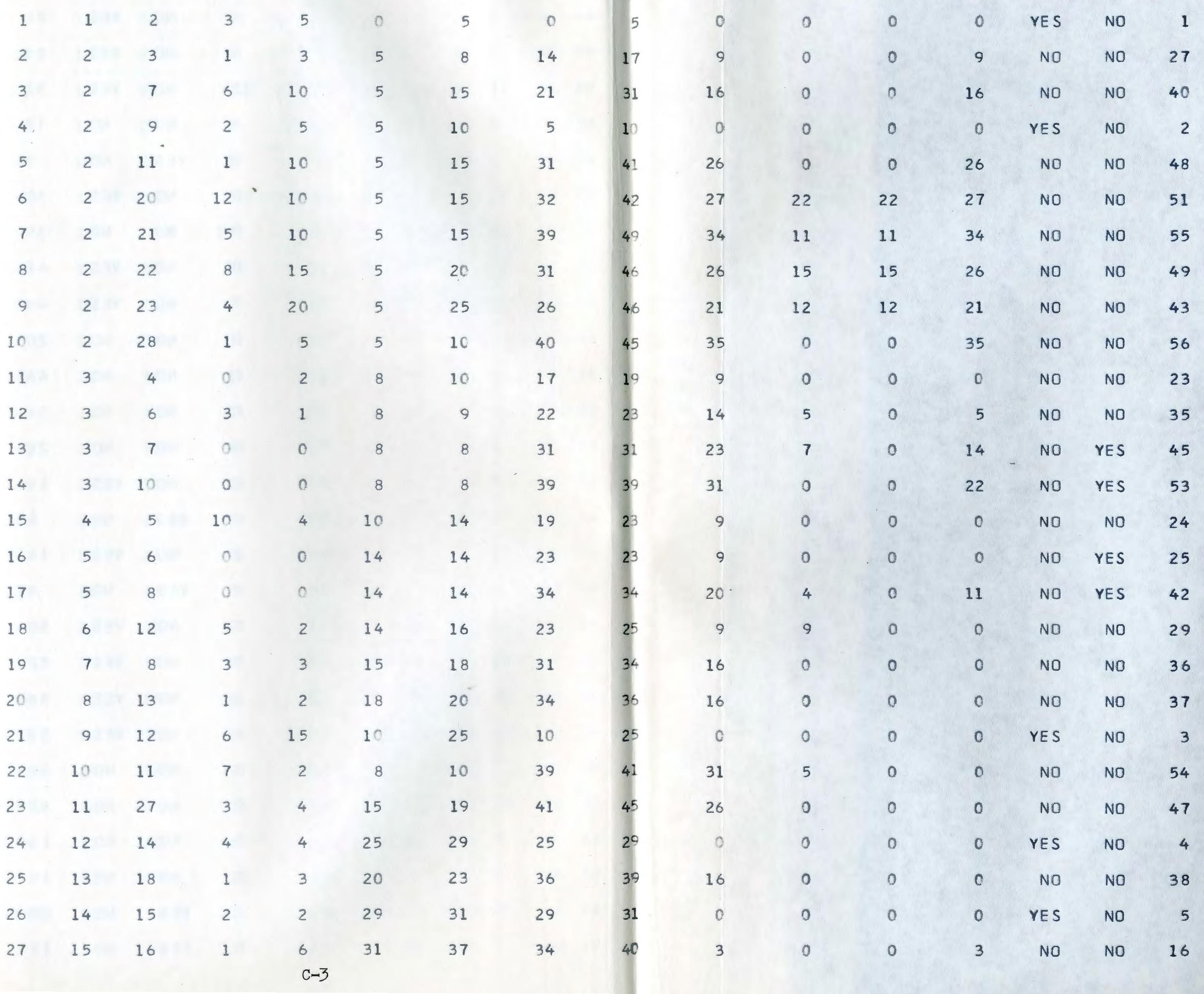




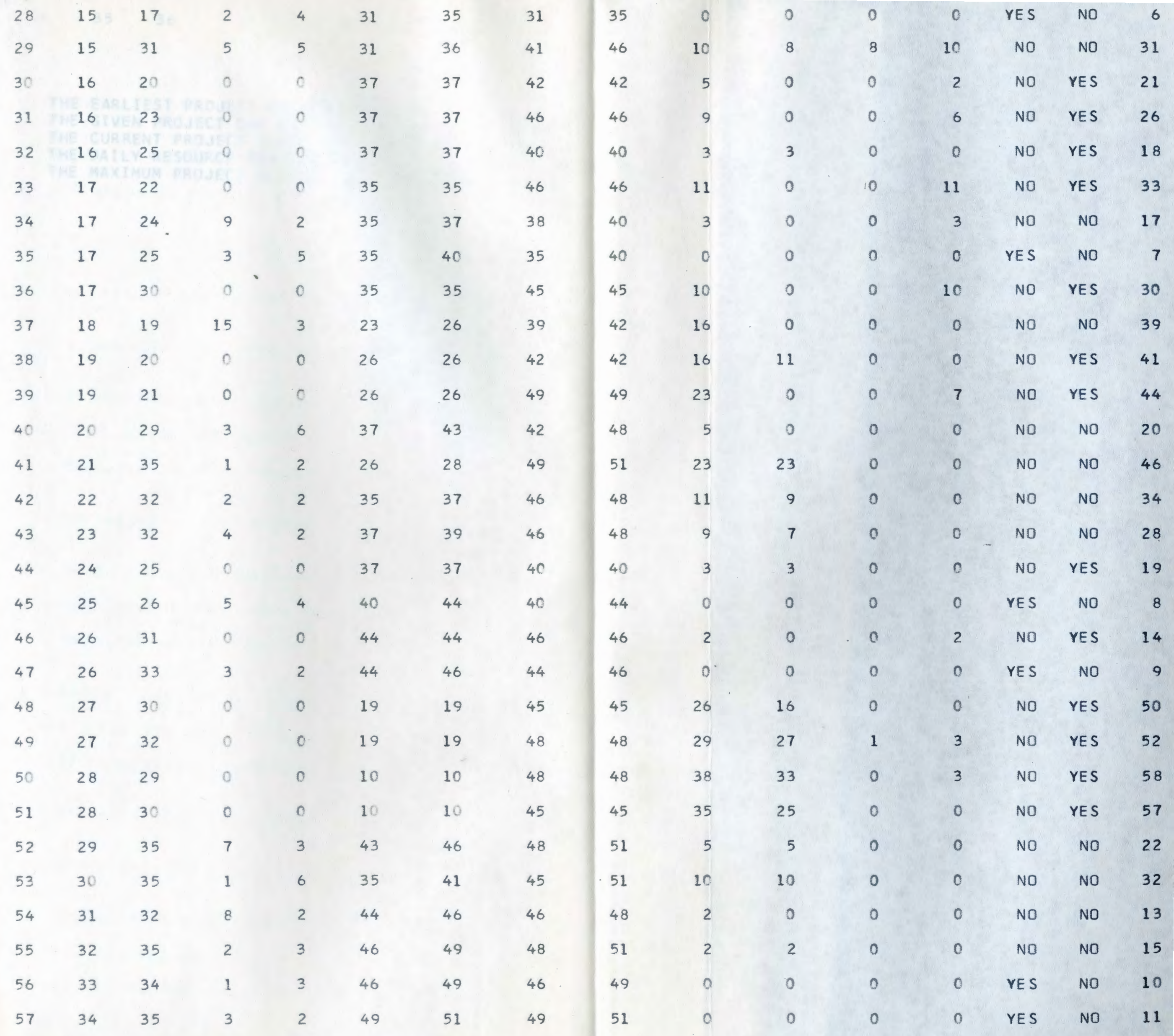


52 UNITS OF TIME

THE EARLIEST PROJECT CONPLETICN TIME IS TIME

THE GIVEN PROJECT DUE DATE IS 60 UNITS DF TIM
THE CURRENT PRDJECT SLACK IS 8 UNITS OF TIME

THE DAILY RESOURCE AVAILABILITY IS 21 UNITS OF RESOURCE

THE MAXIMUM PROJECT SLIPPAGE IS 3 UNITS OF TIME 
NODES LOCATED HERE ARE : 1.

13000000000000000000000000000000000000000000000000000000000

53000000000000000000000000000000000000000000000000000000000 ᄀ

NODES LOCATED HERE ARE : 2 .

6 0 1621*5841900000000000000000000000000000000000000000000000

$701621 * 5841000000000000000000000000000000000000000000000000$

$801621 * 5841000000000000000000000000000000000000000000000000$

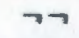

9 $00621 * 5841030000000007000000000000000000000000000000000000$ $\checkmark$

$1000621 * 5841000000000007000000000000000000000000000000000000$ NODES LOCATED HERE ARE : $\overrightarrow{4} \cdot \mathbf{9} .28$.

$1100601 * 58400000 * 00000600000000000000000000000000000000000000$

$1200601 * 58400000 * 0000060000000000000000000000000000000000000$

$1300601 * 58400000 * 0000060000000000000000000000000000000000000$

$1400601 * 58400000 * 0000060000000000000000000000000000000000000$ 
160000000840000000053060300000000000000000000000000000000000

170000000840000000003060300000000000000000000000000000000000

180000000840000000003060300000000000000000000000000000000000 NODES LOCATED HERE ARE ${ }^{\top}: 8$.

ᄀ

190000000840000000000160300000000000000000000000000000000000 NODES LOCATED HERE ARE $: 27$.

200000000840000000000160000000000000000000000000000000000000 NODES LOCATED HERE ARE $: 13$.

210000000040000000000060001000000000000000000000000000000000

220000000040000000000060001000000000000000000000000000000000

230000000040000000000060001000000000000000000000000000000000 NODES LOCATED HERE ARE : 18 .

$24000000004000000000006000000000000000 * 000000000000000000000$

$25000000004000000000006000000000000000 * 000000000000000000000$ NODES LOCATED HERE ARE $: \overrightarrow{1}$.

$26000000000000000000000004000000000000 * 000000000000000000000$

\section{רדיטר}

NODES LOCATED HERE ARE : 19.21

$270000000000000000000000040000000000000 \overrightarrow{0} \overrightarrow{0} \mathbf{1 0 0 0 0 0 0 0 0 0 0 0 0 0 0 0 0 0}$

280000000000000000000000040000000000000000100000000000000000 $\rightarrow$

290000000000000000000000040000000000000000000000000000000000 NODES LOCATED HERE ARE $: 14$.

300000000000000000000000000200000000000000000000000000000000

310000000000000000000000000200000000000000000000000000000000 NODES LOCATED HERE ARE : 15 . 320000000000000000000000000012500000000000000000000000000000 

NODES LOCATED HERE ARE $: 17 \cdot 22.30$.

360000000000000000000000000010500009300000020000000000100000

370000000000000000000000000010000009300000020000000000100000

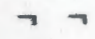

410000000000000000000000000000000000000003000050000000100000 NODES LOCATED HERE ARE :29.

440000000000000000000000000000000000000000000050000007000000 NODES LOCATED HERE ARE :26.31.

450000000000000000000000000000000000000000000000300007080000

460000000000000000000000000000000000000000000000300007080000 NODES LOCATED HERE ARE : 32.33

470000000000000000000000000000000000000000000000000000002100 NODES LOCATED HERE ARE : 34. 

NODES LOCATED HERE ARE : 35 . 520000000000000000000000000000000000000000000000000000000004 NODES LOCATED HERE ARE $: 36$. 
13000000000000000000000000000000000000000000000000000000000

53000000000000000000000000000000000000000000000000000000000 $\neg$

NODES LOCATED HERE ARE : 2 .

6 0 1620*000 1000000000000000000000000000000000000000000000000

$701620 * 0001000000000000000000000000000000000000000000000000$

$801620 * 0001000000000000000000000000000000000000000000000000$ NODES LOCATED HERE ARE : 3.10 .

$900620 * 0001030000000000000000000000000000000000000000000000$ $\rightarrow$

$1000620 * 0001000000000000000000000000000000000000000000000000$ NODES LOTCATED HERE ARE : 4.9 .28 .

$1100600 * 0000000000000 \mathrm{C} 60000000000000000000000000000000000000$

$1200600 \% 0000000000000060000000000000000000000000000000000000$

$1300600 * 0000000000000660000000000000000000000000000000000000$

$1400600 * 0000000000000060000000000000000000000000000000000000$

$1500600 \% 0000000000000060000000000000000000000000000000000000$ $\rightarrow \longrightarrow$

NODES LOCATED HERE ARE : 7 .

$160000 \overrightarrow{1} 000400000 * 0003060000000000000000000000000000000000000$ 
$00001000400000 * 0000060000000000000000000000000000000000000$ ARE : 5.6 .8$.

NODES LOCATED HERE ARE : 5

200000100040000000050167000000000000000000000000000000000000

210000100040000000050167000000000000000000000000000000000000

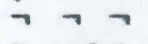

NODES LOCATED HERE ARE $: 13$.

220000100840000000000060001000000000000000000000000000000000

240000100840000000000060001000000000000000000000000000000000 NODES LOCATED HERE ARE $: 18$.

250000100840000000000060000000000000000000000000000000000000 NODES LOCATED HERE ARE : 11.12 .

260000005840000000000000040000000000000000000000000000000000 NODES LOCATED HERE ARE $: 14$.

300000005840000000000000300200000000000000000000000000000000

310000005840000000000000300200000000000000000000000000000000 NODES LOCATED HERE ARE $: \mathbf{1 5 . 2 7 .}$

$\rightarrow 7$ 
350000005840000000000000000012000000000000000000000000000000

NODES LOCATED HERE ARE $: 17.30$. 7 ᄀ $\boldsymbol{7}$

360000000800000000000000000010500000300000000000000000000000 NODES LOCATED HERE ARE :22.

370000000000000000000000000010500009300000020000000000000000 NODES LOCATED HERE ARE, :16.23. ר ר

380000000000000000000000000000500009300000020000000000000000 NODES LOCATED HERE ARE : 24 .

$39000000000000000000000000000050000030 * 000000000000000000000$

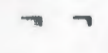

$40000000000000000000000000000050000030 * 000000000000000000000$ NODES LOCATED HERE ARE : 25 .

$41000000000000000000000000000000000000 * 0000 \hat{0} \overline{0} \mathbf{5} 0000000000000$ NODES LOCATED HERE ARE $: 19 \cdot 20 \cdot 21$.

4200000000000000000000000000000000000000031040500000001000000 $\checkmark$

430000000000000000000000000000000000000003100050000000100000 7

440000000000000000000000000000000000000003000050000000100000 NODES LOCATED HERE ARE :26.31.

$\neg 7$

7

450000000000000000000000000000000000000003000000300000180000

460000000000000000000000000000000000000003000000300000180000 NODES LOCATED HERE ARE $: 32.33$

470000000000000000000000000000000000000003000000000000102100 NODES LOCATED HERE ARE :29.

480000000000000000000000000000000000000000000000000007002100

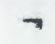

$50 \quad 0000000000000000000000000000000000000000000000000007000030$ 

$52000000000000000000000000000000000000000000000000000000000 \overline{4}$ NODES LOCATED HERE ARE : 36 . 
NODES LOCATEO HERE ARE : 1.

13000000000000000000000000000000000000000000000000000000000

23000000000000000000000000000000000000000000000000000000000

33000000000000000000000000000000000000000000000000000000000

\section{3}

43000000000000000000000000000000000000000000000000000000000

53000000000000000000000000000000000000000000000000000000000

NODES LOCATED HERE ARE : 2 .

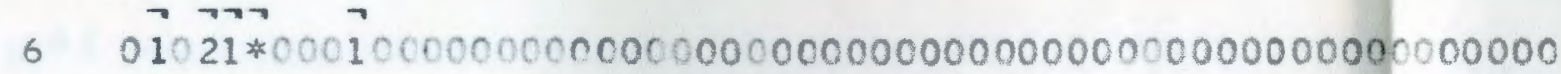

$701021 * 0001000000000000000000000000000000000000000000000000$

$801021 * 0001000000000000000000000000000000000000000000000000$ ' LOCATED HERE ARE : 3.10 .

NODES LOCATED HERE ARE : 3.10 .

9. $00021 * 0001030000000000000000000000000000000000000000000000$

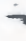

$1000021 * 0001000000000000000000000000000000000000000000000000$ NODES LOCATED HERE ARE : 4.9 .28$.

ᄀ

$1100001 * 0000000000000060000000000000000000000000000000000000$

$1200001 * 0000000000000060000000000000000000000000000000000000$ 
$1900000000400000 \$ 0000060000000000000000000000000000600000000$ $\neg \neg$

NODES LOCATED HERE ARE : 5 . 6 .

200000000840000000000060000000000000000000000000000000000000

210000000840000000000060000000000000000000000000000000000000

220000000840000000000060000000000000000000000000000600000000

230000000840000000000060000000000000000000000000000000000000

0000000840000000000060000000000000000000000000000000000000

0000000840000000000060000000000000000000000000000000000000 $\neg$

260000000840000000050000000000000000000000000000000000000000

270000000840000000050000000000000000000000000000000000000000 NODES LOCATED HERE ARE $: 12$.

280000000840000000000007000000000000000000000000000000000000

290000000840000000000007000000000000000000000000000000000000

NODES LOCATED HERE ARE $: \mathbf{1} \overrightarrow{1}$.

$30 \quad 0060000840000000000000300000000000000000000000000000000000$

310060000840000000000000300000000000000000000000000000000000

330.060000840000000000000300000000000000000000000000000000000 NODES LOCATED HERE ARE : 27. 
370060005000000000000000040000000000000000000000000000000000 NODES LOCATED HERE ARE $: 14^{\top}$

380060005000000000000000000200000000000000000000000000000000

390060005000000000000000000200000000000000000000000000000000 NODES LOCATED HERE ARE : 7.15.

$40 \quad 0000005000000000003000000012500000000000000000000000000000$

410000005000000000003000000012500000000000000000000000000000

420000005000000000003000000012500000000000000000000000000000 NODES LOCATED HERE ARE : 8 .

$430000005000000000000 \hat{1} 00000012500000000000000000000000000000$ NODES LOCATED HERE ARE $: 17.22 .30$.

$4400000050000000000001000000105000003000000 \overrightarrow{2} 0000000000 \overrightarrow{100000}$ NODES LOCATED HERE ARE $: 13$.

$4500000000000000000000000 \hat{1} 01000000 \overline{3} 300000020000000000100000$

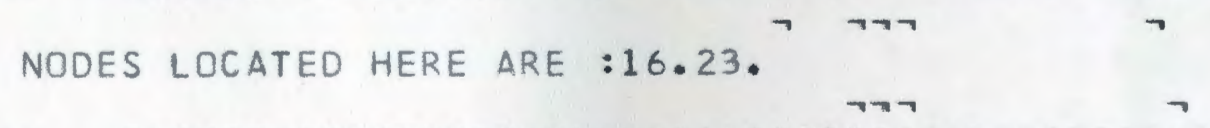

460000000000000000000000001000000009300000004000000000100000 NODES LOCATED HERE ARE $: 24$.

470000000000000000000000001000000000300000004000000000100000 $\rightarrow$ NODES LOCATED HERE ARE $: 18$.

$48000000000000000000000000000000000030 \% 000000000000000100000$ $\neg$ NODES LOCATED HERE ARE : 25 .

$49000000000000000000000000000000000000 * 000000050000000100000$

$50 \quad 000000000000000000000000000000000000 * 000000050000000000000$ วา NODES LOCATED HERE ARE $: 19.20 .21$. 
520000000000000000000000000000000000000003100050000000000000

NODES LOCATED HERE ARE : 26.31.

530000000000000000000000000000000000000003000000300000080000

540000000000000000000000000000000000000003000000300000080000

NODES LOCATED HERE ARE : 32.33 .

560000000000000000000000000000000000000003000000000000002100 NODES LOCATED HERE ARE :29.

570000000000000000000000000000000000000000000000000007002100 NODES LOCATED HERE ARE : 34 .

580000000000000000000000000000000000000000000000000007000030

590000000000000000000000000000000000000000000000000007000030 NODES LOCATED HERE ARE : 35 .

600000000000000000000000000000000000000000000000000000000004 NODES LOCATED HERE ARE : 36 . 
NODES LOCATED HERE ARE : 1.

13000000000000000000000000000000000000000000000000000000000

23000000000000000000000000000000000000000000000000001000000

33000000000000000000000000000000000000000000000000000000000

43000000000000000000000000000000000000000000000000000000000

53000000000000000000000000000000000000000000000000000000000 NODES LOCATED HERE ARE : 2.

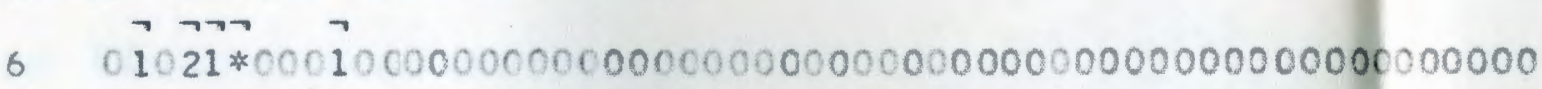

$701021 * 0001000000000000000000000000000000000000000000000000$

$8 \quad 1021 * 0001000000000000000000000000000000000000000000000000$ NODES LOCATED HERE ARE : 3.10 . NODES LOCATED HERE ARE : 3.10 .

9 $00021 * 0001030000000000000000000000000000000000000000000000$ $\neg$

$1000021 \% 0001000000000000000000000000000000000000000000000000$ NODES LOCATED HERE ARE : 4.9 .28$.

11000010000000000000060000000000000000000000000000000000000

$1200001 * 0000000000000060000000000000000000000000000000000000$

$1300001 * 0000000000000060000000000000000000000000000000000000$

$1400001 * 0000000000000060000000000000000000000000000000000000$

$1500001 * 0000000000000060000000000000000000000000000000000000$ 
$1900000000400000 * 0000060000000000000000000000000000000000000$

$200000000 \overline{8} 40000000000060000000000000000000000000000000000000$

0000000840000000000060000000000000000000000000000000000000 $\neg$

260000000840000000050000000000000000000000000000000000000000

270000000840000000050000000000000000000000000000000000000000

290000000840000000000007000000000000000000000000000000000000 NODES LOCATED HERE ARE : 1 i.

330060000840000000000000300000000000000000000000000000000000 NODES LOCATED HERE ARE : 27.

340060000840000000000000040000000000000000000000000000000000 

NODES LOCATED HERE ARE $: 14$.

0060005000000000000000000200000000000000000000000000000000 LOCATED HERE ARE : 7.15 .

NODES LOCATED HERE ARE : 7.15. רד ד

400000005000000000003000000012500000000000000000000000000000

410000005000000000003000000012500000000000000000000000000000

420000005000000000003000000012500000000000000000000000000000 NODES LOCATED HERE ARE': 8 .

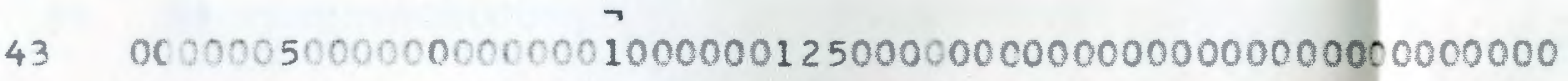
NODES LOCATED HERE ARE $: 17.22 .30$.

440000005000000000000100000010500000300000020000000000100000 NODES LOCATED HERE ARE $: 13$.

$45000000000000000000000000101000000 \hat{T} 300000020000000000100000$ NODES LOCATED HERE ARE $: 16.23$.

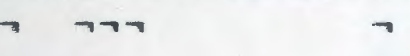
NODES LOCATED HERE ARE :25.

$49000000000000000000000000000000000000 * 000000050000000100000$

$50 \quad 000000000000000000000000000000000000 * 000000050000000000000$ $\neg \neg$ NODES LOCATED HERE ARE $: 19.20 .21$. 
$52 \quad 0000000000000000000000000000000000000003100050000000000000$ NODES LOCATED HERE ARE $: 26.31$.

530000000000000000000000000000000000000003000000300000080000

540000000000000000000000000000000000000003000000300000080000

NODES LOCATED HERE ARE $: 32.33$.

550000000000000000000000000000000000000003000000000000002100

560000000000000000000000000000000000000003000000000000002100 NODES LOCATED HERE ARE :29.

570000000000000000000000000000000000000000000000000007002100 NODES LOCATED HERE ARE $: 34$.

580000000000000000000000000000000000000000000000000007000030

590000000000000000000000000000000000000000000000000007000030 NODES LOCATED HERE ARE : 35 .

60 0000000000000000000000000000000000000000000000000000000004 NODES LOCATED HERE ARE : 36 . 
NODES LOCATEO HERE ARE : 1.

13000000000000000000000000000000000000000000000000000000000

23000000000000000000000000000000000000000000000000000000000

33000000000000000000000000000000000000000000000000000000000

43000000000000000000000000000000000000000000000000000000000

53000000000000000000000000000000000000000000000000000000000

NDDES LOCATED HERE ARE : 2 .

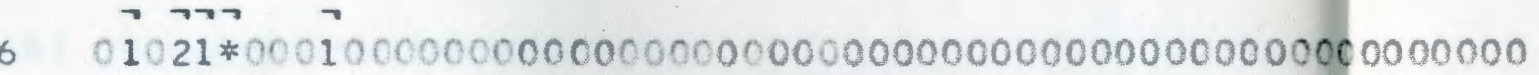

$701021 * 0001000000000000000000000000000000000000000000000000$

$8 \quad 01021 * 0001000000000000000000000000000000000000000000000000$ S LOCATED HERE ARE : 3.10 .

0 $00021 * 0001030000000000000000000000000000000000000000000000$ $\checkmark$

$1000021 * 0001000000000000000000000000000000000000000000000000$ NODES LOCATED HERE ARE : 4.9 .28 .

$1100001 \% 0000000000000060000000000000000000000000000000000000$

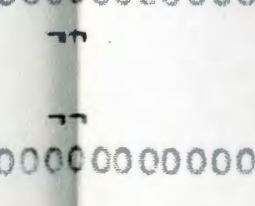

$00001 * 0000000000000060000000000000000000000000000000000000$

$00001 \$ 0000000000000060000000000000000000000000000000000000$

$00001 * 0000000000000060000000000000000000000000000000000000$ 
$1900000000400000 * 0000060000000000000000000000000000000000000$ רד

NODES LOCATED HERE ARE : 5.6 .

200000000840000000000060000000000000000000000000000000000000

0000000840000000000060000000000000000000000000000000000000

0000000840000000000060000000000000000000000000000000000000

0000000840000000000060000000000000000000000000000000000000

0000000840000000000060000000000000000000000000000000000000 $\neg$

26

0000000840000000050000000000000000000000000000000000000000

270000000840000000050000000000000000000000000000000000000000 NODES LOCATED HERE ARE : 12 .

280000000840000000000007000000000000000000000000000000000000

290000000840000000000007000000000000000000000000000000000000 NODES LOCATED HERE ARE $: 1 \overline{1}$.

$30 \hat{0} \overrightarrow{6} 0000840000000000000300000000000000000000000000000000000$ 
370060005000000000000000040000000000000000000000000000000000 NODES LOCATED HERE ARE :14.

380060005000000000000000000200000000000000000000000000000000

390060005000000000000000000200000000000000000000000000000000 NODES LOCATED HERE ARE : 7.15.

400000005000000000003000000012500000000000000000000000000000

410000005000000000003000000012500000000000000000000000000000

420000005000000000003000000012500000000000000000000000000000 NODES LOCATED HERE ARE : 8. 430000005000000000000100000012500000000000000000000000000000 NODES LOCATED HERE ARE $: 17 \cdot 22 \cdot 30$.

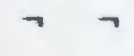

$48000000000000000000000000000000000030 * 000000000000000100000$

$49000000000000000000000000000000000030 * 000000000000000100000$ NODES LOCATED HERE ARE :25.

$50000000000000000000000000000000000000 * 000000050000000000000$ $\neg \neg$ NODES LOCATED HERE ARE $: 19 \cdot 20 \cdot 21$. 
540000000000000000000000000000000000000003000000300000080000

550000000000000000000000000000000000000003000000300000080000

55000000000000000000000000000000000000003000000300000080000

560000000060000000000000000000000000000003000000000000002100 NODES LOCATED HERE ARE :29.

570000000000000000000000000000000000000000000000000007002100

580000000000000000000000000000000000000000000000000007002100 NODES LOCATED HERE ARE : 34 .

59. 00000000000000000000000000000000000000000000000000007000030

600000000000000000000000000000000000000000000000000000000030 NODES LOCATED HERE ARE : 35 .

610000000000000000000000000000000000000000000000000000000004 NODES LOCATED HERE ARE : 36 . 

NODES LOCATED HERE ARE : 1.

13000000000000000000000000000000000000000000000000000000000

23000000000000000000000000000000000000000000000000000000000

33000000000000000000000000000000000000000000000000000000000

43000000000000000000000000000000000000000000000000000000000

53000000000000000000000000000000000000000000000000000000000 7

NODES LOCATED HERE ARE : 2.

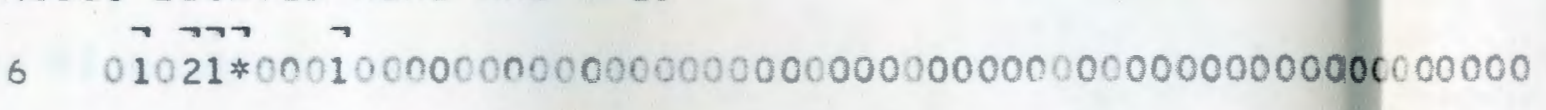

$701021 * 0001000000000000000000000000000000000000000000000000$

$801021 * 0001000000000000000000000000000000000000000000000000$ NODES LOCATED HERE ARE : 3.10.

$900021 * 00010300000000000000000000000000000000000000000000000$ $\rightarrow$

$1000021 * 0001000000000000000000000000000000000000000000000000$ NODES LOCATED HERE ARE : 4.9 .28$.

$1100001 * 0000000000000060000000000000000000000000000000000000$

$1200001 * 0000000000000060000000000000000000000000000006000000$

$1400001 * 0000000000000060000000000000000000000000000000000000$ 
$1900000000400000 * 0000060000000000000000000000000000000000000$ NODES LOCATED HERE ARE : 5.6.

200000000840000000000060000000000000000000000000000000000000

0000000840000000000060000000000000000000000000000000000000

0000000840000000050000000000000000000000000000000000000000

0000000840000000050000000000000000000000000000000000000000

NODES LOCATED HERE ARE $: 12$.

280000000840000000000007000000000000000000000000000000000000

0000000840000000000007000000000000000000000000000000000000 NODES LOCATED HERE ARE $: \hat{1}$.

$30 \quad 0060000840000000000000000000000000000000000000000000000000$

310060000840000000000000000000000000000000000000000000000000

320060000840000000000000000000000000000000000000000000000000 

NODES LOCATED HERE ARE :27. 3900600050000000000000000400000000000000000000000000000000000 NODES LOCATED HERE ARE : $\mathbf{7 . 1}$.

$40 \quad 0000005000000000003000000200000000000000000000000100000000$

410000005000000000003000000200000000000000000000000000000000 NODES LOCATED HERE ARE $: 15$.

420000005000000000003000000012500000000000000000000000000000 NODES LOCATED HERE ARE : 8.

430000005000000000000100000012500000000000000000000000000000

440000005000000000000100006012500000000000000000000000000000 NODES LOCATED HERE ARE $: 13$.

$45000000000000000000000000 \overrightarrow{1} 12500000000000000000000000000000$ NODES LOCATED HERE ARE $: 17 \cdot 22 \cdot 3 \cdot \vec{\jmath}$.

470000000000000000000000001010000009300000020000000000000000. ᄀ ᄀ ᄀน ᄀ NODES LOCATED HERE ARE $: 16 \cdot 18.23 .24$. $7 \rightarrow 7$

$48000000000000000000000000000000000030 * 000020000000000000000$ $\neg \neg$

$49000000000000000000000000000000000030 * 000000 \overrightarrow{0} 00000000 \overrightarrow{1} 00000$

$50000000000000000000000000000000000030 * 000000000000000100000$ NODES LOCATED HERE ARE $: 19 \cdot 20 \cdot 21.25$.

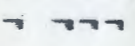

510000000000000000000000000000000000000003104050000000100000 
530000000000000000000000000000000000000003000050000000100000

9

540000000000000000000000000000000000000003000050000000100000 NODES LOCATED HERE ARE :26.31.

$\neg$ ᄀ

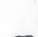

550000000000000000000000000000000000000003000000300000080000

0000000000000000000000000000000000000003000000300000080000 NODES LOCATED HERE ARE $: 29.32 .33$.

$\rightarrow$

10

580000000000000000000000000000000000000000000000000007002100

10

10

NODES LOCATED HERE ARE $: 34$.

60 0000000000000000000000000000000000000000000000000000000030

610000000000000000000000000000000000000000000000000000000030 NODES LOCATEO HERE ARE :35.

620000000000000000000000000000000000000000000000000000000004 NODES LOCATED HERE ARE $: 36$.

630000000000000000000000000000000000000000000000000000000000 